\title{
Economic aspects of treatment for borderline personality disorder. Theory versus practice
}

Citation for published version (APA):

van Asselt, A. D. I. (2008). Economic aspects of treatment for borderline personality disorder. Theory versus practice. [Doctoral Thesis, Maastricht University]. Datawyse / Universitaire Pers Maastricht. https://doi.org/10.26481/dis.20081031aa

Document status and date:

Published: 01/01/2008

DOI:

10.26481/dis.20081031aa

Document Version:

Publisher's PDF, also known as Version of record

\section{Please check the document version of this publication:}

- A submitted manuscript is the version of the article upon submission and before peer-review. There can be important differences between the submitted version and the official published version of record.

People interested in the research are advised to contact the author for the final version of the publication, or visit the DOI to the publisher's website.

- The final author version and the galley proof are versions of the publication after peer review.

- The final published version features the final layout of the paper including the volume, issue and page numbers.

Link to publication

\footnotetext{
General rights rights.

- You may freely distribute the URL identifying the publication in the public portal. please follow below link for the End User Agreement:

www.umlib.nl/taverne-license

Take down policy

If you believe that this document breaches copyright please contact us at:

repository@maastrichtuniversity.nl

providing details and we will investigate your claim.
}

Copyright and moral rights for the publications made accessible in the public portal are retained by the authors and/or other copyright owners and it is a condition of accessing publications that users recognise and abide by the legal requirements associated with these

- Users may download and print one copy of any publication from the public portal for the purpose of private study or research.

- You may not further distribute the material or use it for any profit-making activity or commercial gain

If the publication is distributed under the terms of Article $25 \mathrm{fa}$ of the Dutch Copyright Act, indicated by the "Taverne" license above, 
ECONOMIC ASPECTS OF TREATMENT FOR

BORDERLINE PERSONALITY DISORDER

THEORY VERSUS PRACTICE 
The research in this thesis was supported by grant no. OG-97002 from the fund for evaluative research in medicine of the Dutch Healthcare Insurance Board.

(C) 2008, Thea van Asselt

ISBN 9789052787664

Printed by Datawyse | Universitaire Pers Maastricht 


\title{
ECONOMIC ASPECTS OF TREATMENT FOR BORDERLINE PERSONALITY DISORDER
}

\author{
THEORY VERSUS PRACTICE
}

\begin{abstract}
Proefschrift
Ter verkrijging van de graad van doctor aan de Universiteit Maastricht, op gezag van de Rector Magnificus, prof. mr. G.P.M.F. Mols,

volgens het besluit van het College van Decanen, in het openbaar te verdedigen op vrijdag 31 oktober 2008 om 14.00 uur

door
\end{abstract}

Antoinette Dorothea Isabelle van Asselt

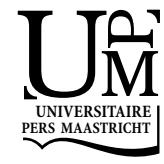




\section{Promotores}

Prof. dr. J.L. Severens

Prof. dr. A. Arntz

\section{Copromotor}

Dr. C.D. Dirksen

\section{Beoordelingscommissie}

Prof. dr. G.A.M. Widdershoven (voorzitter)

Prof. dr. J.J. van Busschbach (Erasmus Universiteit)

Dr. S.M.A.A. Evers

Prof. dr. M.L. Peeters

Prof. dr. J.J. Polder (Universiteit van Tilburg) 


CONTENT

Chapter 1

Introduction

Chapter 2

The cost of borderline personality disorder : Societal cost of illness in BPD patients

Chapter 3

Outpatient psychotherapy for borderline personality disorder: Costeffectiveness of schema-focused therapy versus transference-focused psychotherapy

\section{Chapter 4}

Difficulties in calculating productivity costs: Work disability associated with borderline personality disorder

\section{Chapter 5}

How to deal with cost differences at baseline

\section{Chapter 6}

The EQ-5D: a useful assessment instrument in a borderline personality disorder population?

Chapter 7

General discussion

Samenvatting

Dankwoord

Curriculum Vitae 

INTRODUCTION 
CHAPTER 1 


\section{BORDERLINE PERSONALITY DISORDER}

Personality disorders are a class of mental disorders characterized by rigid and enduring patterns of emotions, thought, and action, experienced by subjects as part of their character. The inflexibility and pervasiveness of these patterns often cause serious personal and social difficulties, as well as a general impairment of functioning. Personality disorders are defined by the American Psychiatric Association as "an enduring pattern of inner experience and behavior that deviates markedly from the expectations of the culture of the individual who exhibits $i t^{\prime \prime(1)}$. The onset of these patterns of behavior can typically be traced back to the beginning of adulthood, and, in rare instances, early adolescence ${ }^{(1)}$. Personality Disorders can be categorized into three clusters. Cluster A includes the odd or eccentric disorders, cluster B the dramatic, emotional, or erratic disorders, and cluster $C$ concerns anxious or fearful disorders.

Borderline Personality Disorder (BPD) is a cluster B personality disorder and is a complex and serious mental disorder characterized by a pervasive pattern of instability of interpersonal relationships, self-image, and affects, and marked impulsivity. Possible symptoms are, for instance, frantic efforts to avoid real or imagined abandonment, impulsivity in areas that are potentially self-damaging (e.g., spending, sex, substance abuse, reckless driving, binge eating), recurrent suicidal behaviour, gestures, or threats, or self-mutilating behaviour, chronic feelings of emptiness, and inappropriate, intense anger or difficulty controlling anger ${ }^{(1)}$

\section{THE BORDERLINE TRIAL}

Until recently, no pharmacological or psychosocial treatment had demonstrated efficacy on all aspects of BPD ${ }^{(2)}$. However, there are two newly developed individual outpatient therapies, Schema Focused Therapy (SFT) and Transference Focused Psychotherapy (TFP). These two therapies have been compared in a multi-center randomized trial in the Netherlands. Eighty-eight patients on the locations Amsterdam, Leiden, Den Haag, and Maastricht, initially enrolled in the trial, of which two were excluded for the analysis. This left 44 patients for SFT and 42 for TFP. Patients received treatment for 3 years, two times a week, and the total time horizon of the study was 4 years. Both therapies proved to be effective in reducing BPD-specific and general psychopathologic dysfunction and measures of SFT/TFP concepts, and in improving quality of life. SFT however proved to be superior on all of these measures $^{(3)}$

\section{ECONOMIC EVALUATION}

In the current, budget-restrained, healthcare system, the cost-effectiveness of an intervention is gaining importance. Calculating the cost-effectiveness of an interven- 
tion in fact is evaluating whether or not this intervention offers value for money compared to an alternative course of action. For if the care as usual (or another intervention in current practice) offers the same effectiveness for a lower price, or higher effectiveness for the same price, then the care as usual is the preferred option, to help as many people as possible with the available budget.

In practice, however, things are slightly more complicated. Very often, for instance, a new intervention is more effective but also more expensive than an existing intervention.

In that case, the question is whether the extra effect is worth the investment. A costeffectiveness analysis is a specific type of an economic evaluation out of four options. The first is a cost-benefit analysis, which puts both costs and effects in monetary terms and calculates the net incremental benefit of an intervention. The second type is a cost-minimization analysis, which only compares the costs of two interventions, when effects are known to be equal. In a cost-effectiveness analysis, the outcome is put in terms of extra costs per unit of effect, for instance, therapy A recovers 1 patient extra compared to therapy $B$ at a cost of 10 Euros. This number of 10 Euros per unit of effect is called the incremental cost-effectiveness ratio (further referred to as ICER), and is calculated in the following way:

$\frac{\text { costs therapy } A-\text { costs of therapy B }}{\text { effects of therapy } A-\text { effects of therapy B }}$

In comparing incremental costs and effects, there are 4 possible combinations, which are represented in table 1 .

Table 1: The possible combinations of incremental costs and effect in a comparison between two treatments

\begin{tabular}{lcc}
\hline & less effect & more effect \\
\hline higher costs & inferior & evaluate ICER \\
lower costs & evaluate ICER & dominant \\
\hline
\end{tabular}

When therapy A is less costly and more effective than therapy B (lower right section in table 1), than the choice is very easy: therapy $A$ is dominant and therapy $B$ should naturally be replaced by therapy $A$. When the situation is the other way around, i.e. when therapy A generates less effect and is more costly (upper left section in table 1), it goes without saying that therapy B is the preferred option. Therapy A is inferior then. In the other two cases the situation is more complicated. If therapy $A$ is more effective and more costly (upper right section in table 1), a situation which is quite frequent in practice, then the ICER becomes relevant, since now the proportion of costs to effects becomes important. In terms of the example mentioned above, the question is whether it is acceptable to spend 10 Euros to recover 1 extra patient. This question should be answered by policy makers, and the answer depends on a number of factors, amongst which, of course, the severity of the disease in question. The last possible situation is where therapy A is less costly, but also leads to less effect than therapy $B$ (lower left section in table 1 ). In theory, this situation is the same as 
the one before (the more effective, more costly combination), and the question would be whether the cost saving and loss of effect are in an acceptable proportion to each other. But is any loss of effectiveness compared to the current situation acceptable at all? And if so, is the accepted ratio of costs to effects, also known as the threshold value, the same as in the upper right section of the quadrant? In other words, if a cost of 10 Euro or less to recover one patient is considered cost-effective, does this also mean that a cost saving of 10 Euro or more should be enough to compensate the fact that there is one extra patient that is not cured? This is a touchy subject on which there is no consensus yet in the cost-effectiveness literature ${ }^{(4,5)}$. As is apparent from the above section, the figure of the ICER is open to more than one interpretation, since a new intervention that is more effective and more costly than an existing intervention can result in the same ICER as a new intervention that is less effective and less costly than the existing intervention, because the ratio of two negative numbers is also positive. Analogously, both an intervention that is more costly and less effective (inferior), and an intervention that is less costly and more effective (dominant) will result in a negative ICER. So, to be able to correct the ICER correctly, it is important to look at the incremental costs and effects, i.e. the nominator and denominator of the ICER, separately.

A cost-utility analysis, the fourth type of economic evaluation, is similar to a costeffectiveness analysis, but the specific feature of a cost-utility analysis is that the effect is put in terms of so-called Quality Adjusted Life Years (QALYs). As one QALY is equal to one year in perfect health, in a cost-utility analysis, the incremental costs per year spent in perfect health is calculated.

When possible, a societal perspective is recommended to perform an economic evaluation. A societal perspective includes all relevant costs inside as well as outside the health care sector, and therefore the societal perspective is the only perspective that never counts as a gain what is really someone else's loss ${ }^{(6)}$. Costs that can arise outside the health care sector are for instance productivity costs, i.e. costs as a consequence of persons not being able to do their job (paid or unpaid), costs of the burden that persons place on their family and friends, costs of alcohol and drug abuse, and costs of over-the-counter medication. Choosing a societal perspective for costs should imply a corresponding perspective for the effects of an intervention in an economic evaluation, and so the valuation of 'perfect health' and other health states to assess QALYs should be made by the general public and not by patients. In contrast, more limited perspectives include a patient perspective, health care perspective, or third party payer perspective.

Summarizing, a cost-effectiveness analysis examines the incremental cost of a new intervention in combination with the incremental effects of this intervention, compared to the new intervention, in most cases to the care as usual. The societal viewpoint is most preferred. 


\section{COSTS OF BPD}

The costs of a disease for society can be calculated in a so-called cost of illness (COI) study. COI studies aim to identify, measure, and estimate all resources consumed because of the illness, the final purpose being that of highlighting the economic importance of a particular disease ${ }^{(7)}$. There are some studies identifying costs of hospitalization as the main cost driver for the financial burden of BPD ${ }^{(8,9)}$. However, these studies did not take a societal perspective. In a study by Smit et al. ${ }^{(10)}$ the societal costs of nine common psychiatric disorders were compared for the Dutch situation. The average annual extra costs (i.e. outside the standard consumption for non-related small health problems) for the average psychiatric patient were $€$ 3.200. That was slightly more than the average costs for a somatic disease, which were estimated at $€$ 3.020. So, one can assume that BPD, being a quite severe psychiatric condition, brings about a substantial cost to society.

\section{AIM OF THE THESIS}

The aim of this thesis is threefold. First, it estimates the total societal monetary burden of Borderline Personality Disorder, the Cost of Illness, for the Netherlands. Second, it is an economic evaluation of two outpatient therapies for the treatment of $\mathrm{BPD}$, and aims to pronounce upon the preferred therapy for this patient population. Third, the thesis discusses how an economic evaluation can be performed in BPD patients, what methodological problems can emerge, and how to resolve those problems. Since, to our knowledge, there has not been a full economic evaluation from a societal viewpoint nor a cost-of-illness study in a BPD population, this thesis aims to give an example on how to manage certain difficulties that arise in the process of measuring and analyzing costs and effects in BPD patients.

\section{OUTLINE OF THE THESIS}

Chapter 2 is a so-called cost-of-illness study, which provides an overview of the total societal costs that are associated with BPD. We performed a prevalence based, bottom-up study, the former meaning that total annual societal costs for all prevalent cases in a certain year were calculated, the latter referring to the fact that costs were calculated directly from patient data.

Chapter 3 is a report of the trial based economic evaluation of SFT versus TFP. Patients were randomized into one of the treatment conditions and received therapy, twice a week, for three years. The economic evaluation was performed with two different outcome measures: the number of patients recovered and Quality of Life with a time horizon of four years.

Chapter 4 focuses on one particular problem that emerged in analyzing the results of chapter 3, which is the fact that a major part of the BPD population is work disabled. This leads to difficulties in calculating the productivity costs, since in economic 
evaluation as it is usually performed, work disabled patients are generally not included. This chapter shows the consequences of excluding or including work disabled patients for the productivity costs of a BPD population.

Chapter 5 describes how to manage another problem we came across: a baseline difference in costs between groups in the RCT. The question is how this should be corrected for in further measurements. In clinical medicine, it is common practice to correct for differences in baseline characteristics, such as for instance age, or clinical measures like blood pressure or body weight. In economic evaluations, baseline costs are never corrected for, if they are reported at all. In this chapter we explain and apply different methods for correction and discuss which one is to be preferred.

Chapter 6 asks whether the EQ-5D, being a general quality of life instrument, is responsive in a BPD population. Since there are no studies available concerning this topic in BPD patients, we essentially do not know whether the EQ-5D is sensitive to change in these patients. In this chapter, we compare the EQ-5D outcomes with those for the BPDSI-IV, which is a clinical instrument indicating the severity of BPD. Chapter 7, the general discussion, briefly summarizes the findings of the previous chapters and discusses those in the light of the aims of this thesis. 


\section{REFERENCES}

1. APA. Diagnostic and Statistical Manual of Mental Disorders, fourth edition. 1994, Washington, D.C.: American Psychiatric Association.

2. APA. Practice guideline for the treatment of patients with borderline personality disorder. Am J Psychiatry, 2001. 158(10 Suppl): p. 1-52.

3. Giesen-Bloo J, van Dyck R, Spinhoven P, et al. Outpatient psychotherapy for borderline personality disorder: randomized trial of schema-focused therapy vs transference-focused psychotherapy. Arch Gen Psychiatry, 2006. 63(6): p. 649-58.

4. Dowie J. No room for kinkiness in a public healthcare system. Pharmacoeconomics, 2005. 23(12): p. 1203-5.

5. Severens JL, Brunenberg DE, Fenwick EA, et al. Cost-effectiveness acceptability curves and a reluctance to lose. Pharmacoeconomics, 2005. 23(12): p. 1207-14.

6. Gold M, Siegel J, Russell L, Weinstein M, eds. Cost-effectiveness in health and medicine. 1996, Oxford University Press: New York.

7. Tarricone R. Cost-of-illness analysis. What room in health economics? Health Policy, 2006. 77(1): p. 51-63.

8. Bateman A, Fonagy P. Health service utilization costs for borderline personality disorder patients treated with psychoanalytically oriented partial hospitalization versus general psychiatric care. Am J Psychiatry, 2003. 160(1): p. 169-71.

9. Stevenson J, Meares R. Psychotherapy with borderline patients: II. A preliminary cost benefit study. Aust N Z J Psychiatry, 1999. 33(4): p. 473-7; discussion 478-81.

10. Smit F, Cuijpers P, Oostenbrink J, et al. Costs of nine common mental disorders: implications for curative and preventive psychiatry. J Ment Health Policy Econ, 2006. 9(4): p. 193-200. 
THE COST OF BORDERLINE PERSONALITY DISORDER Societal Cost of Illness in BPD-patients

A.D.I. van Asselt, C.D. Dirksen, A. Arntz, J.L. Severens

Published in European Psychiatry, 2007 Sep; 22(6):354-61 


\section{ABSTRACT}

BACKGROUND Borderline Personality Disorder (BPD) is a highly prevalent, chronic condition. Because of its very problematic nature, BPD is expected to be associated with substantial societal costs, although this has never been comprehensively assessed.

OBJECTIVE Estimate the societal cost of BPD in the Netherlands.

STUDY DESIGN We used a prevalence-based bottom-up approach with a sample of 88 BPD patients who enrolled in a multicenter clinical trial comparing two kinds of outpatient psychotherapies. Costs were assessed by means of a structured interview, covering all healthcare costs, medication, informal care, productivity losses, and outof-pocket expenses. Only BPD-related costs were included. All costs were expressed in Euros for the year 2000. A bootstrap procedure was performed to determine statistical uncertainty.

PATIENTS All patients had been diagnosed with BPD using DSM-IV criteria. Mean age was 30.5 years and $92 \%$ was female.

RESULTS Based on a prevalence of $1.1 \%$ and an adult population of $11,990,942$, we derived that there were 131,900 BPD patients in the Netherlands. Total bootstrapped yearly Cost of Illness was €2,222,763,789 (€1,372,412,403 - €3,260,248,300), only $22 \%$ was healthcare-related. Costs per patient were $€ 16,852$.

CONCLUSIONS Although healthcare costs of non-institutionalized Borderline patients might not be disproportionate, total societal costs are substantial. 


\section{INTRODUCTION}

Borderline Personality Disorder is a chronic condition, which is estimated to be present in $0.5 \%$ to $2.5 \%$ of the general population ${ }^{(1,3,8,20,32,36)}$. The problematic nature of BPD is characterized by recurring crises, hospitalizations, self-mutilation, suicide attempts, addictions and episodes of depression, anxiety and aggression (DSMIV). Moreover, BPD is very frequently diagnosed in psychiatric inpatients ${ }^{(18,24)}$, substance abusers $^{(6,21,22,31,40)}$, and convicts in general prisons as well as forensic psychiatric institutions ${ }^{(17,35)}$. In addition, suicide in BPD-patients is frequent, even after psychiatric treatment. In several studies, the percentage of BPD-patients that eventually commits suicide is found to be between $2 \%$ and $17 \%$, depending on the length of the follow-up ${ }^{(23,28,43)}$. Quality of Life, as studied in two recently performed clinical trials $^{(15,26)}$ is severely impaired in BPD-patients. Utility scores found in these trials, generated by the EuroQol-5D ${ }^{(9)}$, varied around 0.5 .

Intuitively, considering all the above factors, one would say that BPD must be associated with substantial tangible and intangible costs. Several studies ${ }^{(4,44)}$ have found that BPD-patients continuously use outpatient treatment and take psychotropic medication, thus imposing a significant burden on health care services. Bender et al. also found that BPD-patients, compared to patients with other personality disorders and patients with major depression, used more treatment and medication. A recent paper by Frankenburg and Zanarini ${ }^{(13)}$ showed that patients with active BPD have a higher risk of suffering from chronic physical conditions, making poor health-related lifestyle choices, and using costly forms of medical services than patients with remitted BPD. Smith et al. ${ }^{(34)}$ and Rendu et al. ${ }^{(29)}$ tried to quantify the cost of illness of personality disorders in general. Rendu et al. found that the costs (both healthcare and non-healthcare) for patients with personality disorder were significantly higher than the costs for those without a personality disorder, when the BPD-diagnosis was accompanied by other common mental disorders. BPD in itself was not a significant explanatory factor for higher costs. Although all of the above studies have done some work on exploring the costs of personality disorders in general and BPD in special, a formal cost of illness study using a comprehensive societal perspective for BPD has not yet been performed. The aim of the present study therefore is to estimate the societal cost of illness of BPD in the Netherlands.

\section{MATERIAL AND METHODS}

\section{Design}

In performing a COI, there is a choice between a bottom-up and a top-down approach $^{(11)}$. The first entails that healthcare consumption or cost data of a sample of patients are gathered and extrapolated to the total population. However, extrapolating can be difficult when the sample is not representative for the entire population. Also, not all events which are regarded typical for the cost profile of a specific disease may occur in the sample population and in the sample period. The alterna- 
tive for a bottom-up approach is a top-down estimation, where total cost per healthcare sector are used as a starting point, and fractions of these costs are assigned to a specific disease according to the prevalence of that specific disease for that specific sector. The top-down method does not suffer from the shortcomings mentioned above. However, the problem with top-down for the Borderline population is that, as we experienced, very little diagnosis-specific information is available for this type of patients. Most registrations can only deliver data for personality disorders in general, but not for each specific personality disorder separately. Because of these difficulties with the top-down data, we decided to choose the bottom-up approach, as this was expected to yield more reliable results.

The population for which COI was calculated was based on prevalence, so the results apply to all prevalent cases for a specific point in time, i.e. the year 2000. Cost of lost productivity were calculated according to the Human Capital approach $^{(19)}$. The analysis was performed from a societal perspective.

\section{Study population and data collection}

The baseline cost interviews of 88 BPD-patients who enrolled in a Dutch randomized trial were used ${ }^{(15)}$. This multi-center trial compares two outpatient psychotherapies for BPD patients. All patients had been diagnosed with BPD according to DSMIV criteria ${ }^{(1)}$, using the Structured Clinical Interview for DSM-IV Personality Disorders, the SCID-II ${ }^{(12,42)}$. Patients were referred to the trial by therapist at secondary and tertiary community mental health institutes based on a clinical diagnosis of BPD. Age had to be between 18 and 60 at inclusion, and the severity-score according to the Borderline Personality Disorder Severity Index ${ }^{(2,41)}$ (BPDSI) higher than 20. Exclusion criteria were psychotic disorder of some kind, bipolar disorder, depression with psychotic symptoms at early age, organic causes for the problems, antisocial personality disorder, ADHD, mental retardation, or severe addiction needing clinical detoxification. All patients gave written informed consent and the study was approved by the medical ethical committees of the three participating centers.

The face to face cost interview took place before randomization and onset of therapy and covered a period of three months preceding the inclusion. Items in the interview concerned healthcare costs in mental as well as regular health care institutions, productivity costs due to absence of work and disability, informal care by family and friends, and out-of-pocket expenses. Informal care is an especially important item in mental health care, since patients can place a large burden on their environment. Informal care means that persons near the patient take care of the patient and possibly take over some domestic tasks. These persons can be family, friends, or neighbours. Informal care might in some cases be paid for, but a key characteristic is that the caregiver would not want to care for someone outside of his social environment for a similar wage ${ }^{(37)}$. In the interview, the number of hours the patient receives informal care is collected, and then the costs are calculated by multiplying this number by a shadow price ${ }^{(25)}$.

For all items, only BPD-related costs were taken into account. Unit costs per item were derived from Dutch reference prices ${ }^{(25)}$, unless specified otherwise. All costs are 
expressed in Euros using the 2000 price level, since the majority of the patients enrolled in the trial in that year. On February $1^{\text {st }} 2000,1$ Euro was worth 0.97 US Dollars. Volumes obtained from the interview were multiplied with unit costs resulting in mean costs per three months per patient. These costs were then multiplied by four to obtain mean yearly costs per patient. Since inclusion of patients was scattered throughout the year, there is no structural seasonal effect in the three months covered by the baseline interview. Mean yearly costs were multiplied with the prevalence figure for the adult general population in order to estimate the total cost of illness of BPD to society.

There was a number of BPD-related events that, by definition, could not occur in our sample population, because of the fact that the baseline measurement was a retrospective interview. These events were suicide and imprisonment in a forensic psychiatric institution. To be able to take account of these events, we estimated the costs for suicide and forensic psychiatric institutions by means of the top-down approach.

Sensitivity analysis explored the robustness of the results when varying several parameters. A bootstrap resampling procedure was performed to be able to determine statistical uncertainty of the cost estimate ${ }^{(5,10)}$. Confidence Intervals $(\mathrm{Cl})$ were constructed based on bootstrapped 2.5 and 97.5 percentiles.

\section{RESULTS}

\section{Study population}

Among the 88 patients who completed the baseline cost interview were 81 females $(92 \%)$ and 7 males (8\%). The mean age was 30,5 years (range 20-53). Sixty four of them $(73 \%)$ were insured by the Dutch national sick fund, thirteen $(15 \%)$ had private insurance, and of eleven patients $(12 \%)$ the insurance form was unknown. The mean score on the BPDSI, which has a possible range of 0 to 90 , with higher scores indicating a higher severity, was 33.76 with a standard deviation of 7.97.

\section{Prevalence}

For the base-case analysis, in accordance with a German prevalence study ${ }^{(20)}$, the prevalence of BPD in the Dutch general population aged 20 and over was estimated at $1.1 \%(0.9 \%$ for men and $1.3 \%$ for women). Maier et al. find a prevalence that is somewhere in between the range of $0.5 \%$ to $2.5 \%$ we already mentioned before ${ }^{(1,3,8,20,32,36)}$. Also, Germany is a neighboring country and BPD prevalence in Germany might be similar to BPD prevalence in the Netherlands, although this is merely an assumption. Other prevalence figures will be considered in the sensitivity analyses. In 2000, the Dutch adult population consisted of 11,990,942 residents $^{(7)}$. When applying the prevalence rate of $1.1 \%$ to this population, it can be derived that in the Netherlands 131,900 adults suffered from BPD in 2000. 


\section{Costs of BPD}

Table 1 shows the unit costs, quantities of the units per patient and total costs for all BPD-patients as well as the bootstrapped mean and costs with a confidence intervals based on percentiles. The mean bootstrapped costs and confidence intervals are visually represented in figure 1 . For a number of cost items, details are explained below.

\section{Out-of-pocket costs}

Out-of-pocket costs for BPD patients mainly arise as a consequence of their lifestyle. Of the patients included in the trial, almost $60 \%$ reported to have costs associated with their BPD-problems. The majority of these patients $(63 \%)$ mentioned excessive smoking, shopping and (binge) eating and extremely high phone bills as the main cost drivers. Also mentioned sometimes were, for instance, costs of bandaging selfinflicted wounds and excessive buying of presents for others. Total out-of-pocket costs were on average $€ 1,395$ per patient. In addition to this, we measured costs of medication which was not prescribed, and therefore paid by the patient. These costs were $€ 28$ per patient. Total bootstrapped out-of-pocket costs amounted to $€ 189,144,600$ (CI €123,722,200 - €262,744,800).

\section{Forensic psychiatric institutions (top-down)}

In forensic psychiatry, the majority of patients suffers from a personality disorder. Within this group, the prevalence of antisocial and borderline personality disorder is by far the largest ${ }^{(8)}$. Of the 657 inpatients at the end of 1997, $34(5.18 \%)$ had a primary diagnosis $\mathrm{BPD}^{(14)}$. Total costs of Forensic Psychiatric institutions in the Netherlands in 2000 were $€ 78,297,000$ which implies total BPD costs of $€ 4,051,900$ top-down.

\section{Productivity costs due to morbidity}

Patients reported to have been absent from their job for 218 hours per year. When valued against actual wages, mean productivity costs due to absence from work for the trial sample were $€ 1,320$ per patient per year, implying total costs to be $€ 174,108,000$. With respect to disability, almost $32 \%$ (28) of the patients was fully disabled. Furthermore, 8 patients $(9 \%)$ were partially disabled with a mean of $64 \%$ disablement, varying from $35 \%$ to $95 \%$. This implies a total of 46,996 fully disabled and 6,065 partially disabled individuals due to BPD for the Netherlands. The average gross yearly income in the Netherlands in 2000 was $€ 31,000$ for men and $€ 16,200$ for women ${ }^{(7)}$. Using these wages resulted in total bootstrapped productivity costs of $€ 888,214,600$ ( $\mathrm{Cl} € 649,211,800$ - $€ 1,138,692,700)$ due to disability. 


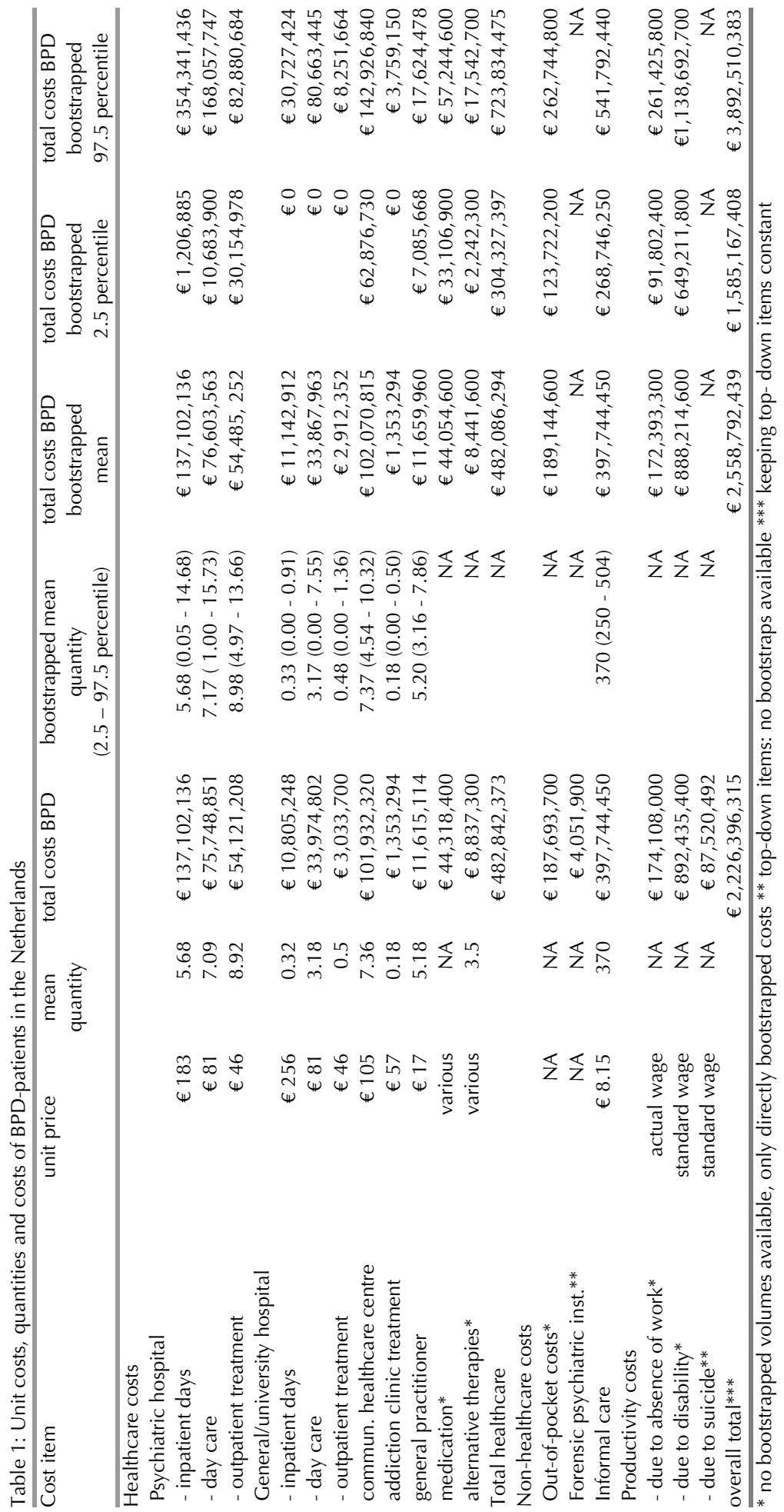




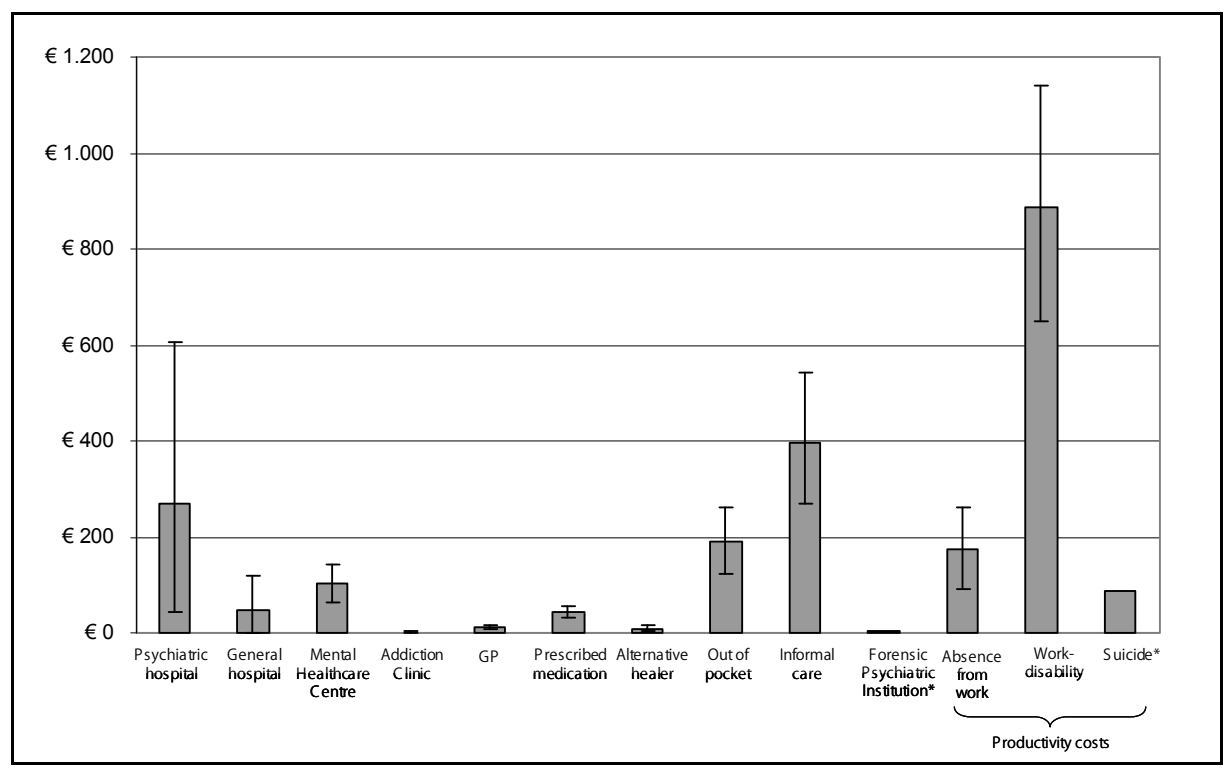

Figure 1: Mean bootstrapped costs and 2.5 and 97.5 percentiles in million Euros for BPD-patients in the Netherlands * top-down items have no error bars because there is no bootstrap available

\section{Productivity costs due to mortality (top-down)}

In national registrations, no figures concerning BPD-suicides were available. However, the suicide rate in BPD-patients has been found to be considerable. Paris et al. ${ }^{(27)}$ for instance, report a chance of $10.3 \%$ over a 27 -year follow-up. Based on this publication, the instantaneous suicide risk was calculated at $0.49 \%$ per year, which means 646 BPD-related suicides in the Netherlands each year. However, taking into account that $40.90 \%$ of these patients were already disabled and therefore not productive, as we have calculated in the preceding section, this leaves 382 suicides which lead to actual production losses. Next, production losses were assessed by assigning the expected net value of production, corrected for age and sex, to these suicides, according to the Human Capital method. Average production in the Netherlands $^{(7)}$ was used for these calculations. Total top-down production losses due to premature mortality were $€ 87,520,492$.

\section{Total costs}

Total bootstrapped Cost of Illness was $€ 2,222,763,789$ (Cl $€ 1,372,412,403$ $€ 3,260,248,300)$. This total COI includes the top-down estimates for forensic psychiatric institutions and lost productivity due to suicide. When we leave these two items out, the total bottom up COI amounts to $€ 2,131,191,397$, which is $4 \%$ less. The larger part of total COI was not healthcare-related. Total bootstrapped healthcare costs were $€ 482,086,294$ ( $\mathrm{Cl} € 304,327,297$ - $€ 723,834,475)$, representing $21.69 \%$ of 
total COI and $0.63 \%$ of total Dutch health care expenditure in 2000, respectively. When translating the total cost of illness to a 'yearly cost per inhabitant' figure, this cost is $€ 140$. These numbers were calculated using the entire population, including children. The costs per case, which are the costs per BPD-patient in the Netherlands per year, are $€ 16,852$.

Table 2: Outcome univariate sensitivity analysis

\begin{tabular}{|c|c|c|c|c|c|c|c|}
\hline \multirow[t]{3}{*}{ Parameter } & \multicolumn{3}{|c|}{ Range } & \multicolumn{4}{|c|}{ Outcome Cost of Illness } \\
\hline & Base-case & Low & High & Low & & High & \\
\hline & & & & $\mathrm{COI}(€)$ & $\Delta \%$ & $\mathrm{COI}(€)$ & $\Delta \%$ \\
\hline BPD prevalence & $1 \%$ & $0.5 \%$ & $2.0 \%$ & $1,011,998,325$ & -54.55 & $4,047,993,300$ & 81.82 \\
\hline Rate of disability & $33 \%$ & $10 \%$ & $50 \%$ & $1,512,823,493$ & -27.94 & 2868.135763 & 20.65 \\
\hline Suicide rate & $0.49 \%$ & $0.1 \%$ & $0.8 \%$ & $2,156,737,148$ & -3.13 & $2,281,766,422$ & 2.49 \\
\hline \% Discounting* & $5 \%$ & $0 \%$ & $8 \%$ & $2,281,024,832$ & 2.45 & $2,208,452,337$ & -0.81 \\
\hline Out of pocket costs & $€ 187,693,700$ & $\downarrow 50 \%$ & $\uparrow 50 \%$ & $2,038,834,515$ & -8.42 & $2,414,090,015$ & 8.43 \\
\hline $\begin{array}{l}\text { Unit price of: } \\
\text { psychiatric hospital }\end{array}$ & & & & & & & \\
\hline inpatient day & 183 & 92 & 366 & $2,158,219,843$ & -3.06 & $2,363,498,451$ & 6.16 \\
\hline day care & 81 & 41 & 162 & $2,188,989,475$ & -1.68 & $2,302,145,166$ & 3.40 \\
\hline outpatient treatment & 46 & 23 & 92 & $2,199,335,711$ & -1.22 & $2,280,517,523$ & 2.43 \\
\hline $\begin{array}{l}\text { non-psychiatric hospital } \\
\text { inpatient day }\end{array}$ & 256 & 128 & 512 & $2,220,993,691$ & -0.24 & $2,237,201,563$ & 0.49 \\
\hline day care & 81 & 41 & 162 & $2,209,618,635$ & -0.75 & $2,260,371,117$ & 1.53 \\
\hline outpatient treatment & 46 & 23 & 92 & $2,224,879,465$ & -0.07 & $2,229,430,015$ & 0.14 \\
\hline $\begin{array}{l}\text { community health } \\
\text { center }\end{array}$ & 105 & 53 & 219 & $2,175,915,547$ & -2.27 & $2,328,328,635$ & 4.58 \\
\hline ambul. addiction trtmnt & 57 & 29 & 114 & $2,225,731,539$ & -0.03 & $2,227,749,609$ & 0.06 \\
\hline GP visit & 17 & 9 & 34 & $2,220,930,379$ & -0.25 & $2,230,495,767$ & 0.18 \\
\hline 1 hour of informal care & 8.15 & 4 & 16 & $1,023,863,865$ & -9.10 & $2,609,499,865$ & 17.21 \\
\hline
\end{tabular}

* for calculating costs of lost productivity due to suicide

\section{Sensitivity Analysis}

The parameters used in the present study were, at least to some extent, subject to uncertainty. To test the robustness of the results to changes in prevalence and unit prices, a univariate sensitivity analysis was performed. Ranges for unit prices were obtained by roughly dividing and multiplying the base-case unit price by two. The results of the sensitivity analysis for the mean total $\mathrm{COI}$ are shown in table 2 .

Most striking is the fact that unit prices are not of much influence on the outcome, except for the unit price of informal care. The prevalence of BPD in the general population is the most important factor, as was to be expected, since this parameter has an impact on all cost items. The second most important factor is the disability rate. Varying the out-of-pocket costs has a moderate influence on total costs, but one should bear in mind that, because of the subjective nature of this cost category, the results of the sensitivity analysis for the out-of-pocket costs are highly relevant. 


\section{DISCUSSION}

The goal of the present study was to assess the burden of BPD on Dutch society. Total bootstrapped costs for BPD were $€ 2,222,763,789$. Less than a quarter of these costs arose in the healthcare sector. Direct medical costs represent $0.63 \%$ of total Dutch health care expenditure in 2000. Given the fact that the prevalence of BPD is estimated to be more than $1 \%$ of the general population, it seems that BPD-patients use up a less than proportionate share of healthcare budget, although one should bear in mind that institutionalized patients are not part of our sample. On the other hand, non-healthcare costs form a large part (more than $77 \%$ ) of total COI. This is not surprising, regarding the large impact of BPD on the personal and professional life of the patient, which is typical for psychiatric disorders, and BPD in particular. It is difficult to say whether or not these non-healthcare costs are high or not, since very little research has been done in this field. However, it is plausible that for chronic somatic diseases of patients in the same age category, the ratio of healthcare costs to non-healthcare costs is much higher.

The patient sample used here may not be representative of the entire BPDpopulation. There are several reasons to assume that this leads the cost of illness to be an overestimation. First, patients included in the sample are treatment seekers, which means that they experience symptoms which are serious enough to seek help, and therefore these patients probably generate more costs than the non-treatment seekers. In the same manner, it is plausible that costs mount up to the point of start of treatment because of these serious symptoms, and therefore the three months previous to this point might not be representative for the whole year preceding. Second, to be included in the trial, a patient had to score over 20 on the BPDSI, which also implies the presence of considerable symptoms and, consequently, costs.

However, there are also reasons to assume the contrary. Due to the exclusion criteria used in the trial, the bottom-up sample does not contain psychotic patients, patients with bipolar disorder, patients with serious addictions needing inpatient detoxification (like heroin), mentally retarded and forensic patients, or clinical inpatients. Also, the most severe BPD cases might be so demoralized that they do not apply for treatment. These groups of patients represent the most problematic individuals within the BPD-population, and the fact that they are not in the bottom-up sample could lead to underestimation of true costs.

Furthermore, the researchers of the clinical paper found that patients who declined to take part in the study had the same baseline characteristics as patients who participated (J. Giesen-Bloo, personal communication, March $20^{\text {th }} 2007$ ). This speaks for a representative sample, but one should bear in mind that the patients who declined to participate did already pass the criteria for in- and exclusion and were therefore a sub-sample of the population.

Summing up these factors, it is difficult to say whether the population in the trial is more or less costly than the average BPD-patient. 
To solve the problem of the representativeness of the trial population, a top-down $\mathrm{COI}$ study could be performed. For many diseases, this is very well possible. However, national registrations do not always have diagnosis-specific data, and especially for mental diseases it is very difficult to assign costs. For instance, there are no national databases which contain the number of contacts at the general practice, prescribed medication, or absenteeism at work specified down to the diagnosis level. For psychiatric illnesses, there is another problem involved with performing a topdown $\mathrm{COI}$ calculation. For defining the disease, the standard practice in COI studies is to include only the primary diagnosis to avoid overlap ${ }^{(30)}$. However, in the case of psychiatric illnesses, the registered primary diagnosis may not always be accurate. When patients present themselves with somatic problems outside the mental healthcare setting, BPD will generally not be identified as the underlying problem. It is very likely that BPD-patients are large consumers of care at General Practitioners, Emergency Rooms, outpatient clinics and general hospitals. However, this type of care is not traceable in the registrations, since BPD will not be registered as the primary diagnosis in these cases.

In addition, a top-down study is not suitable for a disease for which for instance burden to the family, lost productivity in non-paid activities, out-of-pocket costs, alternative therapies, or non-prescribed drugs are the main cost drivers. For the BPDpopulation this is exactly the case, which means that in a top-down COI design, all these costs could, if at all, only be captured with great difficulty.

The arguments summed up above lead us to believe that a top-down COI calculation will probably result in a $\mathrm{COI}$ estimate which is much less accurate than the bottomup calculation performed in the present study.

Apart from the choice for bottom-up or top-down, we defined a prevalence based approach. In contrast, an incidence approach would have resulted in a figure which informs about lifetime costs of a patients that can be avoided when one case of BPD is prevented. Our prevalence based-approach informs about the cost related to the disease of a patient that can be avoided each year when one case of BPD is cured. Since prevention of BPD is very difficult, and incident cases are not easily traced, the prevalence approach is therefore more useful for current decision making.

A drawback of the instrument we used for assessing the costs, i.e. the cost-interview, is that it entirely relies on the patient's memory and also on the patient's judgment of what costs are BPD-related and what costs are not. Although a 3-month recall period is generally thought of as acceptable ${ }^{(33,38)}$, we realize that the BPD-population may be different in that respect. However, validating the information by, for instance checking hospital or insurance records, turned out to be very difficult. The reasons for this are partly in the registration system in the Netherlands, which does not account for mental health care consumption on an individual basis, and partly in the fact that patients could have gone everywhere for their care, and we could not possibly check every health care facility in the country. The difficulties with obtaining data from healthcare providers and insurers have been described in the literature ${ }^{(16,39)}$, and are even more serious here, because it concerns a patient group which is difficult to diagnose and very hard to follow through the system. Moreover, costs made directly by the patient, such as out-of-pocket costs, alcohol and drug use, and over the 
counter medication cannot be validated by definition. In brief, in our case, it is virtually impossible to obtain complete and reliable data from anywhere else than the patient. As an alternative for our calculations choosing the FC method to value productivity costs would consequently mean leaving out productivity costs due to disability completely. This will therefore lead to a lower estimate of the total COI.

However, disabled persons are a cost to society, and in case a certain illness indicates a high risk of becoming disabled, then this increased risk should be expressed in the societal cost of illness. Thus, since rather a large portion of BPD-patients are partly or fully disabled, the currently used human capital approach seems more comprehensive.

\section{RECOMMENDATIONS AND FINAL REMARKS}

In order to overcome problems with respect to representativeness of the sample in a bottom-up design, we recommend to assess prevalence and COI in a combined design. First, prevalence is assessed in an open population. Subsequently, those subjects diagnosed with BPD should be followed for a predefined period of time in order to determine true COI. For psychiatric illnesses, it is not recommendable to perform a top-down $\mathrm{COI}$ calculation because of problems of under-registration, difficulty with calculating certain cost categories and inaccurate primary diagnoses.

The present study is the first to investigate the true societal costs of BPD, and leads to the conclusion that, although healthcare costs of non-institutionalized Borderline patients might not be disproportionate, total societal costs, especially the burden to family and friends and lost productivity, are substantial.

\section{Acknowledgements}

The authors would like to thank Martin Knapp for his very useful comments to an earlier version of the present paper.

The present study was supported by grant no. OG 97-002 from the fund for evaluative research in medicine of the Dutch Healthcare Insurance Board. Publication of the study results was not in any way contingent on the sponsor's approval or censorship of the manuscript. 


\section{REFERENCES}

1. American Psychiatric Association. Diagnostic and Statistical Manual of Mental Disorders, fourth edition. Washington, D.C.: American Psychiatric Association; 1994.

2. Arntz A, van den Hoorn M, Cornelis J, Verheul R, van den Bosch WM, de Bie AJ. Reliability and validity of the borderline personality disorder severity index. J Personal Disord 2003;17(1):4559.

3. Bateman A, Fonagy P. Psychotherapy for borderline personality disorder. Mentalization-based treatment. Oxford: Oxford University Press; 2004.

4. Bender DS, Skodol AE, Pagano ME, Dyck IR, Grilo CM, Shea MT, et al. Prospective assessment of treatment use by patients with personality disorders. Psychiatr Serv 2006;57(2):254-7.

5. Briggs AH, Wonderling DE, Mooney CZ. Pulling cost-effectiveness analysis up by its bootstraps: a non-parametric approach to confidence interval estimation. Health Econ 1997;6(4):327-40.

6. Brooner RK, King VL, Kidorf M, Schmidt CW, Jr., Bigelow GE. Psychiatric and substance use comorbidity among treatment-seeking opioid abusers. Arch Gen Psychiatry 1997;54(1):71-80.

7. Central Bureau for Statistics Statline. www.cbs.nl. Accessed in 2000.

8. Dolan BM, Coid JW. Psychopathic and antisocial personality disorders: Treatment and research issues. London: Gaskell; 1993.

9. Dolan P. Modeling valuations for EuroQol health states. Med Care 1997;35(11):1095-108.

10. Efron B, Tibshirani RJ. An introduction to the bootstrap. Londen: Chapmann \& Hall; 1993.

11. Evers SM, Struijs JN, Ament AJ, van Genugten ML, Jager JH, van den Bos GA. International comparison of stroke cost studies. Stroke 2004;35(5):1209-15.

12. First MB, Spitzer RL, Gibbon M. Structured Clinical Interview for DSM-IV Axis II personality disorders (SCID-II, version 2.0): New York State Psychiatric Institute; 1994.

13. Frankenburg FR, Zanarini MC. The association between borderline personality disorder and chronic medical illnesses, poor health-related lifestyle choices, and costly forms of health care utilization. J Clin Psychiatry 2004;65(12):1660-5.

14. GGZ. figures from PiGGz regarding psychiatric hospitals, community health care centers, addiction treatment and forensic psychiatry. Annual report 1997. Utrecht: GGZ Nederland

15. Giesen-Bloo J, van Dyck R, Spinhoven P, van Tilburg W, Dirksen C, van Asselt T, et al. Outpatient psychotherapy for borderline personality disorder: randomized trial of schema-focused therapy vs transference-focused psychotherapy. Arch Gen Psychiatry 2006;63(6):649-58.

16. Goossens ME, Rutten-van Molken MP, Vlaeyen JW, van der Linden SM. The cost diary: a method to measure direct and indirect costs in cost-effectiveness research. J Clin Epidemiol 2000;53(7):688-95.

17. Greeven PGJ. The inpatient treatment of forensic patients with a personality disorder (in Dutch). Deventer: Universiteit van Utrecht; 1997.

18. Grilo CM, McGlashan TH, Quinlan DM, Walker ML, Greenfeld D, Edell WS. Frequency of personality disorders in two age cohorts of psychiatric inpatients. Am J Psychiatry 1998;155(1):140-2.

19. Hodgson TA, Meiners MR. Cost-of-illness methodology: a guide to current practices and procedures. Milbank Mem Fund Q Health Soc 1982;60(3):429-62.

20. Maier W, Lichtermann D, Klingler T, Heun R, Hallmayer J. Prevalences of personality disorders (DSM-III-R) in the community. J Pers Disorders 1992;6(3):187-196.

21. McGovern MP, Xie H, Segal SR, Siembab L, Drake RE. Addiction treatment services and cooccurring disorders: Prevalence estimates, treatment practices, and barriers. J Subst Abuse Treat 2006;31(3):267-75.

22. Morgenstern J, Langenbucher J, Labouvie E, Miller KJ. The comorbidity of alcoholism and personality disorders in a clinical population: prevalence rates and relation to alcohol typology variables. J Abnorm Psychol 1997;106(1):74-84.

23. Oldham JM. Borderline personality disorder and suicidality. Am J Psychiatry 2006;163(1):20-6. 
24. Oldham JM, Skodol AE, Kellman HD, Hyler SE, Rosnick L, Davies M. Diagnosis of DSM-III-R personality disorders by two structured interviews: patterns of comorbidity. Am J Psychiatry 1992;149(2):213-20.

25. Oostenbrink JB, Bouwmans CAM, Koopmanschap MA, Rutten FF. Manual for cost research. Methods and unit-prices for economic evaluations in health care (in Dutch). Updated version. Amstelveen: College voor zorgverzekeringen; 2004.

26. Palmer S, Davidson K, Tyrer P, Gumley A, Tata P, Norrie J, et al. The cost-effectiveness of cognitive behavior therapy for borderline personality disorder: results from the BOSCOT trial. J Personal Disord 2006;20(5):466-81.

27. Paris J, Zweig-Frank H. A 27-year follow-up of patients with borderline personality disorder. Compr Psychiatry 2001;42(6):482-7.

28. Pompili M, Girardi P, Ruberto A, Tatarelli R. Suicide in borderline personality disorder: a metaanalysis. Nord J Psychiatry 2005;59(5):319-24.

29. Rendu A, Moran P, Patel A, Knapp M, Mann A. Economic impact of personality disorders in UK primary care attenders. Br J Psychiatry 2002;181:62-6.

30. Rice DP. Estimating the cost of illness. Washington: Department of Health, Education and Welfare; 1966.

31. Rounsaville BJ, Kranzler HR, Ball S, Tennen H, Poling J, Triffleman E. Personality disorders in substance abusers: relation to substance use. J Nerv Ment Dis 1998;186(2):87-95.

32. Samuels J, Eaton WW, Bienvenu OJ, 3rd, Brown CH, Costa PT, Jr., Nestadt G. Prevalence and correlates of personality disorders in a community sample. Br J Psychiatry 2002;180:536-42.

33. Severens JL, Mulder J, Laheij RJ, Verbeek AL. Precision and accuracy in measuring absence from work as a basis for calculating productivity costs in The Netherlands. Soc Sci Med 2000;51(2):243-9.

34. Smith K, Shah A, Wright K, Lewis G. The prevalence and costs of psychiatric disorders and learning disabilities. Br J Psychiatry 1995;166(1):9-18.

35. Timmerman IG, Emmelkamp PM. The relationship between traumatic experiences, dissociation, and borderline personality pathology among male forensic patients and prisoners. J Personal Disord 2001;15(2):136-49.

36. Torgersen S, Kringlen E, Cramer V. The prevalence of personality disorders in a community sample. Arch Gen Psychiatry 2001;58(6):590-6.

37. van den Berg B, Brouwer WB, Koopmanschap MA. Economic valuation of informal care. An overview of methods and applications. Eur J Health Econ 2004;5(1):36-45.

38. van den Brink M, van den Hout WB, Stiggelbout AM, Putter H, van de Velde CJ, Kievit J. Selfreports of health-care utilization: diary or questionnaire? Int J Technol Assess Health Care 2005;21(3):298-304.

39. van den Brink $M$, van den Hout WB, Stiggelbout AM, van de Velde CJ, Kievit J. Cost measurement in economic evaluations of health care: whom to ask? Med Care 2004;42(8):740-6.

40. Verheul R, Hartgers C, Van den Brink W, Koeter MW. The effect of sampling, diagnostic criteria and assessment procedures on the observed prevalence of DSM-III-R personality disorders among treated alcoholics. J Stud Alcohol 1998;59(2):227-36.

41. Weaver TL, Clum GA. Early family environments and traumatic experiences associated with borderline personality disorder. J Consult Clin Psychol 1993;61(6):1068-75.

42. Weertman A, Arntz A, Kerkhofs. Gestructureerd klinisch interview voor DSM-IV persoonlijkheidsstoornissen (Ned. bewerking van First et al. SCID-II, version 2.0 1996). Maastricht: Universiteit Maastricht; 1996.

43. Zanarini MC, Frankenburg FR, Hennen J, Reich DB, Silk KR. Prediction of the 10-year course of borderline personality disorder. Am J Psychiatry 2006;163(5):827-32.

44. Zanarini MC, Frankenburg FR, Hennen J, Silk KR. Mental health service utilization by borderline personality disorder patients and Axis II comparison subjects followed prospectively for 6 years. J Clin Psychiatry 2004;65(1):28-36. 


\section{OUTPATIENT PSYCHOTHERAPY FOR BORDERLINE PERSONALITY DISORDER}

Cost-effectiveness of schema-focused therapy versus transference-focused psychotherapy

A.D.I. van Asselt, C.D. Dirksen, A. Arntz, J.H. Giesen-Bloo, R. van Dyck, P. Spinhoven, W. van Tilburg, I.P. Kremers, M. Nadort, J.L. Severens 


\section{ABSTRACT}

BACKGROUND Recently, Schema Focused Therapy (SFT) and Transference Focused Psychotherapy (TFP) for Borderline Personality Disorder (BPD) were compared in a randomized multi-centre trial.

AIMS To assess societal cost-effectiveness of STF versus TFP in treating BPD.

METHOD Costs were assessed by interview. Health-related Quality of Life was measured using EQ-5D. Outcomes were costs per recovered patient as measured with the BPDSI-IV, and costs per QALY.

RESULTS Mean 4-year bootstrapped costs for SFT were $€ 37,826$, and $€ 46,795$ for TFP (95\% UI for difference: - €21,775; €3,546). QALYs were 2.15 for SFT and 2.27 for $\operatorname{TFP}(-0.51 ; 0.28)$. Percentage recovered patients was $52.3 \%$, and $28.6 \%$ respectively. SFT is less costly and more effective than TFP (dominant), for recovery. SFT saves €90,457 for one QALY loss.

CONCLUSIONS Despite the initial slight disadvantage in QALYs, there is a high probability that, compared to TFP, SFT is a cost-effective treatment for BPD. 


\section{INTRODUCTION}

Borderline Personality Disorder (BPD) is well known as a severe psychiatric condition. The prevalence of BPD is estimated at $1-2.5 \%$ in the population ${ }^{(1)}$ and $10-50 \%$ in psychiatric patients. Societal costs associated with BPD are substantial ${ }^{(2)}$. Recently, the effectiveness of two outpatient psychotherapies, Schema Focused Therapy (SFT) and Transference Focused Psychotherapy (TFP) was compared ${ }^{(3)}$. Both treatments aim at full BPD-recovery, as opposed to other therapies ${ }^{(4)}$. Both TFP and SFT succeeded in reducing BPD-specific and general psychopathologic dysfunction, measures of SFT/TFP concepts and improving health related quality of life (HRQoL), with SFT being more effective on all measures. However, the most effective treatment is not necessarily the most cost-effective treatment. In the context of health care budget constraints, an economic evaluation can inform decisions which health care services to offer to patients. Therefore, a cost-effectiveness analysis was performed comparing SFT versus TFP.

\section{METHODS}

\section{Patients and assessments}

In a multi-centre trial, 86 patients from 4 study locations were randomly allocated to either SFT (44) or TFP (42). Table 1 shows baseline characteristics. A prerandomisation assessment was performed. Then, 3-monthly assessments were made for 3 years. A final follow-up assessment was made at 4 years after baseline. SFT and TFP were individual therapies consisting of 50-minute sessions twice a week for three years. Central to SFT is the assumption of 4 schema modes specific to BPD. Recovery in SFT is achieved when dysfunctional schemas no longer control or rule the patient's life. Central to TFP is a negotiated treatment contract between patient and therapist, being the treatment frame. Recovery in TFP is reached when good and bad representations of self (and others) are integrated and when fixed primitive internalized object relations are resolved. Twelve SFT patients and 22 TFP patients dropped out. Six (13.6\%) SFT patients and 2 (4.8\%) TFP patients successfully (according to therapist and patient) terminated treatment within 3 years. For details, see Giesen-Bloo et al. ${ }^{(3)}$.

\section{Resources used}

At every assessment, a structured cost interview was administered by an independent research assistant. Formal registries such as hospital information systems or insurer's databases are considered to be incomplete, since a considerable amount of resource use is situated outside (mental) health care institutions ${ }^{(5)}$. Besides, individual patient data cannot be retraced from registries. Therefore, patient reported prospective cost diaries $^{(6)}$ or retrospective cost interviews ${ }^{(7)}$ are the preferred instruments covering all relevant events. 
Table 1: Baseline characteristics of 86 study participants

\begin{tabular}{|c|c|c|c|}
\hline & SFT $(n=44)$ & $\operatorname{TFP}(n=42)$ & p-value \\
\hline Age in yrs, mean (SD) & $31.70(8.9)$ & $29.45(6.5)$ & $.15^{*}$ \\
\hline Women & $40(90.9)$ & $40(95.2)$ & $.43^{*}$ \\
\hline \multicolumn{4}{|l|}{ Education } \\
\hline Graduate/Professional & $6(13.6)$ & $4(9.5)$ & \\
\hline College Graduate & $3(6.8)$ & $7(16.7)$ & \\
\hline Some College & $17(38.6)$ & $14(33.3)$ & $.22^{*}$ \\
\hline High school graduate & $5(11.4)$ & $10(23.8)$ & \\
\hline grades $7-11$ & $13(29.6)$ & 7 (16.7) & \\
\hline \multicolumn{4}{|l|}{ Employment status } \\
\hline Housewife & $8(18.2)$ & $5(119)$ & \\
\hline Student & $3(6.8)$ & $6(14.3)$ & \\
\hline Employed & $9(20.5)$ & 8 19.0) & $.89 *$ \\
\hline Disability & $17(38.6)$ & $17(40.5)$ & \\
\hline Welfare & $7(5.9)$ & $6(14.3)$ & \\
\hline
\end{tabular}

* based on the Pearson Chi-square test

We chose a three month recall interview ${ }^{(8)}$, since a prospective cost diary was expected to lead to more missing items given the patient characteristics.

Given a societal perspective, the cost-interview covered work status and absence, sources of income, domestic activities, informal care, medication use, alcohol and drugs, out-of-pocket expenses, and consumption of health care and societal resources (including general practitioners, hospitals, psychiatrists and psychologists, crisis centres, alternative healers, social work, and drug rehabilitation centres). Informal care is an important item in mental health care, since patients can place a large burden on their environment: persons near the patient (family, friends or neighbours) take care of the patient and take over domestic tasks. A key characteristic of informal care is that caregivers would not want to care for someone outside of his social environment for a similar wage ${ }^{(9)}$. Out-of-pocket costs are actual expenses reported by the patient and are highly relevant in BPD patients. These costs are related to, for instance, excessive smoking and shopping, (binge) eating and extremely high phone bills ${ }^{(5)}$.

The cost interview (based on the cost diary by Goossens et al. ${ }^{(6)}$ ) was judged by various experts and pilot tested by research assistants in patients, after which both face validity and content validity were improved. The cost interview contained items that were read to the patients, and patients indicated whether or not they had been absent from work, used a certain health care facility, etc.

Only BPD-related costs were considered relevant because non-BPD related costs were not expected to differ between the treatment groups. Patients were explicitly asked whether they thought resource use was linked to their BPD problems. In the very rare case where resource use was probably BPD-related whereas patients indicated it was not, patients' judgements were overruled. For instance, if patients had regular contact with social services because of problems raising their children, and patients rated this as non BPD-related, the contacts were still included in the analysis. Since for alcohol and drugs it is difficult to decide which part is BPD- 
related, all alcohol and drugs expenses were considered BPD-related. The number of therapy sessions was registered by the therapist. The number, duration, and time (inside or outside office hours) of telephone contacts with the therapist were extracted from the standardized session form therapists filled out after each session. Training/supervision costs were not taken into account as they are training costs and as such not part of the therapy.

\section{Unit prices}

Standardised Dutch unit prices were used ${ }^{(10)}$. When a standardised unit price was not available, prices were based on tariffs. Medication costs were obtained from the Dutch Pharmacotherapeutic Compass ${ }^{(11)}$. Productivity costs, occurring when patients are unable to perform paid work, were calculated according to the Human Capital Approach $^{(12)}$, implying that the number of hours patients were absent from their job was multiplied with the actual gross wage per hour. For unpaid work and study, the number of hours absent was multiplied with a shadow price. The shadow price was also applied to the informal care. All unit prices were expressed in 2000 Euros (€).

\section{Outcome measures}

Effectiveness was expressed as the proportion of recovered patients according to the BPDSI, the Borderline Personality Disorder Severity Index-IV ${ }^{(3,13)}$. The BPDSI is a 70item index with 9 dimensions, representing the DSM-IV BPD criteria. Total score ranges from 0 to 90 . When the BPDSI-score was below 15 at follow-up, patients were considered to be recovered. Additionally, effectiveness was expressed as Quality Adjusted Life Years (QALY). A QALY is a measure of life expectancy, weighted by the health-related quality of life (HRQoL) represented by utility scores. HRQoL was measured with the EQ-5D, which contains 5 dimensions: mobility, selfcare, daily activities, pain/discomfort, and depression/anxiety ${ }^{(14)}$. Each dimension is rated at three levels: no problems, some problems, and major problems. Based on preferences elicited from a general UK population, EQ-5D health states can be converted into utility scores ${ }^{(15)}$. The maximum possible number of QALYs within 4 years is 4 (4 years multiplied with 1 , optimal health state).

\section{Cost-effectiveness}

Two Incremental Cost-Effectiveness Ratios (ICERs) were determined. An ICER is calculated by dividing the difference in costs between the treatments by the difference in effectiveness between the treatments. An ICER represents the extra amount of money that has to be invested or will be saved to gain or lose one extra unit of effect. The first ICER is the cost per recovered patient. The second ICER is the cost per QALY gained. 


\section{Data analysis}

Costs and effects were discounted at $4 \%{ }^{(10)}$. Missing items in otherwise completed assessments were imputed with SPSS Missing Value Analysis, option regression. Completely missing assessments because of patients who dropped out or completed the treatment before the three year-limit were analysed by carrying the last observation forward, in accordance with Giesen-Bloo et al. ${ }^{(3)}$.

For BPDSI recovery status results after 4 years, a logistic regression with treatment group and baseline BPDSI-IV as covariates was performed, again in accordance with Giesen-Bloo (submitted). Since cost data are generally highly skewed, and not distributed normally, bootstrap simulations with 1000 replications were performed $^{(16,17)}$ to estimate uncertainty intervals around the mean costs. For the same reasons, QALY scores and both ICERs were bootstrapped with 1000 replications. The uncertainty interval is represented by the $2.5^{\text {th }}$ and $97.5^{\text {th }}$ percentiles. Results of ICER bootstraps are presented in cost-effectiveness planes and cost-effectiveness acceptability curves (CEACs). Cost-effectiveness planes show differences in costs on the vertical axis and differences in effect on the horizontal axis. Bootstrapped costeffectiveness pairs located in the north-west quadrant indicate SFT to be inferior to TFP (more costly and less effective than TFP). Cost-effectiveness pairs located in the south-east quadrant show SFT to be dominant over TFP (more effective and less costly than TFP). With respect to the other two quadrants (higher costs for better effectiveness and lower costs for lower effectiveness), the choice of an intervention depends on the threshold value, i.e. what society is prepared to pay for an effectiveness gain, or willing to accept as savings for effectiveness loss. The CEAC ${ }^{(18)}$ represents the probability that, given a certain threshold for the willingness to pay for a QALY or for recovering a patient, the intervention is cost-effective.

Secondary analyses

Secondary analyses were performed to assess robustness of the results.

1. Using last observation carried forward for patients who completed the therapy early with consent of the therapist, but did not complete later assessments, and imputing baseline values for true dropouts, i.e. patients who stopped therapy without consent of the therapist.

2. A completers analysis: analysing only those patients that completed treatment. Patients who completed early with consent of their therapist were included in this analysis, dropouts were not.

3. As costs at baseline were not comparable between both groups, a correction was performed for the following measurements by means of a regression analysis as recommended by Manca et al. ${ }^{(19)}$. A correction was also performed for utility and BPDSI scores.

4. An analysis per recovered patient with a healthcare perspective, meaning that only direct healthcare costs, including costs of therapy, were considered.

5. An investigation of the impact of the unit price of a therapy session, the unit price of informal care, and out of pocket costs on total costs. We separately doubled and halved the costs of these items. 
The results of the first four secondary analyses are again represented in a CEAC, combined with the CEAC of the main analysis.

\section{RESULTS}

\section{Costs}

\section{Baseline}

At baseline, costs were not distributed normally $(p=0.029, \mathrm{~K}-\mathrm{S}$ test). The bootstrapped total costs at baseline were $€ 4,324$ for TFP and $€ 3,331$ for SFT, a difference of about $€ 900$. However, neither one of the cost categories, nor the total societal costs were significantly different between conditions.

\section{After start of treatment}

Bootstrapped societal costs over four years were $€ 46,795$ for TFP and $€ 37,826$ for SFT (non significant difference, see Table 2). The direct non-health care costs were significantly different between SFT and TFP, mainly caused by informal care costs. With respect to direct health care costs, treatment costs (including costs of telephone contacts with the therapist for SFT) were about $€ 2,200$ higher for SFT, whereas the costs of visits to mental healthcare centres and other healthcare facilities were about $€ 3,500$ higher for TFP. Table 3 presents mean societal costs, EQ-5D utility scores, BPDS-IV scores, and percentage recovered patients per measurement. Costs in both groups decreased with time. In addition, aside from measurement 2, where costs are comparable between both groups, TFP costs were continuously higher.

\section{Effectiveness}

\section{BPDSI-IV}

The proportion of recovered patients after 4 years was $52.3 \%$ for SFT and $28.6 \%$ for TFP (Table 3). Logistic regression analysis with treatment group and BPDSI-IV baseline as covariates showed a significant effect in favor of SFT (Wald=4.45, $p=0.035$, $\mathrm{OR}=2.64$ with $\mathrm{CI}[1.07-6.49])$. Without baseline BPDSI-IV, the group effect was similar. For details of the BPDSI-IV results, see Giesen-Bloo et al. ${ }^{\text {(3\&submitted). }}$

\section{Quality Adjusted Life Years}

For 1 patient, no EQ-5D scores were available, therefore QALY results, and ICERs for cost per QALY are based on 85 patients. Table 3 shows that baseline utilities were not distributed normally ( $p=0.037, \mathrm{~K}-\mathrm{S}$ test). Baseline utility scores were 0.49 for TFP and 0.46 for SFT, ( $p=0.734$, Mann-Whitney test). In TFP, utility scores increased early in treatment and more or less remained stable, whereas in SFT utility 
Table 2: Total mean costs per cost item and bootstrapped mean costs (SD) for subtotals per patient for SFT $(\mathrm{n}=44)$ and TFP $(\mathrm{n}=42)$

\begin{tabular}{lllll}
\hline Cost category & TFP costs & SFT costs & Incremental & $2.5-97.5$
\end{tabular}

\section{Direct health care costs}

Psychotherapy

Contact w. therapist by tele-

Other care at treatment centre

10,876

12,946

$2 \quad 132$

General practitioner

Health care other\#

Medication

Alternative healers

Subtotal

Bootstrapped subtotal

\section{Direct non-healthcare costs}

Paid help

Societal services*

Informal care

Subtotal

Bootstrapped subtotal

\section{Costs of lost production}

Paid work

Unpaid work

Domestic tasks

Subtotal

Bootstrapped subtotal

\section{Out of pocket costs}

Reported by patient ${ }^{\wedge}$

Alcohol \& Drugs

Subtotal

Bootstrapped subtotal

TOTAL COSTS

BOOTSTRAPPED TOTAL COSTS
255

353

8,223

8,831

$8,915(2,189)$

890

3,612

7,107

11,609

$11,495(2,886)$

2,821

3,238

6,059

6,073 (897)

47,010

$46,795(5,630)$
170

238

3,053

3,460

2,016

536

8,255

10,807
3,482 (785)

$-5,433$

$-10,385-1,469$

$10,704(2,394)$

$-791$

$-8,204+6,443$

\# consists of: crisis help, first aid, psychotherapy other than the intervention under study, community health care, psychiatric hospital, general hospital, physiotherapy; * consists of: social work, addiction clinic and counseling, sex counseling, and abortion clinic; $\wedge$ consist mostly of costs of binge eating, excessive smoking, excessive use of mobile phone, impulsive shopping

scores continued to increase. As a result, total QALYs over the 4-year period were 2.15 for SFT and 2.27 for TFP. The bootstrapped difference in QALYs between SFT and TFP of $-0.12(95 \%$ UI -0.51 to 0.28 ) was not statistically significant. 


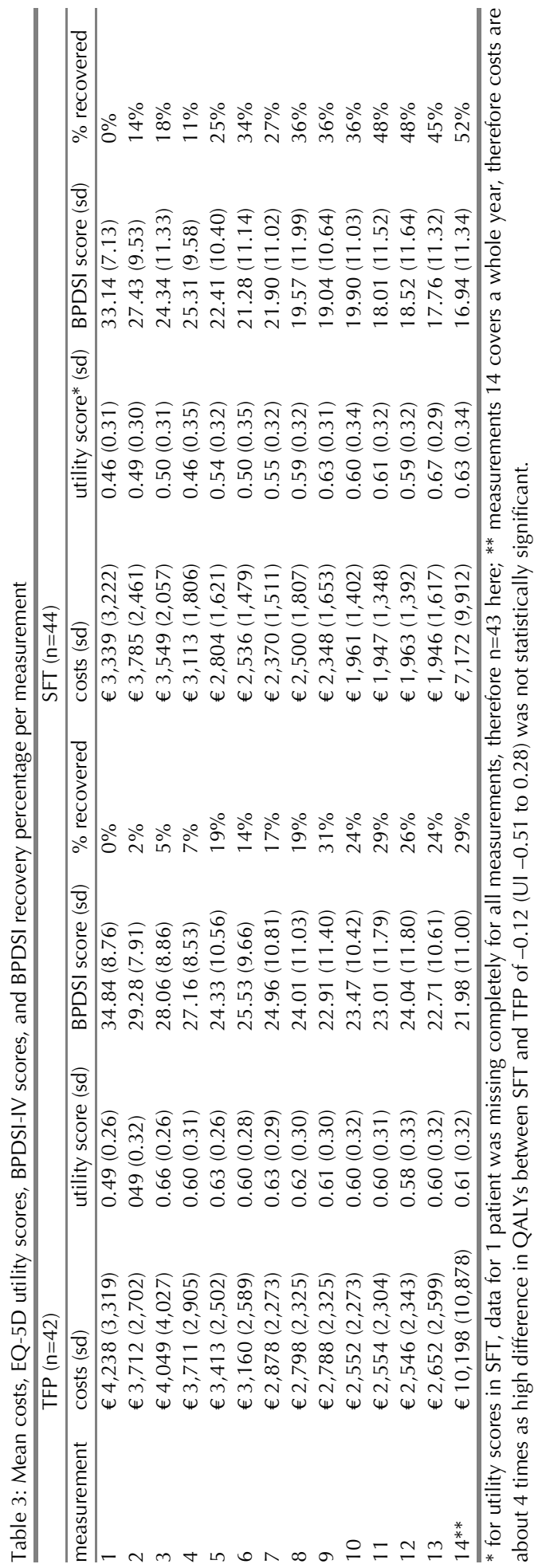




\section{Cost-effectiveness}

Societal costs per recovered patient

As societal costs for SFT were lower and recovery rate was higher compared to TFP, SFT was dominant over TFP (table 4). The bootstrapped results (figure 1) show that $91 \%$ of the cost-effectiveness pairs is in the south-east quadrant, where SFT is dominant. Another $8 \%$ lies in the north-east, i.e. more costly, more effective, quadrant, and $1 \%$ is located in both west quadrants, where SFT is less effective than TFP. The CEAC (see figure 3, main analysis) indicates that, regardless of the threshold value, the chance that SFT is cost-effective is over $90 \%$.

\section{Societal cost per QALY}

The ICER based on the QALY shows that $€ 90,457$ is saved when one QALY is sacrificed, as SFT was less costly and less effective than TFP (table 4). The bootstrapped results (figure 2) show that $68 \%$ of the cost-effectiveness pairs is in the south-west quadrant, where SFT is less costly and less effective. The south-east quadrant, i.e. the dominance quadrant, contains $28 \%$ of the replications, and the final $4 \%$ is located in the inferiority quadrant. The CEAC (figure 4, main analysis) indicates that the probability of SFT being cost-effective decreases with an increasing threshold value. Assuming that society's maximum willingness to pay is $€ 20,000$ for a QALY gain or, vice-versa, accepts a minimum compensation of $€ 20,000$ for a QALY loss, the probability that SFT is cost-effective is $84 \%$.

\section{Secondary analyses}

\section{Costs per recovered patient}

Table 4 also shows the secondary analyses. For costs per recovered patient, results were robust, meaning that SFT dominates TFP. The CEACs demonstrate that, irrespective of the threshold value, the probability that SFT is cost-effective is consistently over $90 \%$ (Figure 3). From a healthcare perspective, the cost-effectiveness acceptability curve is less favourable for SFT. With respect to varying the unit prices and the out-of-pocket costs, total costs of SFT stayed below costs of TFP in all cases.

\section{Costs per QALY}

With respect to costs per QALY (table 4), results were robust when using the completers analysis and the regression corrected analyses. However, using the baseline values for imputation of missing values, SFT became dominant. The CEACs (figure 4) show that baseline value imputation leads to more favourable results for SFT compared to the main analysis. However, regression correction or a completers analysis both lead to less favourable results for SFT. The descending cost-effectiveness acceptability curves mean that the probability of SFT being cost-effective decreases if the value society attaches to a QALY increases, dropping from $96 \%$ (best case) to $53 \%$ (worst case). 


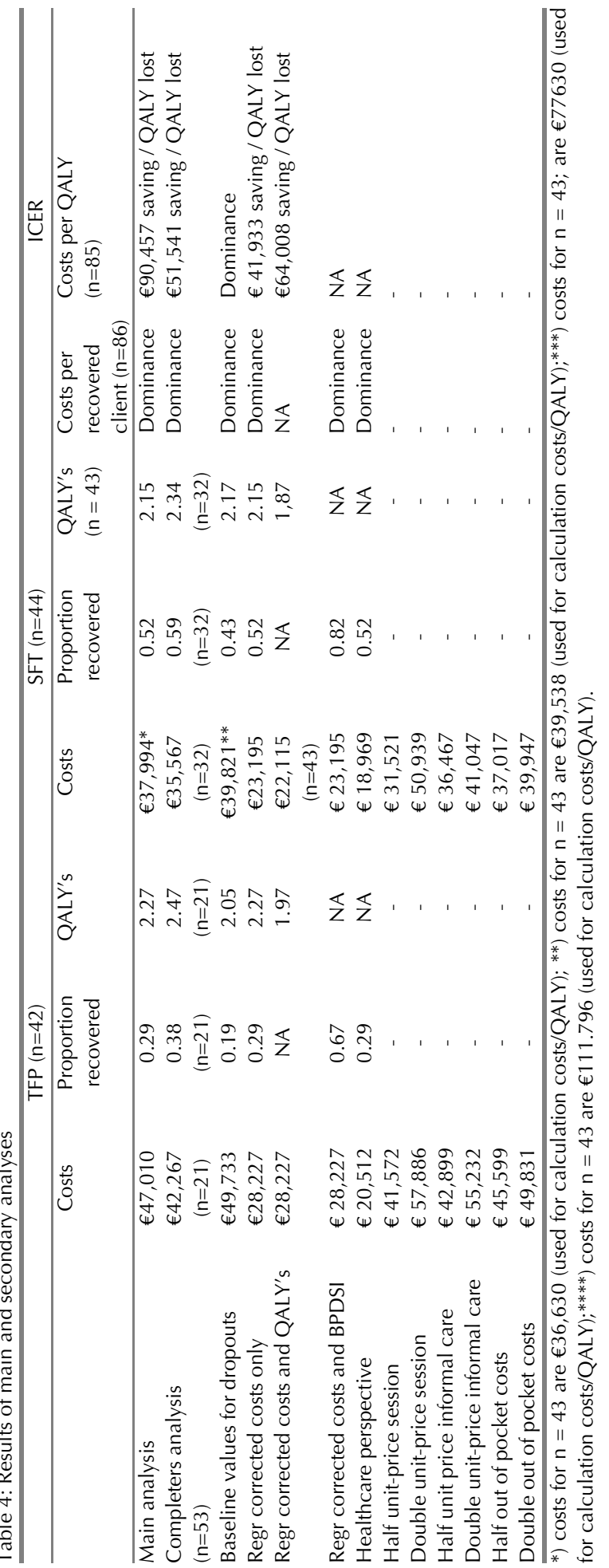




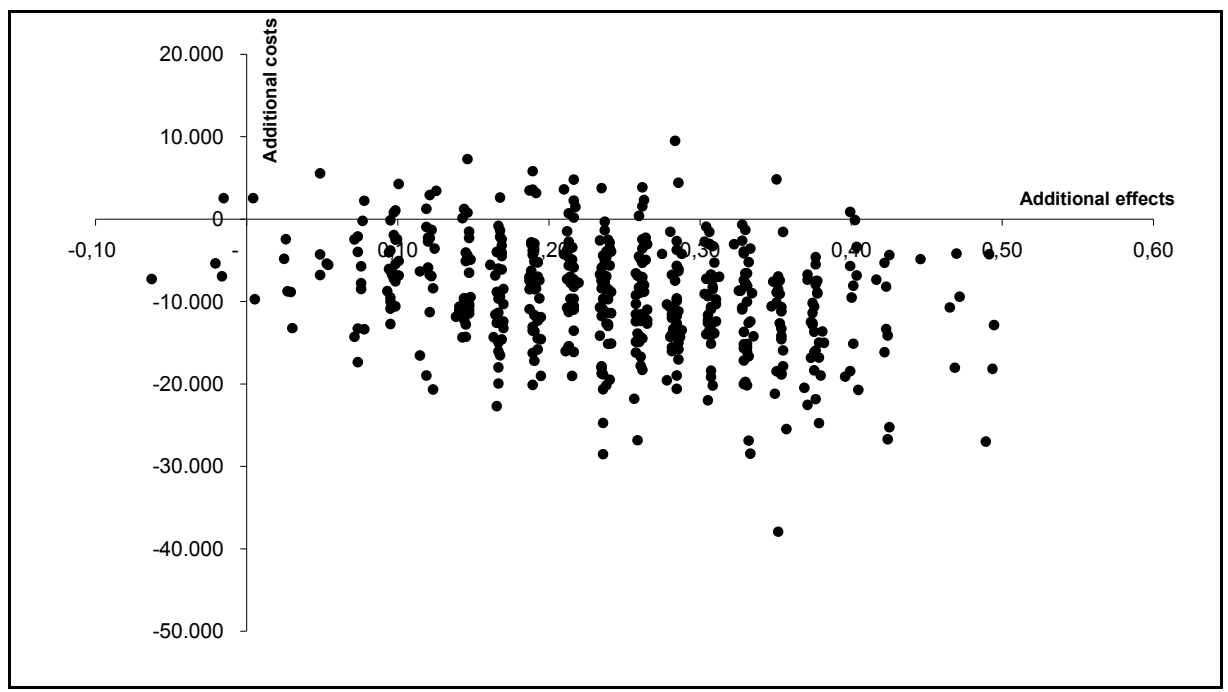

Figure 1: Bootstrapped costs and effects for cost per recovered patient, showing 1000 bootstrap replications for incremental cost-effectiveness of SFT compared to TFP. Costs are on the $y$-axis, and effects on the $x$ axis, so a bootstrap replication in the south-east quadrant means that SFT is less costly and more effective than TFP for that replication.

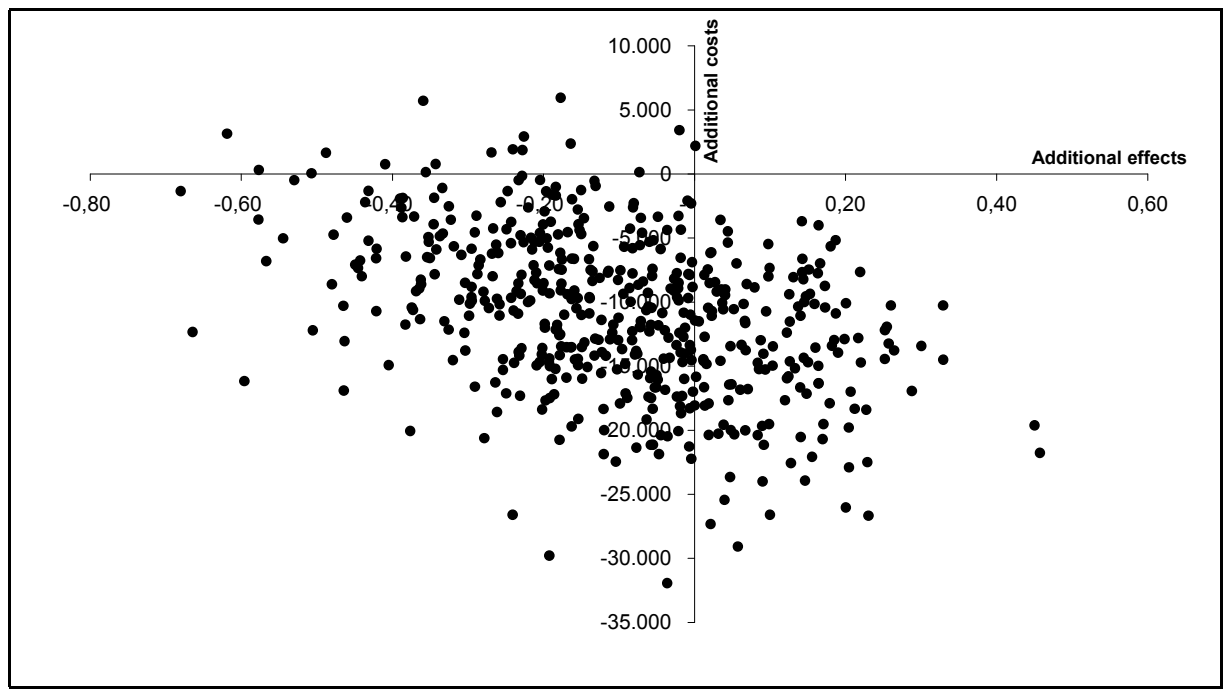

Figure 2: Bootstrapped costs and effects for cost per QALY, showing 1000 bootstrap replications for incremental cost-effectiveness of SFT compared to TFP. Costs are on the $y$-axis, and effects on the $x$-axis, so a replication in the south-west quadrant means that SFT is less costly but also less effective than TFP for that replication. 


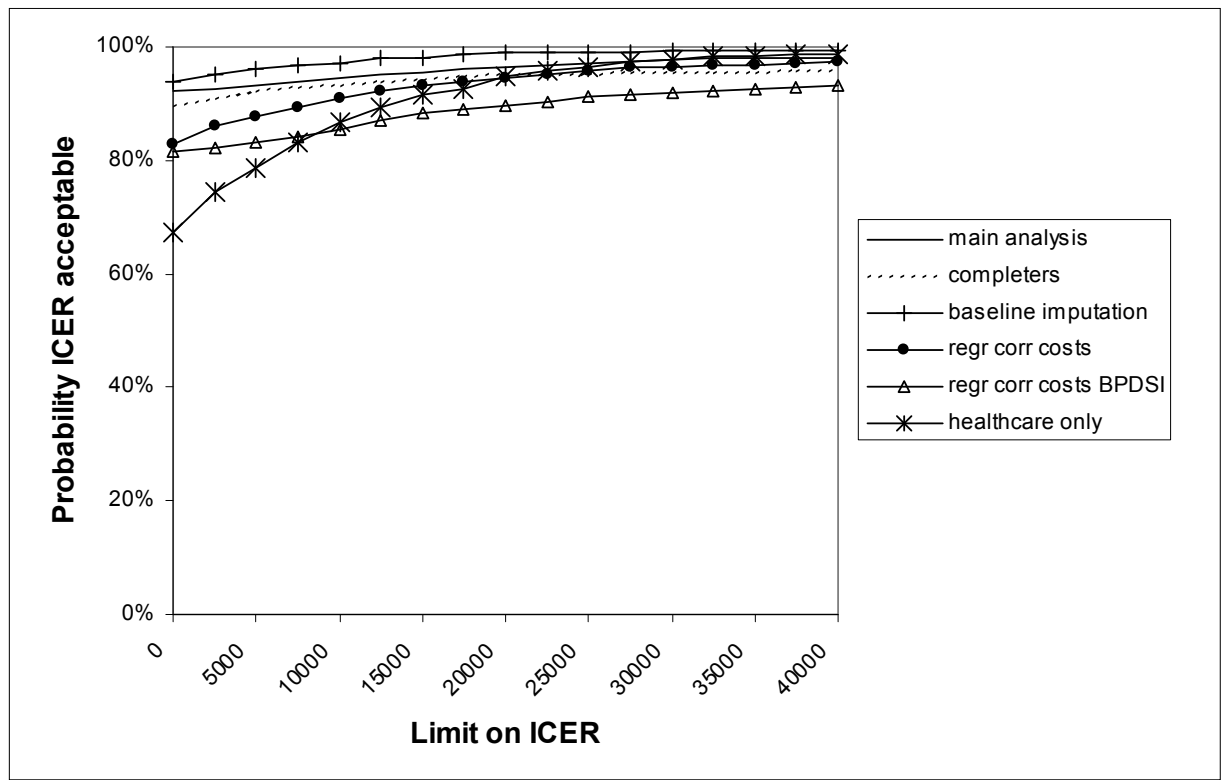

Figure 3: Cost-effectiveness acceptability curves for secondary analyses on cost per recovered patient. The curves indicate the probability ( $y$-axis) of SFT being cost-effective compared to TFP, given the threshold value (x-axis) for recovering a patient.

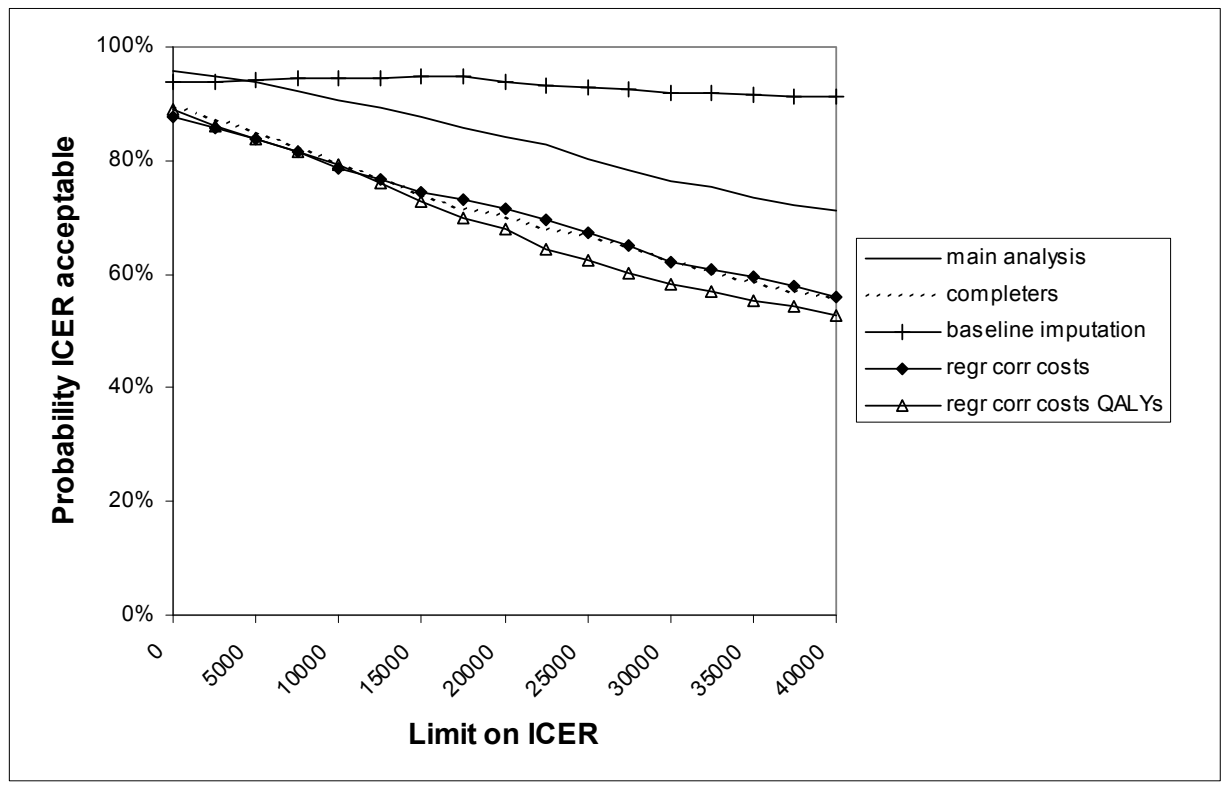

Figure 4: Cost-effectiveness acceptability curves for secondary analyses on cost per QALY. The curves indicate the probability ( $y$-axis) of SFT being cost-effective compared to TFP, given the threshold value (xaxis) for a QALY. 


\section{DISCUSSION}

\section{General results}

SFT, compared to TFP, was cost-effective when clinical outcome was considered. However, results as to QALYs were uncertain. Total societal costs were not statistically significantly different between treatments, although costs for TFP were almost $€$ 9,000 higher than for SFT. Only the costs of informal care were significantly higher for TFP. This might be a consequence of the fact that in SFT, professional support is a central part of therapy, offering patients the possibility of telephone contacts and extra sessions with their therapist, whereas TFP may be relying more on informal care. The fact that the larger part of total costs in both therapies was outside the healthcare sector demonstrates the importance of using a societal viewpoint in economic evaluations of interventions for BPD. Although direct health care costs were not statistically significantly different, there were notable differences between both groups. For SFT, costs of psychotherapy and telephone contacts were higher, whereas for TFP, the costs of GP, mental and other health care facilities were higher. Again, it can be speculated that these differences may be explained by the fact that patients found more comfort and support in SFT, whereas in TFP this was additionally sought in other health care facilities.

\section{QALYs}

Utility scores increased from 0.49 to 0.61 in TFP patients, and from 0.46 to 0.63 in SFT patients, an improvement of 0.12 and 0.17 , respectively. The minimally important difference for EQ-5D utility scores is considered to be 0.03 points $^{(20)}$. So, both therapies had a clinically relevant effect on HRQoL. Therefore, in the present sample, the EQ-5D can be considered sensitive to change. However, the resulting QALY was unable to significantly discriminate between SFT and TFP, although the proportion of recovered patients was higher for SFT. QALYs based on the 4-year period were slightly lower for SFT, resulting in an ICER indicating a saving of over $€ 90,000$ for a QALY loss.

To date, there is no consensus about a reasonable threshold value for costeffectiveness. Most studies with the explicit goal to determine a threshold resulted in values ranging from $€ 10,000$ to $€ 27,000^{(21-23)}$. However, in practice, thresholds used for appraisal of new interventions may be higher, around $€ 40,000^{(24)}$ for the UK and $€ 80,000$ for the Netherlands ${ }^{(25)}$. The CEACs show a range of thresholds, varying from $€ 0$ to $€ 40,000$. In the present study, when applying a $€ 20,000$ per QALY threshold, SFT in the main analysis would have an $84 \%$ probability of being cost-effective. In the secondary analyses, the worst-case scenario had a probability of $68 \%$, and the best-case scenario had a probability of $94 \%$. Given this range, the probability that SFT is more cost-effective than TFP in terms of QALYs can be considered moderate to high, in addition to the fact that this probability was already very high for the analysis per recovered patient. 


\section{BPDSI versus EQ-5D}

It is difficult to explain what the reason for the divergence between BPDSI and QALY results might be. When a patient recovers from BPD, one would expect the patient's HRQoL to improve correspondingly to at least some extent. In the long run, this was indeed the case: the slopes in increase of HRQoL were significantly steeper in SFT than in TFP ${ }^{(3)}$. But, during the first half year of treatment, QALYs and BPDSI diverged markedly, and as a consequence, during the first two years of treatment, HRQoL inSFT patients is lower than HRQoL in TFP patients This difference is difficult to understand as it was not paralleled in any of the clinical outcome measures. At follow-up at 4 years, HRQoL in SFT patients was slightly higher than HRQoL in TFP patients, but not enough to offset the total QALY difference. Maybe SFT is initially experienced as more burdensome by patients, and it may take time for clinical improvement to be translated into an increase in HRQoL. Another reason for the discrepancy might be a difference in responsiveness between the EQ-5D, which has 5 items with 3-point scale responses each, and the BPDSI, which has 70 items with, mostly, 10-point scale responses. There is very little information in the literature concerning the use of the EQ-5D in a BPD population. For depression, the EQ-5D seems useful and sensitive to change $\mathrm{e}^{(26,27)}$. In schizophrenic patients, results are contradictory $^{(28,29)}$.

\section{Limitations}

A number of limitations should be addressed. First, we used LOC-F to impute missing assessments. Although this is in accordance with the clinical study, LOC-F is regarded as a naïve method ${ }^{(30)}$. We therefore also performed a multiple imputation $(\mathrm{MI})^{(31)}$. However, probably because of the high cumulative dropout at the last three measurements, point estimates resulting from the MI tended very heavily towards extreme (and even impossible) values. Because this tendency could not be justified from the trends in the observed data, we did not include the MI results in the present paper. Second, the fact that we only included BPD-related costs might have lead to bias in the estimate of the total costs, since patient judgement of what is and what is not BPD-related may be flawed. However, as we do not expect patients' judgment in the SFT group to differ systematically from that in the TFP group, this presumably did not impact the incremental costs. Third, the time horizon of the analysis was 4 years. More long-term information should be collected to confirm the results now presented. Fourth, the economic evaluation is limited to the comparison of only two possible alternatives. Other alternatives, such as natural course and care as usual, have not been considered. The use of a single RCT as a vehicle for economic evaluation is often a non-sufficient basis for decision making, because decision-makers need to be informed about costs and effects for the full range of alternative interventions $^{(32)}$. In that respect, the present study has contributed evidence to the broader case of cost-effectiveness of treatment for BPD. 


\section{Conclusions \& Recommendations}

As this is the first cost-effectiveness analysis of psychotherapy in the field of BPD from a comprehensive societal perspective, it is difficult to place the results in a broader perspective. Even for the much better documented case of treatment for depression, comparisons between studies are complicated because of vastly different interventions, outcome measures, and cost perspectives ${ }^{(33)}$. The same applies to personality disorders in general and BPD in particular.

However, our study shows that long term psychotherapy for BPD improves HRQoL and decreases societal costs. In terms of recovered patients, there is a high probability that SFT is more cost-effective than TFP. In terms of QALYs, the probability that SFT is cost-effective is moderate to high.

Future research should further investigate the reason for the discrepancy between the BPDSI-IV and QALY scores, and the relation between the EQ5D and other measures for Quality of Life in a BPD population. Furthermore, we agree with Giesen-Bloo et al. ${ }^{(3)}$ that different comparators such as care as usual and natural course should be studied, including economic evaluations with a longer follow-up.

\section{Acknowledgements}

We are grateful to all patients, research assistants, and therapists who took part in this trial. We thank Fons Kessels for his support in performing the statistical analyses. The clinical trial and the economic evaluation were financially supported by the Dutch Healthcare Insurance Board (CVZ grant OG 97-002). 


\section{REFERENCES}

1. American Psychiatric Association. Diagnostic and Statistical Manual of Mental Disorders, fourth edition. American Psychiatric Association, 1994.

2. ten Have M, Lorsheyd J, Bijl R, Osterthun P. Annual Report Mental Health Care [in Dutch]. De Tijdstroom, 1995.

3. Giesen-Bloo J, van Dyck R, Spinhoven P, van Tilburg W, Dirksen C, van Asselt T, Kremers I, Nadort M, Arntz A. Outpatient psychotherapy for borderline personality disorder: randomized trial of schema-focused therapy vs transference-focused psychotherapy. Arch Gen Psychiatry 2006; 63: 649-658.

4. Linehan MM, Armstrong HE, Suarez A, Allmon D, Heard HL. Cognitive-behavioral treatment of chronically parasuicidal borderline patients. Arch Gen Psychiatry 1991; 48: 1060-1064.

5. van Asselt ADI, Dirksen CD, Arntz A, Severens JL. The cost of Borderline Personality Disorder: societal cost of illness in BPD-patients. European Psychiatry 2007; 22: 354-61.

6. Goossens ME, Rutten-van Molken MP, Vlaeyen JW, van der linden SM. The cost diary: a method to measure direct and indirect costs in cost-effectiveness research. J Clin Epidemiol 2000; 53: 688-695.

7. van den Brink M, van den Hout WB, Stiggelbout AM, Putter H, van de Velde CJ, Kievit J. Selfreports of health-care utilization: diary or questionnaire? Int J Technol Assess Health Care 2005; 21: 298-304.

8. Severens JL, Mulder J, Laheij RJ, Verbeek AL. Precision and accuracy in measuring absence from work as a basis for calculating productivity costs in The Netherlands. Soc Sci Med 2000; 51: 243-249.

9. van den Berg B, Brouwer WB, Koopmanschap MA. (2004) Economic valuation of informal care. An overview of methods and applications. Eur J Health Econ 2004; 5: 36-45.

10. Oostenbrink JB, Bouwmans CAM, Koopmanschap MA, Rutten FF. Manual for cost research. Methods and unit-prices for economic evaluations in health care [in Dutch] actualized version. College voor zorgverzekeringen, 2004.

11. Dutch Health Insurance Board. Pharmacotherapeutic Compass [in Dutch]. Amstelveen, 2000.

12. Rice DP, Cooper BS. The economic value of human life. Am J Public Health Nations Health 1967; 57: 1954-1966.

13. Arntz A, van den Hoorn M, Cornelis J, Verheul R, van den Bosch WM, de Bie AJ. Reliability and validity of the borderline personality disorder severity index. J Personal Disord 2003; 17: 45-59.

14. Brooks R. EuroQol: the current state of play. Health Policy 1996; 37: 53-72.

15. Dolan P. Modeling valuations for EuroQol health states. Med Care 1997; 35: 1095-1108.

16. Briggs AH, Wonderling DE, Mooney CZ. (1997) Pulling cost-effectiveness analysis up by its bootstraps: a non-parametric approach to confidence interval estimation. Health Econ 1997; 6: 327-340.

17. Efron B, Tibshirani RJ. An introduction to the bootstrap. Chapmann \& Hall, 1993.

18. van Hout BA, Al MJ, Gordon GS, Rutten FF. Costs, effects and C/E-ratios alongside a clinical trial. Health Econ 1994; 3: 309-19.

19. Manca A, Hawkins N, Sculpher MJ (2005) Estimating mean QALYs in trial-based costeffectiveness analysis: the importance of controlling for baseline utility. Health Econ 2005; 14: 487-496.

20. Marra CA, Woolcott JC, Kopec JA, Shojania K, Offer R, Brazier JE, Esdaile JM, Anis AH. A comparison of generic, indirect utility measures (the HUI2, HUI3, SF-6D, and the EQ-5D) and disease-specific instruments (the RAQoL and the HAQ) in rheumatoid arthritis. Soc Sci Med 2005; 60: 1571-1582.

21. Gyrd-Hansen, D. (2003) Willingness to pay for a QALY. Health Econ, 12, 1049-1060.

22. King JT Jr, Tsevat J, Lave JR, Roberts MS. Willingness to pay for a quality-adjusted life year: implications for societal health care resource allocation. Med Decis Making 2005; 25: 667-677. 
23. Laupacis A, Feeny D, Detsky AS, Tugwell PX. How attractive does a new technology have to be to warrant adoption and utilization? Tentative guidelines for using clinical and economic evaluations. Cmaj 1992; 146: 473-481.

24. Devlin N, Parkin D. Does NICE have a cost-effectiveness threshold and what other factors influence its decisions? A binary choice analysis. Health Econ, 2004; 13: 437-452.

25. Council for Public Health and Health Care. Sensible and sustainable care [in Dutch]. Den Haag, 2006.

26. Hayhurst H, Palmer S, Abbott R, Johnson T, Scott J. Measuring health-related quality of life in bipolar disorder: relationship of the EuroQol (EQ-5D) to condition-specific measures. Qual Life Res 2006; 15: 1271-1280.

27. Sapin C, Fantino B, Nowicki ML, Kind P. Usefulness of EQ-5D in assessing health status in primary care patients with major depressive disorder. Health Qual Life Outcomes, 2004; 2: 20.

28. van de Willige G, Wiersma D, Nienhuis FJ, Jenner JA. Changes in quality of life in chronic psychiatric patients: a comparison between EuroQol (EQ-5D) and WHOQoL. Qual Life Res 2005; 14: 441-451.

29. Prieto L, Sacristan JA, Hormaechea JA, Casado A, Badia X, Gomez JC. Psychometric validation of a generic health-related quality of life measure (EQ-5D) in a sample of schizophrenic patients. Curr Med Res Opin 2004; 20: 827-835.

30. Oostenbrink JB, Al MJ. The analysis of incomplete cost data due to dropout. Health Econ 2005; 14: 763-776.

31. Rubin DB, Schenker N. Multiple imputation in health-care databases: an overview and some applications. Stat Med 1992; 10: 585-598.

32. Sculpher MJ, Claxton K, Drummond M, McCabe C. Whither trial-based economic evaluation for health care decision making? Health Econ 2006; 15: 677-687.

33. Barrett B, Byford S, Knapp M. Evidence of cost-effective treatments for depression: a systematic review. J Affect Disord 2005; 84: 1-13. 
DIFFICULTIES IN CALCULATING PRODUCTIVITY COSTS Work disability associated with borderline personality disorder

A.D.I van Asselt, C.D. Dirksen, A. Arntz, J.L. Severens

Published in Value in Health, 2008; 11(4):637-644 


\section{ABSTRACT}

BACKGROUND In trial-based analyses, the Human Capital (HC) approach is currently applied alternately with and without the incorporation of productivity costs for persons who are work disabled at baseline of the trial. We call these methods $\mathrm{HC}$ extended (HCEXT) and $\mathrm{HC}$-limited (HCLM), respectively. Aim of the paper is to compare productivity costs according to $\mathrm{HC}_{\mathrm{EXT}}$ with $\mathrm{HC}_{\mathrm{LIM}}$ and the Friction Cost (FC) method, in patients with Borderline Personality Disorder (BPD).

METHODS Data were obtained from a multi-center randomized trial in the Netherlands, comparing two types of outpatient psychotherapy, Schema Focused Therapy (SFT, $n=44)$ versus Transference Focused Psychotherapy (TFP, n=42) for BPD. Mean age was 31.7 for SFT and 29.5 for TFP. A cost-interview was administered every three months for three years, and once again after the fourth year. Productivity costs were calculated according to $\mathrm{HC}_{\mathrm{LIM}}, \mathrm{HC}_{\mathrm{EXT}}$ and FC. A nonparametric bootstrap resampling method was performed.

RESULTS During the trial, the number of work-disabled patients increased for both treatments. Total productivity costs for $\mathrm{HC}_{\mathrm{EXT}}$ were higher than for $\mathrm{HC}_{\mathrm{LIM}}$ and FC. In addition, the incremental costs (TFP - SFT) pointed in the same direction for HCLM $(€ 1,028 ; 95 \%$ UI $-€ 7,563, € 4,700)$ and $\mathrm{FC}(€ 1,445 ; € 5,739, € 2,912)$, but turned around for $\mathrm{HC}_{\mathrm{EXT}}$ (minus $\left.€ 1,219 ; € 9,973, € 7,911\right)$. None of the increments were statistically significantly different from zero .

CONCLUSIONS The classical and frequently discussed contrast between HC and FC is not the only difference when it concerns productivity costs. Including productivity costs for patients who are work-disabled at baseline can lead to contradictory conclusions. 


\section{INTRODUCTION}

When performing an economic evaluation from the societal perspective, the costs of lost productivity are a relevant item in the analysis. However, the way that lost productivity should be valued is still a point of dispute. For the monetary valuation of lost productivity two approaches can be distinguished. One option is the Human Capital Approach (HC), which estimates the value of all potentially lost production ${ }^{(1)}$. When a person gets sick, disabled or dies, the resulting lost productivity is valued by calculating the expected or potential earnings lost, for which the actual gross earnings of that person or, preferably, age- and sex- adjusted standard wages are used. One of the basic principles of the human capital method is the assumption that there is full use of labour (i.e. no unemployment). The second option is the Friction Cost Method (FC), which assumes that all sick, disabled, or deceased workers will eventually be replaced ${ }^{(2)}$. In FC, productivity costs are only counted as long as it takes to replace someone. The friction period is defined as the time needed to restore the initial production level. After this friction period, costs to society fall back to zero. Apart from the costs associated with lost production, the friction cost method also includes for instance costs of recruiting and training a new employee. The speed with which a replacement can be found is dependent on the situation on the labour market. In times of large unemployment, the friction period is shorter than when the labour market is very tense. So, the Human Capital approach estimates the value of all potentially lost production, whereas the Friction Cost method attempts to quantify actual production losses. Furthermore, $\mathrm{HC}$ can also be used to estimate productivity costs for non-paid labour (i.e. domestic activities, volunteer work, study). For example, the Dutch guidelines advise to value the hours of domestic activities lost against the wage rate of a paid housekeeper. FC does not include an approach to non-paid activities, probably due to the fact that replacement is a less obvious option for domestic activities and volunteer work and not on option for study activities. Of course, FC for paid work and $\mathrm{HC}$ for non-paid work can be used next to each other. The differences between $\mathrm{HC}$ and $\mathrm{FC}$ have been described extensively in previous research $^{(3-13)}$. As is to be expected, $\mathrm{HC}$ in general leads to higher productivity costs than FC. The younger the population, the larger HC losses will be compared to FC, because of the longer period over which productivity is lost. Also, the difference between both methods will be larger in cases of permanent disability and deaths, because HC fully takes account of productivity costs in these cases whereas FC only takes account of these costs for the duration of the friction period.

\section{Problem definition}

In trial based economic evaluations, the employment status at baseline of the study is an important factor for the way productivity losses are calculated. When there is no employment at baseline (i.e. the patient is on welfare or on unemployment benefits), no productivity losses are counted. When a patient has a paid job but is with sick leave at baseline, there are productivity losses, but the magnitude depends on the 
method used and the length of the period of sick leave. When a patient is work disabled at baseline, it also depends on the method used whether or not there are productivity losses. When applying the FC method in the Netherlands, the friction period is typically treated as having already passed at the moment that a person is declared disabled for work, because official disability for work is always preceded by a year of 'normal' absence from work. Of course, in other countries, this period of normal absence preceding official disability might be much shorter, even shorter than the friction period. In that case, FC productivity costs are not necessarily zero. It is also possible to be declared disabled for work directly after leaving school or when on welfare. In that case, productivity costs are zero, because that person never had paid work. So, for the Dutch situation, according to FC, productivity costs associated with work disability are zero by definition. However, when studying trial-based economic evaluations using $\mathrm{HC}$, the way that work disability-related costs at the start of the study are valued is found to be rather indistinct. To the best of our knowledge, in most randomized trials only productivity costs of patients with paid employment at baseline of the study ${ }^{(9,14-20)}$, were calculated, implying that patients who were disabled for work already at baseline were assigned zero productivity costs, even though their disability might be caused by the disease under study. Although strictly speaking, this methodology cannot be seen as an individual approach, as it is merely a flaw in the application of the $\mathrm{HC}$ in daily practice, we will, for the sake of clarity, from now on refer to this methodology as the $\mathrm{HC}$ limited approach: $\mathrm{HC}_{\mathrm{LIM}}$. In a number of cases, the publication did not clearly reveal whether costs due to work disability at baseline had been included in the calculation of productivity $\operatorname{costs}^{(21-24)}$. Only in a minority of economic evaluations costs of work disability at baseline had actually been included in the estimation of productivity costs ${ }^{(25-27)}$. We will refer to the latter as the $\mathrm{HC}$ extended approach: $\mathrm{HC}_{\mathrm{EXT}}$. So, the Human Capital approach is often put into practice as $\mathrm{HC}_{\mathrm{LIM}}$, since in the majority of trial-based economic evaluations disease-related work disability is not counted as productivity costs when it already exists at the baseline of a study. Summarizing, the difference between the two HC approaches and FC are twofold. First, when absence lasts longer than the friction period a difference arises between $\mathrm{HC}$ in general and FC. Second, when a person is disabled for work at baseline of a study, a difference arises between $\mathrm{HC}_{\mathrm{LIM}}$ and $\mathrm{FC}$ on the one hand and $\mathrm{HC}_{\mathrm{EXT}}$ on the other hand. To our knowledge, there has been no previous research comparing the different approaches for valuing work disability-related productivity costs. Therefore, the aim of the present paper is to investigate for paid work if, and how much, productivity costs according to HCEXT on the one hand differ from productivity costs according to $\mathrm{HC}_{\text {LIM }}$ and $\mathrm{FC}$ on the other hand, in a population characterized by frequent disablement for work.

\section{Borderline Personality Disorder}

Individuals who suffer from Borderline Personality Disorder (BPD) constitute a very severe group of psychiatric patients, who are difficult to treat. The problematic nature of BPD is characterized by recurring crises, hospitalisations, self-mutilation, suicide 
attempts, addictions and episodes of depression, anxiety and aggression. Also typical for BPD is its chronic nature. The onset of BPD generally takes place in adolescence, and prevalence in the general population is estimated to be ranging from 0.5 to $2.0 \%{ }^{(28,29)}$. The suicide risk is estimated up to $10 \%{ }^{(30)}$. From this description, it may be clear that BPD-patients face many difficulties in completing an education and in their professional life. In a cost-of-illness study investigating the economic burden of BPD on society, productivity costs, calculated with $\mathrm{HC}_{\mathrm{EXT}}$, accounted for almost $42 \%$ of total $\operatorname{costs}^{(31)}$, a large part of which was due to work disability.

A multi-centre randomised trial was performed in the Netherlands, comparing two types of outpatient psychotherapy for 86 patients with Borderline Personality Disorder. The trial compared Schema Focused Therapy (SFT, $n=44$ ) to Transference Focused Psychotherapy (TFP, $n=42$ ) over a period of four years. For details of the study, see Giesen-Bloo et al. ${ }^{(32)}$. Alongside the RCT an economic evaluation was performed from the societal perspective, including costs for lost productivity.

\section{METHODS}

\section{Data collection}

Data regarding productivity losses were obtained by means of a face-to-face structured interview performed by a research assistant. During the trial, patients had an interview every 3 months over 3 years, and a final follow-up interview after 4 years. At each of the interviews, the use of resources since the previous interview was recorded. In this way the entire period from baseline to final follow up was covered. In total 14 interviews were administered, of which the first interview (the baseline interview) covered 3 months prior to start of the trial. Absence from work was measured in days as well as hours.

\section{Data analysis}

Baseline characteristics were tested for normality with the Kolmogorov-Smirnov test. When data were distributed normally, a t-test was performed. In the case of nonnormality, a Mann-Whitney test was used for variables with at least an ordinal scale. A Pearson Chi-Square test was used for binary variables.

For the calculation of the costs of lost productivity, hours of absence were used, and only BPD-related absence from work was considered. The distinction between what was BPD-related and what was not BPD-related was made according to the opinion of the patient. Data were analysed using intention to treat, for which missing cases (due to study dropouts) were analysed using the 'last observation carried forward' (LOCF) method. When a patient was full-time absent from work at the last interview before drop-out, the LOCF was performed in such a way that after a year of absence this patient was declared disabled for work.

Because the Dutch situation on disability for work is rather complicated, we made some choices regarding the analysis. For $\mathrm{HC}_{\mathrm{EXT}}$, when a patient was on welfare or 
unemployment benefits at baseline, and switched to work disablement during the course of the trial, this patient was analysed as work disabled throughout the trial, since probably the non-productive status at baseline was already disease-related and only a matter of inaccurate classification by the social security authorities. On the other hand, when a patient was work disabled at baseline and moved over to welfare or unemployment benefits later in the trial (which was, in practice, a very infrequent event), this was regarded as a change in productivity, in the sense that work disablement was counted as productivity costs, and welfare and unemployment were not. For an overview of all assumptions used, see table 1.

Table 1: Assumptions made

\begin{tabular}{|c|c|c|c|c|}
\hline & $\mathrm{HC}_{\mathrm{EXT}}$ & $\mathrm{HC}_{\mathrm{LIM}}$ & $\mathrm{FC}$ & $\mathrm{FC}_{2}$ \\
\hline welfare $\rightarrow$ disablement & $\begin{array}{c}\text { work disabled } \\
\text { work disablement }\end{array}$ & not included & not included & not included \\
\hline disablement $\rightarrow$ welfare & $\begin{array}{l}\text { counted as } \\
\text { productivity costs, } \\
\text { welfare not }\end{array}$ & not included & not included & not included \\
\hline part-time absence & $\begin{array}{c}\text { productivity costs } \\
\text { proportional }\end{array}$ & $\begin{array}{c}\text { productivity costs } \\
\text { proportional }\end{array}$ & $\begin{array}{l}\text { productivity costs } \\
\text { proportional, no } \\
\text { replacement, i.e. } \\
\text { friction period } \\
\text { does not end }\end{array}$ & $\begin{array}{l}\text { productivity costs } \\
\text { proportional, no } \\
\text { replacement, i.e. } \\
\text { friction period } \\
\text { does not end }\end{array}$ \\
\hline $\begin{array}{l}\text { sick leave at baseline, } \\
\text { length of period } \\
\text { unknown }\end{array}$ & $\begin{array}{c}\text { productivity costs } \\
\text { as usual }\end{array}$ & $\begin{array}{l}\text { productivity costs } \\
\text { as usual }\end{array}$ & $\begin{array}{l}\text { friction period has } \\
\text { already passed }\end{array}$ & $\begin{array}{l}\text { friction period has } \\
\text { just started }\end{array}$ \\
\hline
\end{tabular}

For FC, standardised FC tariffs as well as the friction period of 154 days were obtained from the Dutch Manual for Costing studies ${ }^{(33)}$. The tariffs are calculated based on the average value added per working person. For $\mathrm{HC}$ both limited and extended approach, standardised wages (adjusted for age and gender) were used, also in accordance with common practice. Standardised wages were obtained from the Central Bureau of Statistics ${ }^{(34)}$. FC tariffs and wages used are presented in table 2.

Table 2: FC tariffs and HC standardised wages per hour in 2000 euros

\begin{tabular}{lcccc}
\hline & \multicolumn{2}{c}{ Friction cost method* } & \multicolumn{2}{c}{ Human Capital approach } \\
\hline Age categories & Men & Women & Men & Women \\
\hline $15-24$ & $€ 19.04$ & $€ 18.65$ & $€ 8.57$ & $€ 8.35$ \\
$25-34$ & $€ 30.43$ & $€ 27.76$ & $€ 14.50$ & $€ 13.29$ \\
$35-44$ & $€ 37.97$ & $€ 31.23$ & $€ 18.05$ & $€ 14.80$ \\
$45-54$ & $€ 42.17$ & $€ 31.79$ & $€ 20.27$ & $€ 15.07$ \\
$55-64$ & $€ 44.44$ & $€ 33.84$ & $€ 21.21$ & $€ 15.60$ \\
$\geq 65$ & $€ 44.44$ & $€ 33.84$ & $€ 15.23$ & $€ 15.24$ \\
\hline
\end{tabular}

FC was calculated according to the standards, implying that when a patient was continuously absent for more than 154 days, it was assumed that this patients' place in the production process was filled again and productivity returned to its original level. Therefore, after these 154 days had passed, productivity costs were zero. For patients who were absent only a few hours per day or a few days per week (part-time absence), it was assumed that there was no replacement. In cases where a patient 
was with sick leave at baseline of the study, but the period of absence was unknown, it was assumed that the friction period had already passed and productivity costs were set to zero. In addition, we performed a sensitivity analysis in which, for those patients with an unknown period of absence at baseline, we assumed that the absence had just started the day before the assessment, so they were assigned a full friction period (see also table 1).

For persons who were work-disabled at baseline, including those who were declared work disabled after leaving school, it was not known whether they had (or would have had) a full-time or part-time job, or a job at all. Therefore, to calculate $\mathrm{HC}_{\mathrm{EXT}}$, we assigned them an average job, in which part-time versus full-time proportion and unemployment rates in the general population were accounted for, fitting age and sex of the person, and counted the wages for these jobs as productivity costs for the 4 years of the study. Part-time work-disability was treated proportional. To calculate $\mathrm{HC}_{\mathrm{LIM}}$, only productivity costs for persons with a paid job at baseline were counted. For comparability of results, the $80 \%$ elasticity of working hours in relation to productivity that is commonly used for FC was also used for both HC approaches here. This $80 \%$ elasticity reflects the fact that when people work less hours (for instance as a consequence of illness), their production decreases less than proportionate. In the Netherlands, the elasticity has been found to be $80 \%{ }^{(2)}$, which implies that when working hours decrease by $10 \%$, productivity only decreases by $8 \%$. As the cost data were not normally distributed and skewed, a nonparametric bootstrap resampling method with 1,000 replications was used as an alternative to the geometric mean ${ }^{(35}$, 36). Costs are expressed in 2000 euros.

\section{RESULTS}

\section{Patient characteristics}

Patient characteristics are presented in table 3. None of the patient characteristics were statistically different between TFP and SFT. All work disablement cases were, at least partly, BPD-related.

\section{Development in work disability}

In table 4, the switches in work disability status that patients made during the trial are quantified. Note that, as mentioned earlier, switches from welfare or unemployment to work disablement are not included in these numbers. Figure 1 represents the proportion of work disabled patients during the study for both treatment groups. The high percentage of patients moving to work disablement in the SFT-group is caused mainly by patients who were already long-term absent at baseline and reached their year of absence shortly after the start of the study. 
Table 3: Patient characteristics at baseline (interview). Categories of occupational status are not mutually exclusive, meaning that a persons can be, for instance, both in paid employment and (partly) work disabled.

\begin{tabular}{lccc}
\hline & TFP $(\mathrm{n}=42)$ & SFT $(\mathrm{n}=44)$ & P-value \\
\hline Females (\%) & $40(95 \%)$ & $40(91 \%)$ & .434 \\
Age (SD) & $29.5(6.5)$ & $31.7(8.9)$ & .377 \\
In paid employment (\%) & $22(52 \%)$ & $22(50 \%)$ & .825 \\
$\quad$ Contract hours (SD) & $341(178)$ & $284(158)$ & .281 \\
& $(26$ hrs/week) & $(22$ hrs/week) & .707 \\
Fulltime (>= 36 hrs/wk) employment & $9(41 \%)$ & $8(36 \%)$ & .810 \\
(\% from patients in paid employment) & & & \\
Sick leave, fully or partly (\% from patients in paid & $5(23 \%)$ & $6(27 \%)$ & .953 \\
employment) & & & .684 \\
$\quad$ sick leave $>$ friction period & $3(14 \%)$ & $3(14 \%)$ & .813 \\
$\quad$ unknown if sick leave $>$ friction period & $2(9 \%)$ & $3(14 \%)$ & .584 \\
Hours of sick leave (SD) & $140(202)$ & $126(164)$ & .931 \\
On Unemployment benefits (\%) & $1(2.4 \%)$ & $2(4.5 \%)$ & .690 \\
On Welfare $(\%)$ & $6(14 \%)$ & $6(14 \%)$ & .581 \\
Receiving work disability benefits (\%) & $18(43 \%)$ & $17(39 \%)$ & .508 \\
Fully ( $\geq 80 \%)$ disabled (\% from disabled patients) & $16(89 \%)$ & $14(82 \%)$ & $89 \%(23.0)$ \\
Degree of disablement (SD) & $95 \%(13.3)$ & & \\
\hline
\end{tabular}

Table 4: Numbers of patients switching to and from work disablement (not disabled = paid job, absent from work or study, and not receiving work disability benefits), hours of absence, proportion of patients with absence, and number of patients reaching the friction period of 154 days. Only the most frequent and relevant switches are specified. Numbers can be deviant from table 3, since persons in paid employment can also be (partly) work disabled. For this table, these persons are classified as disabled.

\begin{tabular}{|c|c|c|c|c|}
\hline baseline & course of study & at follow-up & $\operatorname{TFP}(\mathrm{N}=42)$ & SFT $(N=44)$ \\
\hline not disabled & - & disabled & $3(7 \%)$ & $7(16 \%)$ \\
\hline not disabled & Disabled & not disabled & $1(2 \%)$ & $2(5 \%)$ \\
\hline not disabled & not disabled & not disabled & $16(38 \%)$ & $13(30 \%)$ \\
\hline disabled & - & not disabled & $2(5 \%)$ & - \\
\hline disabled & not disabled & disabled & $2(5 \%)$ & - \\
\hline disabled & Disabled & disabled & $14(33 \%)$ & 17 (39\%) \\
\hline disabled & welfare/unemployed* & disabled & - & $1(2 \%)$ \\
\hline welfare/unemployed & disabled** & not disabled & $1(2 \%)$ & - \\
\hline welfare/unemployed & disabled** & disabled & - & $4(9 \%)$ \\
\hline \multicolumn{3}{|c|}{ total mean hours of absence (SD) } & $208(552)$ & $188(529)$ \\
\hline \multicolumn{3}{|c|}{ proportion of patients having absence } & $50 \%$ & $43 \%$ \\
\hline \multicolumn{3}{|c|}{ number of patients reaching friction period } & 1 & 2 \\
\hline
\end{tabular}

* The welfare/unemployment was only partly. For $\mathrm{HC}_{\mathrm{EXT}}$, this part is not counted as productivity costs. For HCLIM and FC, these patients are not included. ** For HCEXT, these patients are counted as being work disabled throughout the course of the study. For $\mathrm{HC}_{\mathrm{LIM}}$ and $\mathrm{FC}$, these patients are not included.

\section{Productivity costs}

Figure 2 shows the productivity costs for each measurement according to FC, HCLM and $\mathrm{HC}_{\mathrm{EXT}}$ for both treatment arms, including the productivity costs at baseline. $\mathrm{FC}_{2}$ represents the sensitivity analysis. $\mathrm{HC}_{\mathrm{EXT}}$ clearly leads to higher productivity costs than both $\mathrm{HC}_{\mathrm{LIM}}$ or $\mathrm{FC}$ at each measurement, whereas the difference in productivity costs between $\mathrm{HC}_{\mathrm{LIM}}$ and $\mathrm{FC}$ is less pronounced. Table 5 shows the total productivity costs over 4 years for SFT and TFP, excluding the productivity costs of the baseline measurement. Comparing $\mathrm{FC}$ with $\mathrm{HC}_{\mathrm{LIM}}$, total productivity losses valued with $\mathrm{FC}$ are about 


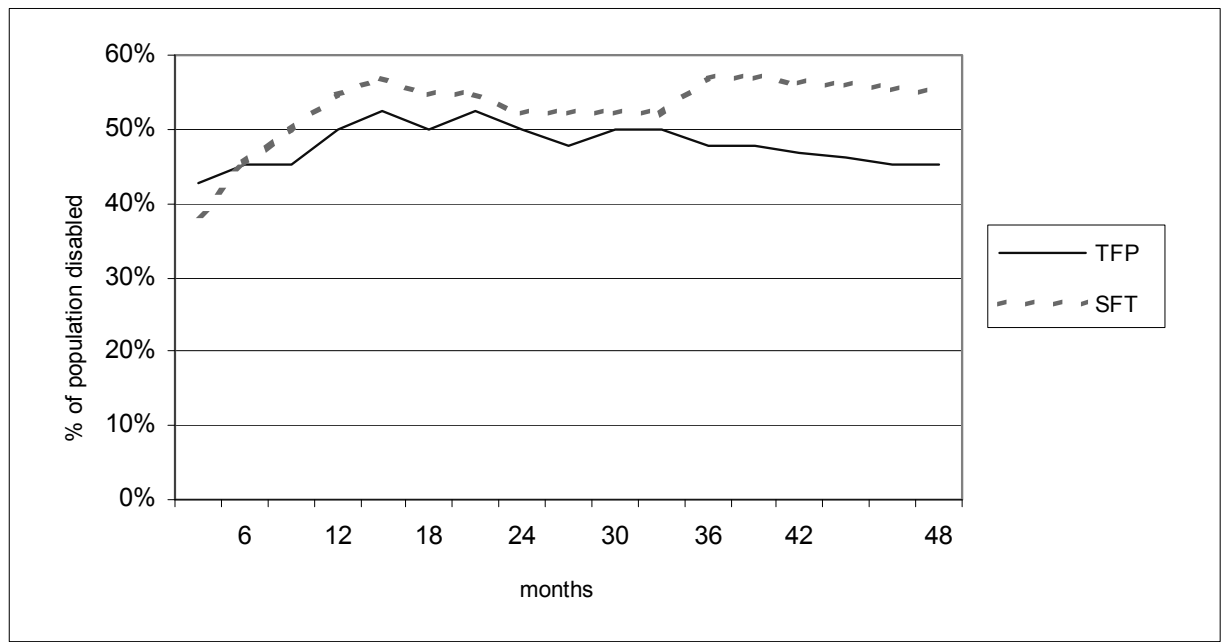

Figure 1: Proportion of BPD-related work-disabled patients

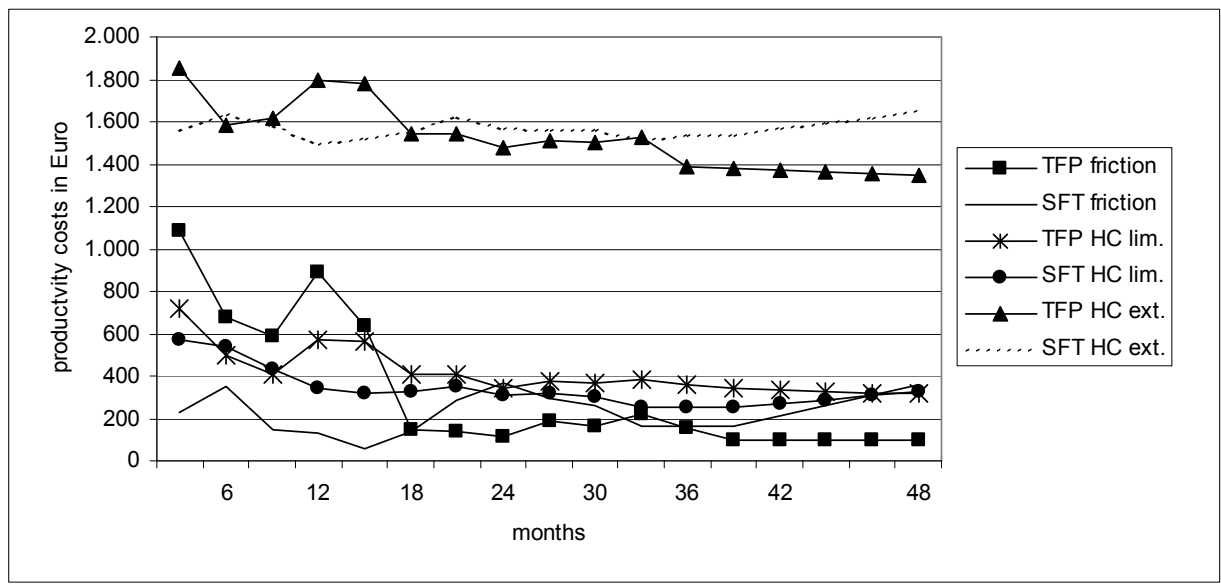

Figure 2: Productivity costs with and without work disability in time (all patients

$€ 3,000$ lower for both TFP and SFT. Although the hourly wage is much higher for FC, the higher productivity costs of HCLIM were caused by patients whose friction period had already passed at baseline and patients who turned absent and/or disabled for work after baseline. Both $\mathrm{FC}$ and $\mathrm{HC}_{\mathrm{LI}}$ indicate that the mean total productivity costs are higher for TFP compared to SFT, although not statistically significantly. When $\mathrm{HC}_{\mathrm{EXT}}$ is used instead of $\mathrm{HC}_{\mathrm{LIM}}$, in other words: when productivity costs due to work disability at baseline are included, productivity costs increase with $227 \%$ for TFP and $290 \%$ for SFT. Moreover, mean total productivity costs of TFP are now lower compared to SFT, although, again, not statistically significant. Productivity costs of FC remain unchanged, because for patients who are disabled for work at baseline, the friction period by definition has passed. For the sensitivity analysis $\left(\mathrm{FC}_{2}\right)$, when we assign the persons with an unknown period of absence at baseline a full friction 
period, total costs increase more for SFT, resulting in a lower increment between TFP and SFT.

Table 5: Mean total productivity costs (SD) and bootstrapped mean (2.5 and 97.5 percentiles) per patient over 4 years

\begin{tabular}{lllllll}
\hline & TFP & \multicolumn{3}{c}{ SFT } & \multicolumn{2}{c}{ TFP - SFT } \\
\hline FC & mean & bootstrap & mean & bootstrap & mean & Bootstrap \\
& $€ 3,999$ & $€ 3,950$ & $€ 2,667$ & $€ 2,744$ & $€ 1,332$ & $€ 1,206$ \\
& $(9,276)$ & $(+1,644$ & $(10,082)$ & $(+429$ & & $(-2,835$ \\
HC & & $+6,719)$ & & $+6,034)$ & $+4,844)$ \\
& $€ 7,041$ & $€ 7,135$ & $€ 6,013$ & $€ 5,967$ & $€ 1,028$ & $€ 1,168$ \\
& $(15,342)$ & $(+2,988$ & $(13,601)$ & $(+2,466$ & & $(-4,700$ \\
HC EXT $_{\text {EIM }}$ & $€ 24,042$ & $€ 24,048$ & $€ 25,261$ & $€ 25,288$ & $-€ 1,219$ & $-€ 1,240$ \\
& $(23,180)$ & $(+17,495$ & $(22,592)$ & $(+19,071$ & & $(-9,973$ \\
& & $+30,490)$ & & $+31,825)$ & & $+7,911)$ \\
FC $_{2}$ & $€ 4,343$ & $€ 4,355$ & $€ 3,366$ & $€ 3,336$ & $€ 977$ & $€ 1,019$ \\
& $(9,678)$ & $(+1,716$ & $(10,409)$ & $(+964$ & & $(-3,068$ \\
& & $+7,566)$ & & $+6,822)$ & & $+4,952)$ \\
\hline
\end{tabular}

\section{DISCUSSION}

In agreement with previous studies, HCLIM resulted in higher productivity losses than FC. For both FC and HCLIM, productivity costs for TFP were higher than for SFT, although not statistically significant. Applying $\mathrm{HC}_{\mathrm{EXT}}$ increased the total productivity costs in both study arms considerably. In addition, productivity costs for TFP now became lower compared to SFT. Although none of the increments was statistically significantly different from zero, this case clearly shows that the disparity between the methods regarding work disability may lead to contradicting conclusions.

In cost-of-illness studies aimed at illustrating the economic burden of disease on society, the costs of disability for work are usually included when using the Human Capital approach. However, in economic evaluations it seems to be common practice in $\mathrm{HC}$ to include only persons with a paid job at baseline for calculation of productivity losses, i.e. to use $\mathrm{HC}_{\text {LIM. }}$ In a high number of cases, Borderline Personality Disorder leads to disease-related work disability. So, if a therapy aimed at curing or improving BPD has the effect that patients will return to the workforce, this effect should be quantified as savings (which are in fact a decrease in productivity costs) in an economic evaluation. Although not commonly applied, $\mathrm{HC}$ in theory is able to do so and according to the principles of $\mathrm{HC}$, this should be done. The way that FC takes account of patients returning to the workforce is that, in the medium term, labour scarcity diminishes, and the friction period shortens, with overall decreasing productivity costs as a consequence ${ }^{(2)}$. Although on a macro-economic level this will correctly reflect the events that have taken place, FC does not take into consideration the short term individual productivity gains of patients in a trial-based economic evaluation.

So, there seems to be a discrepancy between the standard in cost-of-illness studies, which includes the costs of baseline work disability, and both the friction cost 
method and $\mathrm{HC}_{\mathrm{LIM}}$, which do not include these costs. A cost-of-illness study involves an estimation of the total economic burden which an illness poses on society, with its main objective is to translate the burden on society into monetary costs. Typically in a cost-of-illness study all costs associated with a particular illness are identified and measured. Results of cost-of-illness studies can be used to gain insight in how much society is spending on a disease, and how much potentially can be saved if effective therapy is offered. Also, it identifies the different cost categories and the size of the contribution of each sector in society. The information coming from cost-ofillness studies can be helpful in setting priorities for health care efficiency research ${ }^{37-}$ ${ }^{39)}$. So, when a therapy is effective in reintegrating people to the workforce, it would make sense to be able to quantify the potential relief of this economic burden in an economic evaluation. However, FC (at the micro-economic level) and $\mathrm{HC}_{\mathrm{LIM}}$ fail to do this.

In addition, in an economic evaluation based on a decision model, COI studies might be used as input. When COI-productivity estimates (based on $\mathrm{HC}_{\mathrm{EXT}}$ ) are the input for a modelling-based economic evaluation, this only adds to the inconsistency and confusion regarding the estimation of productivity costs. Furthermore, for decision-making based on results of economic evaluations, one should be aware that not the absolute productivity costs matter (which may indeed differ between HC and FC), but the incremental productivity costs. Including the costs associated with work disability in $\mathrm{HC}_{\mathrm{EXT}}$ did not only influence the absolute productivity costs, but also the incremental productivity costs in such a way that, solely on the basis of productivity costs, TFP became more favourable compared to SFT, because in the TFP treatment group, more patients returned to the workforce during treatment after being work disabled at baseline. Although the differences were not statistically significant here, in cases where productivity costs constitute a large part of the total societal costs, these findings may have a substantial effect on the incremental cost-effectiveness ratio, and when bootstrap procedures and cost-effectiveness acceptability curves ${ }^{(40)}$ are used for drawing conclusions, $\mathrm{FC}$ or $\mathrm{HC}_{\mathrm{LIM}}$ could point in the opposite direction than HCEXT.

In the present study, because of the limited time-horizon, only few patients returned to work after work disability. However, in the near future, it is to be expected that more patients will start working again, as both therapies have proven to be effective. Both FC, and HCLIM for a large part, do not account for these gains to society. Another difficulty in using $\mathrm{FC}$ and $\mathrm{HC}_{\text {LIM }}$ is, that when a patient who was initially work disabled starts working again and then turns absent, would cause productivity costs without officially having been productive. In the present analysis we have not counted these costs, since we did not include productivity costs for patients who were disabled at baseline, but it is an interesting theoretical problem which could be addressed in future research.

A limitation that should be addressed is that, although there were no significantly different baseline imbalances, the TFP patients worked 26 hours per week on average, versus 22 hours for the SFT patients. This could have had an impact on the results in the sense that because the TFP patients worked more, they also might have had more absence. Therefore, when we would have corrected for this difference, the 
increment between TFP and SFT for all three methods might have been smaller. However, it is not to be expected that this baseline difference of 4 hours per week had a noticeable effect on the differences between the three methods, since it is not related to the number of work disabled patients at baseline.

Of course, it is possible to calculate the consequences of using different approaches in a sensitivity analysis. However, in the case of BPD, productivity costs constitute a large part of the total societal costs, so they may have a considerable impact on the cost-effectiveness ratio. In general, for chronic diseases in relatively young populations, like mental health disorders, the way that costs associated with work disability are valued can have a major influence on the outcome. This statement holds especially in this population with borderline personality disorder, of which a large part is disabled for work, and where the disability is not considered to be irreversible. So, variability in methods to calculate productivity costs is actually a practical problem, in the sense that using different costing methods could lead to different policy conclusions. Therefore, to adequately inform policy makers it is relevant to have a reliable estimate, calculated by a standardised method. The choice for using a certain method is first and foremost dependent on the theoretical background of the methods, i.e. does one want to calculate macro-economic (FC) or micro-economic (HC) productivity costs? One could say that, to be consistent with a societal perspective, one should take into account the macro-economic consequences of an illness on the productivity level. However, there are some practical problems involved in applying FC in special cases such as we have outlined in this paper. Therefore, it would be helpful if there were specific instructions how to use FC in case of disabled persons returning to the workforce. For instance, how can one calculate the shortened friction period? For the time being, because methods are still being developed $^{(41)}$ researchers should be very explicit and elaborate about the methods they use for calculating productivity costs.

\section{Acknowledgements}

We are grateful to all patients, research assistants, and therapists who took part in this trial. 


\section{REFERENCES}

1. Rice DP, Cooper BS. The economic value of human life. Am J Public Health Nations Health, 1967. 57(11): p. 1954-66.

2. Koopmanschap MA, Rutten FF, van Ineveld BM, van Roijen L. The friction cost method for measuring indirect costs of disease. J Health Econ, 1995. 14(2): p. 171-89.

3. Borghouts JA, Koes BW, Vondeling H, Bouter LM. Cost-of-illness of neck pain in The Netherlands in 1996. Pain, 1999. 80(3): p. 629-36.

4. Goeree R, O'Brien BJ, Blackhouse G, et al. The valuation of productivity costs due to premature mortality: a comparison of the human-capital and friction-cost methods for schizophrenia. Can J Psychiatry, 1999. 44(5): p. 455-63.

5. Huscher D, Merkesdal S, Thiele K, et al. Cost of illness in rheumatoid arthritis, ankylosing spondylitis, psoriatic arthritis and SLE in Germany. Ann Rheum Dis, 2006.

6. Hutubessy RC, van Tulder MW, Vondeling H, Bouter LM. Indirect costs of back pain in the Netherlands: a comparison of the human capital method with the friction cost method. Pain, 1999. 80(1-2): p. 201-7.

7. Kaitelidou D, Ziroyanis PN, Maniadakis N, Liaropoulos LL. Economic evaluation of hemodialysis: implications for technology assessment in Greece. Int J Technol Assess Health Care, 2005. 21(1): p. 40-6.

8. Liu JL, Maniadakis N, Gray A, Rayner M. The economic burden of coronary heart disease in the UK. Heart, 2002. 88(6): p. 597-603.

9. Lofland JH, Locklear JC, Frick KD. Different approaches to valuing the lost productivity of patients with migraine. Pharmacoeconomics, 2001. 19(9): p. 917-25.

10. Norum J, Holtmon M. Adjuvant fluorouracil, epirubicin and cyclophosphamide in early breast cancer: is it cost-effective? Acta Oncol, 2005. 44(7): p. 735-41.

11. Oliva J, Lobo F, Lopez-Bastida J, et al. Indirect costs of cervical and breast cancers in Spain. Eur J Health Econ, 2005. 6(4): p. 309-13.

12. van Beeck EF, van Roijen L, Mackenbach JP. Medical costs and economic production losses due to injuries in the Netherlands. J Trauma, 1997. 42(6): p. 1116-23.

13. Verstappen SM, Boonen A, Verkleij $\mathrm{H}$, et al. Productivity costs among patients with rheumatoid arthritis: the influence of methods and sources to value loss of productivity. Ann Rheum Dis, 2005. 64(12): p. 1754-60.

14. Brown MC, Nimmerrichter AA, Guest JF. Cost-effectiveness of mirtazapine compared to amitriptyline and fluoxetine in the treatment of moderate and severe depression in austria. Eur Psychiatry, 1999. 14(4): p. 230-44.

15. Fernandez JL, Montgomery S, Francois C. Evaluation of the cost effectiveness of escitalopram versus venlafaxine XR in major depressive disorder. Pharmacoeconomics, 2005. 23(2): p. 15567.

16. Goossens ME, Rutten-Van Molken MP, Kole-Snijders AM, et al. Health economic assessment of behavioural rehabilitation in chronic low back pain: a randomised clinical trial. Health Econ, 1998. 7(1): p. 39-51.

17. Li X, Gignac MA, Anis AH. The indirect costs of arthritis resulting from unemployment, reduced performance, and occupational changes while at work. Med Care, 2006. 44(4): p. 304-10.

18. Osterhaus JT, Gutterman DL, Plachetka JR. Healthcare resource and lost labour costs of migraine headache in the US. Pharmacoeconomics, 1992. 2(1): p. 67-76.

19. Schermer TR, Thoonen BP, van den Boom G, et al. Randomized controlled economic evaluation of asthma self-management in primary health care. Am J Respir Crit Care Med, 2002. 166(8): p. 1062-72.

20. Wong JB, Singh G, Kavanaugh A. Estimating the cost-effectiveness of 54 weeks of infliximab for rheumatoid arthritis. Am J Med, 2002. 113(5): p. 400-8.

21. Byford S, Knapp M, Greenshields J, et al. Cost-effectiveness of brief cognitive behaviour therapy versus treatment as usual in recurrent deliberate self-harm: a decision-making approach. Psychol Med, 2003. 33(6): p. 977-86. 
22. Kobelt G, Jonsson L, Young A, Eberhardt K. The cost-effectiveness of infliximab (Remicade) in the treatment of rheumatoid arthritis in Sweden and the United Kingdom based on the ATTRACT study. Rheumatology (Oxford), 2003. 42(2): p. 326-35.

23. Puolakka K, Kautiainen H, Pekurinen M, et al. Monetary value of lost productivity over a five year follow up in early rheumatoid arthritis estimated on the basis of official register data on patients' sickness absence and gross income: experience from the FIN-RACo trial. Ann Rheum Dis, 2006. 65(7): p. 899-904.

24. Wade AG, Toumi I, Hemels ME. A pharmacoeconomic evaluation of escitalopram versus citalopram in the treatment of severe depression in the United Kingdom. Clin Ther, 2005. 27(4): p. 486-96.

25. Fritzell $P$, Hagg O, Jonsson D, Nordwall A. Cost-effectiveness of lumbar fusion and nonsurgical treatment for chronic low back pain in the Swedish Lumbar Spine Study: a multicenter, randomized, controlled trial from the Swedish Lumbar Spine Study Group. Spine, 2004. 29(4): p. 42134; discussion Z3.

26. Lambert CM, Hurst NP, Forbes JF, et al. Is day care equivalent to inpatient care for active rheumatoid arthritis? Randomised controlled clinical and economic evaluation. Bmj, 1998. 316(7136): p. 965-9.

27. Schadlich PK, Zeidler H, Zink A, et al. Modelling cost effectiveness and cost utility of sequential DMARD therapy including leflunomide in rheumatoid arthritis in Germany: I. Selected DMARDs and patient-related costs. Pharmacoeconomics, 2005. 23(4): p. 377-93.

28. APA. Diagnostic and Statistical Manual of Mental Disorders, fourth edition. 1994, Washington, D.C.: American Psychiatric Association.

29. Samuels J, Eaton WW, Bienvenu OJ, 3rd, et al. Prevalence and correlates of personality disorders in a community sample. Br J Psychiatry, 2002. 180: p. 536-42.

30. Paris J. The treatment of borderline personality disorder in light of the research on its long term outcome. Can J Psychiatry, 1993. 38 Suppl 1: p. S28-34.

31. van Asselt AD, Dirksen CD, Arntz A, Severens JL. The cost of borderline personality disorder: societal cost of illness in BPD-patients. Eur Psychiatry, 2007, doi: 10.1016/j.eurpsy. 2007.04.001 (in press)

32. Giesen-Bloo J, van Dyck R, Spinhoven P, et al. Outpatient psychotherapy for borderline personality disorder: randomized trial of schema-focused therapy vs transference-focused psychotherapy. Arch Gen Psychiatry, 2006. 63(6): p. 649-58.

33. Oostenbrink JB, Bouwmans CAM, Koopmanschap MA, Rutten FF. Manual for cost-research. Methods and unit prices for economic evaluations in healthcare (in Dutch). Actualised version. 2004, Amstelveen: College voor zorgverzekeringen.

34. Dutch Central Bureau for Statistics. http: \\www.cbs.nl. accessed in 2004.

35. Briggs AH, Wonderling DE, Mooney CZ. Pulling cost-effectiveness analysis up by its bootstraps: a non-parametric approach to confidence interval estimation. Health Econ, 1997. 6(4): p. 32740.

36. Efron B, Tibshirani RJ. An introduction to the bootstrap. 1993, Londen: Chapmann \& Hall.

37. Ament A, Evers S. Cost of illness studies in health care: a comparison of two cases. Health Policy, 1993. 26(1): p. 29-42.

38. Polder JJ, Meerding WJ, Bonneux L, van der Maas PJ. Healthcare costs of intellectual disability in the Netherlands: a cost-of-illness perspective. J Intellect Disabil Res, 2002. 46(Pt 2): p. 168-78.

39. Rice DP, Miller LS. The economic burden of affective disorders. Br J Psychiatry Suppl, 1995(27): p. 34-42.

40. Fenwick E, Byford S. A guide to cost-effectiveness acceptability curves. Br J Psychiatry 2005. 187:106-8

41. Koopmanschap M, Burdorf A, Jacob K, et al. Measuring productivity changes in economic evaluation: setting the research agenda. Pharmacoeconomics, 2005. 23(1): p. 47-54. 


\section{HOW TO DEAL WITH COST DIFFERENCES AT BASELINE}

A.D.I. van Asselt, G.A.P.G. van Mastrigt, C.D. Dirksen, A. Arntz, J.L. Severens, A. Kessels 


\section{ABSTRACT}

BACKGROUND To our knowledge, adjustment for baseline imbalances in costs has never been performed in trial-based cost-effectiveness analyses.

METHODS We used data from a clinical trial performed in the Netherlands comparing two outpatient psychotherapies, Schema Focused Therapy (SFT) versus Transference Focused Psychotherapy (TFP). Costs were assessed with a cost-interview. Outcome was the proportion of recovered patients measured with the Borderline Personality Severity Index, the BPDSI-IV.

We used three methods to adjust the costs for baseline: 1) Mean difference adjustment, calculating total costs after baseline by adjusting the difference between groups with the difference of the mean baseline costs, 2) Delta adjustment, calculating the difference between individual patient baseline and the subsequent measurements. Concerning incremental costs, this is the same as mean difference adjustment, and 3) Regression-based adjustment, adjusting total costs with a regression model with total costs as dependent variable, and baseline costs as the independent variable.

RESULTS Mean baseline costs were $€ 3,339$ for SFT and €4,238 for TFP, a mean difference of $€ 899$. Total unadjusted follow-up costs were $€ 30,822$ for SFT and $€ 36,812$ for TFP. The fraction of recovered patients was $45 \%$ for SFT and $24 \%$ for TFP. Cost Effectiveness Acceptability Curves show that mean difference and delta adjustments are different from the regression-based methods.

CONCLUSIONS Although the routine starting point of an analysis should always be an unadjusted analysis of the cost-effectiveness, a baseline difference between treatment groups should be adjusted for. This should be done by reported patient characteristics, or, when these are not sufficiently present, by baseline costs as a substitute. This adjustment should be done most preferably with a regression-based method. 


\section{INTRODUCTION}

In analyses of intervention studies comparing outcomes between groups, imbalanced baseline characteristics necessitates adjustment certainly in studies with a small sample size ${ }^{(1)}$. This is especially important in observational studies but also holds for randomized trials ${ }^{(2,3)}$. The necessity for this adjustment is not dependent on the statistical significance of this covariate or confounder but is determined by the influence of inclusion of this covariate in the model on the regression coefficient of the treatment ${ }^{(4)}$. In economic evaluations, sometimes these adjustments for baseline characteristics are applied when QALYs are involved ${ }^{(5)}$ but when costs are compared, to our knowledge, these adjustments are never made. Manca et al. ${ }^{(6)}$ argue that one should adjust for a baseline imbalance in Quality of Life because a patient's baseline utility is expected to be predictive of their utility values during follow-up, and because baseline utility is included in the QALY calculation. Although contrary to QALYs, baseline costs are not part of the total costs, one could still expect that a patient's cost level at baseline, defined as the accumulated costs over a prespecified period of time preceding the baseline measurement, will influence his or her cost level during the trial and that it is important to investigate this influence. Therefore, it is quite surprising that in most trial-based economic evaluations, baseline costs are not even reported at all. After all, when baseline cost level is unknown, it is not possible to attribute a difference that is found afterwards to the intervention that has taken place. Of course, costs are a reflection of resource use and disease severity and as such are influenced by patient and disease characteristics. So, when a baseline imbalance in one of these characteristics is found in combination with a baseline cost difference, the imbalance in patient or disease characteristics should be adjusted for first, being the underlying factor of the cost difference. However, it is possible that a baseline cost difference exists independent from a difference in patient or disease characteristics. . This could be caused by characteristics that are not included in the assessments. In such a case, the baseline cost difference itself is the only variable that can be adjusted for. The methods that Manca et al. ${ }^{(6)}$ proposed for adjusting for baseline imbalances in QALYs do not allow to apply bootstrap techniques and construct cost-effectiveness acceptability (CEAC) curves, because they do not provide patient level data and variability ${ }^{(7-9)}$. The methods we will demonstrate do adjust at the patient level and therefore enable bootstrapping and CEAC curve construction. We will illustrate several adjustment methods with data from an RCT, and make recommendations regarding which method to apply.

\section{METHODS}

\section{Clinical example}

We used data of a randomised clinical trial performed in the Netherlands ${ }^{(10)}$. This trial compared Schema Focused Therapy (SFT), which is a cognitive behavioural therapy, with a psychoanalytical psychotherapy called Transference Focused Psychotherapy 
(TFP) in 86 patients with Borderline Personality Disorder. SFT and TFP were individual therapies consisting of 50-minute sessions twice a week for three years. Central to SFT is the assumption of 4 schema modes specific to BPD, explaining the patients sudden emotional shifts. SFT integrates techniques derived from cognitive, behavioural, experiential and attachment perspectives in an integrated schema model. Important elements are the attempt of the therapist to repair unsafe attachment through a safe attachment relationship with the therapist, and emotional and cognitively processing of childhood traumas. Central to TFP is the focus on how personality pathology manifests itself in the therapist-patient relationship (hence the term 'transference-focused'). The therapists elucidates and confronts the patient with the so-called object representations (representations of the self and the other person) projected onto the therapist and activated in the patient him/herself, that tend to be extreme and inconsistent in BPD. A negotiated treatment contract between patient and therapist forms the treatment frame. For further details, see Giesen-Bloo et al. ${ }^{(10)}$ Cost interviews were held at baseline, then every three months for three years. The cost interviews captured the three-month period preceding the date of the interview and contained items about lost productivity from both paid and unpaid work, healthcare consumption, burden to the family, medication, use of alcohol and drugs, and out-of-pocket expenses. For the analysis, we only distinguished the baseline measurement and total costs, the latter being an accumulation of all costs after baseline up to three years.

The outcome measure used was recovery based on the Borderline Personality Disorder Severity Index (BPDSI) ${ }^{(11)}$. The BPDSI is a 70-item index with 9 dimensions, such as for instance unstable relationships, lack of anger control, recurrent suicidal behaviour, and chronic feelings of emptiness. The aggregated score ranges from 0 to 90 with a higher score indicating a more severe condition. To be included, patients had to score over 20 on this Index. When the BPDSI-score was below the cut-off score of 15 at follow-up, the patient was considered to be recovered. The BPDSI was assessed at the same time points as the costs.

\section{Adjustment procedures}

There are several options to adjust for baseline differences. These adjustments should be made at the patient data level in order to utilize the bootstrap and CEAC curve techniques for assessing uncertainty in the treatment cost differences.

\section{Mean difference adjustment}

The mean difference adjustment implies calculating total post-randomization costs by adjusting the difference between groups with the difference of the mean baseline costs. From figure 1 it can be seen that treatment A has a lower baseline cost level than treatment $B$. We have subtracted the difference at baseline from the treatment group with the highest baseline costs (group $B$ ). This procedure sets the baseline costs of treatment $B$ to the level of treatment $A$, and the post-randomization costs of 
group B are reduced by the baseline difference. Please note that the graphs only serve an illustrative purpose and are hypothetical examples. One could, instead of subtracting the difference from the treatment group with the highest costs, also add the difference to the treatment group with the lowest baseline costs. Another way would be to add half the difference to the treatment group with the lowest baseline costs, and subtract half the difference from the treatment group with the highest baseline costs. We have only illustrated the first method, i.e. subtracting the difference from the treatment group with the highest baseline costs, in figure 1, as all these methods will result in the same adjusted incremental costs. As, in practice, the length of the baseline period will often differ from the length of the study period, it is necessary to adjust for this, i.e. the difference should be multiplied by the quotient of total study length and the length of the baseline period (in our study 36 and 3 months respectively, so baseline should be multiplied by 12). An important assumption of these methods is that the difference between the groups in generating costs at baseline is constant, i.e. when there are multiple post-randomization measurement moments, the adjustment is the same for each time point.

\section{Delta adjustment}

In this strategy, total costs are adjusted individually by subtracting the baseline costs from total post-randomization costs. Here also the baseline costs should be adjusted for study length. The results cannot be read as costs, but should be interpreted as a cost change. To obtain more realistic values, the overall mean baseline costs, i.e. the mean baseline costs of both groups taken together, could be added to the individual cost change (figure 1). The incremental costs after delta adjustment will be the same as after mean difference adjustment, but the distributions will not be the same, since the mean difference adjustment uses the same value to adjust for all patients, and the delta adjustment uses an individual value. This causes the cost-effectiveness plane and CEAC for the delta adjustment to be slightly different from those for the mean difference adjustment.

Both methods mentioned above assume that the adjustment with the difference between the groups at baseline is unchanged for time points after baseline, since the adjustment factor is constant. Although one could expect that a patient who has a tendency to incur high costs at baseline will continue to have this tendency during follow-up, as we mentioned before, there are also factors which might work in the opposite direction. Patients who show a high value of specific outcome at baseline can be expected, on the average, to have less high values on subsequent measurements, and vice versa. This phenomenon is called regression to the mean ${ }^{(12,13)}$. In our study, this would imply that, independent of treatment, patients with high baseline costs will often show a reduced value at follow-up. The other way around, patients with low baseline costs will later often show an increased value. It may be clear that subtracting the mean difference or calculating a delta score will not incorporate these processes. 


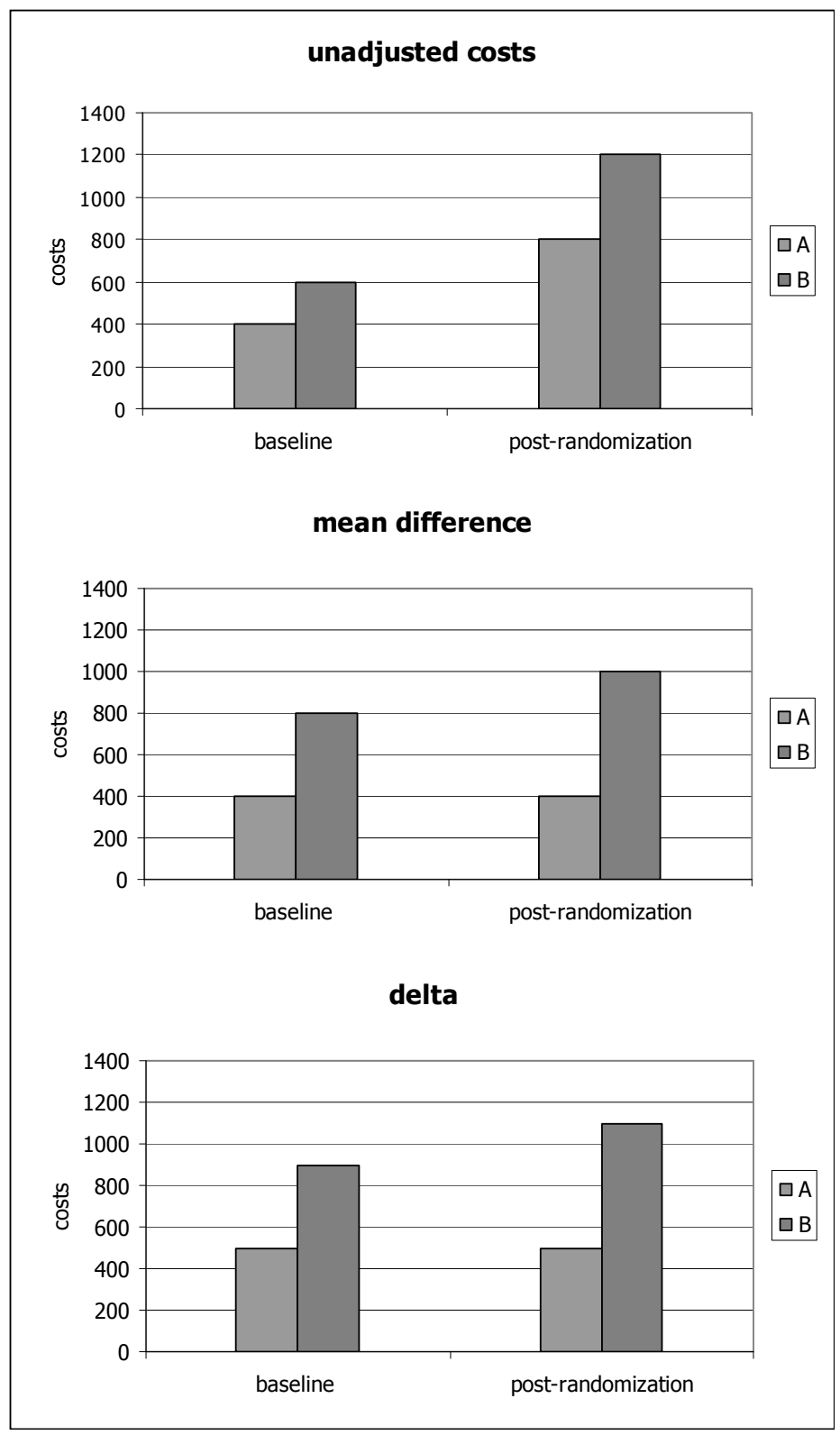

Figure 1: Unadjusted costs, mean difference adjustment and delta adjustment for baseline and postrandomization costs in two treatment groups. Please note that these graphs are hypothetical examples and only serve an illustrative purpose.

\section{Regression-based adjustment}

A linear regression analysis adjusts for the baseline cost difference but also takes into account regression to the mean effects and systematic changes in generating costs. In our case the regression model will include total costs during follow-up as the de- 
pendent variable, and baseline costs and treatment condition as independent variables. The regression equation used is:

$$
\text { costs }_{j}=\alpha+\beta_{\text {baseline }^{*}} \text { baseline }_{j}+\beta_{\text {treatment }} * \text { treatment }_{j}
$$

Where $\operatorname{costs}_{\mathrm{j}}=$ observed costs after baseline for patient $\mathrm{j}$ (in Euros)

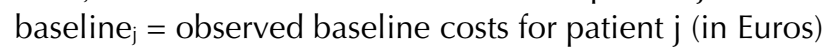

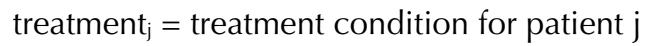

$(0=$ standard treatment, 1 = experimental treatment $)$

The adjustment

$$
\text { adjustment }_{j}=\text { costs }_{j}-\beta_{\text {baseline }} \text { baseline }_{j}=\alpha+\beta_{\text {treatment }^{*}} \text { treatment }_{j}
$$

will be independent of the baseline costs. Here also, by adding $\beta_{\text {baseline }}$ times the mean overall baseline costs to this variable approximations of the total costs are obtained. This results in the following formula for total costs for patient $\mathrm{j}$ adjusted for baseline:

$$
\text { costs_adjusted } d_{j}=\operatorname{costs}_{j}-\beta_{\text {baseline }}{ }\left(\text { baseline }_{j}-\text { baseline }_{\text {mean }}\right)
$$

Where baseline $_{\text {mean }}=$ mean baseline costs for all patients, and

$\beta_{\text {baseline }}=$ the resulting $\beta_{\text {baseline }}$ from equation (1)

So, to calculate the regression adjusted costs, one first performs a regression as in equation (1) and, with the $\beta_{\text {baseline }}$ that results from that regression, one fills in equation (3). When $\beta_{\text {baseline }}$ equals 1 , the adjusted costs will be equal to costs ${ }_{j}$ - baseline b $_{j}+$ baseline $_{\text {mean }}$ (see equation (3)), and so the regression adjustment will produce the same results as the delta adjustment does. When $\beta_{\text {baseline }}$ is lower than 1 the adjustment is smaller than the difference between individual baseline and overall mean baseline. When $\beta_{\text {baseline }}$ is higher than 1 , the adjustment is larger than the difference between individual baseline and overall mean baseline. The direction of the difference between the individual baseline and the overall baseline is also important for the adjustment. When the individual baseline costs are lower then the overall baseline costs (a more frequent situation in the treatment group with the lowest baseline costs), then costs will be adjusted upwards. When individual baseline costs are higher than the overall baseline costs (a more frequent situation in the treatment group with the highest baseline costs), then costs will be adjusted downwards.

A necessary condition for a least square linear regression analysis is a normal distribution of the residuals. In cost-effectiveness studies costs are often not normally distributed. This non-normality of the residuals can be caused by various phenomena, including: outliers, a bi or multimodal distribution, and skewness like in the form of excess zeroes, which is a very common phenomenon in cost data, since many patients have zero or very low costs, and only a few have high costs. It should 
be tested whether this affects the normality assumption and if so, (log-) transformation usually solves the problem, although transformation in itself also can be problematic ${ }^{(14)}$. Additionally, cost distributions frequently show a small number of patients with exceptionally high costs necessitating a different statistical approach than with a normal distribution. First, a criterion for identifying outliers should be defined. We suggest to try out several cut-offs, like the $90^{\text {th }}$ or $95^{\text {th }}$ percentile, maybe guided by the shape of the distribution, and check whether omitting values above a certain cutoff leaves a normal distribution of the, whether or not transformed, cost residuals. If these outliers are defined three methods to tackle this problem could be applied: first, analyse the main group and the outliers with two separate regression models (split regression), second, analyse the main group with a regression model and substitute outliers with the value of the unadjusted cut-off afterwards (trimmed regression), third, analyse the main group with a regression model and add the outliers with their original (unadjusted) value afterwards (replacement regression). So, in the split regression and the replacement regression, outliers are included in the total costs, although adjusted in the case of split regression, whereas in the trimmed regression, they are decreased to a cut-off value. We also performed a regression for the group as a whole, outliers or not. We called this regression 'standard regression'. In our example, we did not use a log-transformation, and we used the $90^{\text {th }}$ percentile of the unadjusted costs to define outliers.

\section{General methods applied to the sample data}

Before adjusting for the baseline difference, we applied the following methods to the data in our sample. Missing assessments due to dropouts were extrapolated using the last observation carried forward principle. Missing data within completed assessments were imputed by means of SPSS missing value analysis, option regression. We discounted costs at a rate of $4 \%$, as recommended by the Dutch guidelines for cost research $^{(15)}$. For the unadjusted data and all adjustment methods a cost-effectiveness analysis was performed using the non-parametric bootstrap method in Microsoft Excel with 1000 resamples $^{(7)}$. We first performed the adjustment procedure and then performed the bootstrap with the adjusted data. To be able to detect differences that arise as a consequence of using these different adjustment methods, we also constructed CEAC curves $^{(9)}$.

\section{RESULTS}

Table 1 shows the unadjusted costs as well as the costs for all adjustment methods, accompanied by the bootstrapped differences and the $95 \%$ uncertainty interval (which consists of the $2.5^{\text {th }}$ and $97.5^{\text {th }}$ percentile). Figure 2 shows a scatterplot of baseline costs versus 3-year costs after baseline, with SFT, TFP, recovered and notrecovered patients distinguished. Mean baseline costs were $€ 3,339$ for the SFT condition and $€ 4,238$ for the TFP condition, a mean difference of $-€ 899$. The bootstrapped difference between the two groups was $-€ 877$, with a 2.5 percentile of 
- €2,241 and a 97.5 percentile of $€ 486$. Total costs over the three year period excluding the baseline were $€ 30,822$ for the SFT condition and $€ 36,812$ for TFP, a mean difference of $-€ 5,989$. The bootstrapped difference was $-€ 5,826$ with a 2.5 percentile of $-€ 16,250$ and a 97.5 percentile of $€ 2,627$. The number of recovered patients was 20 out of $44(45 \%)$ for the SFT condition and 10 out of $42(24 \%)$ for TFP.

Table 1: Mean costs per treatment group and mean and bootstrapped differences

\begin{tabular}{|c|c|c|c|c|c|}
\hline Adjustment method & TFP costs (SD) & $\begin{array}{l}\text { SFT costs } \\
\text { (SD) }\end{array}$ & $\begin{array}{l}\text { difference } \\
(\text { SFT - TFP) }\end{array}$ & $\begin{array}{l}\text { bootstrapped } \\
\text { difference }\end{array}$ & $\begin{array}{c}\text { bootstrapped } 95 \% \\
\text { UI } \\
\text { for difference }\end{array}$ \\
\hline no adjustment & $\begin{array}{l}€ 36,812 \\
(28,120)\end{array}$ & $\begin{array}{l}€ 30,822 \\
(15,785)\end{array}$ & $-€ 5,989$ & $-€ 5,826$ & $\begin{array}{l}-€ 16,250 \text { to } \\
€ 2,627\end{array}$ \\
\hline mean difference & $\begin{array}{l}€ 26,024 \\
(28,200)\end{array}$ & $\begin{array}{l}€ 30,822 \\
(15,785)\end{array}$ & $€ 4,798$ & $€ 4,792$ & $\begin{array}{l}-€ 6,056 \text { to } \\
€ 13,396\end{array}$ \\
\hline delta & $\begin{array}{l}-€ 14,044 \\
(25,331)\end{array}$ & $\begin{array}{l}-€ 9,246 \\
(37,602)\end{array}$ & $€ 4,798$ & $€ 4,586$ & $\begin{array}{l}-€ 8,860 \text { to } \\
€ 16,934\end{array}$ \\
\hline \multicolumn{6}{|l|}{ regression } \\
\hline standard & $\begin{array}{l}€ 34,987 \\
(19,836)\end{array}$ & $\begin{array}{l}€ 32,564 \\
(17,422)\end{array}$ & $-€ 2,422$ & $-€ 2,320$ & $\begin{array}{l}-€ 9,569 \text { to } \\
€ 4,894\end{array}$ \\
\hline replacement & $\begin{array}{l}€ 36,573 \\
(27,898)\end{array}$ & $\begin{array}{l}€ 31,050 \\
(15,647)\end{array}$ & $-€ 5,523$ & $-€ 5,559$ & $\begin{array}{l}-€ 15,457 \text { to } \\
€ 2,637\end{array}$ \\
\hline trimmed & $\begin{array}{l}€ 32,527 \\
(14,938)\end{array}$ & $\begin{array}{l}€ 30,556 \\
(14,406)\end{array}$ & $-€ 1,970$ & $-€ 2,130$ & $\begin{array}{l}-€ 7,959 \text { to } \\
€ 4,092\end{array}$ \\
\hline separate & $\begin{array}{l}€ 35,485 \\
(22,446)\end{array}$ & $\begin{array}{l}€ 32,088 \\
(18,584)\end{array}$ & $-€ 3,397$ & $-€ 3,328$ & $\begin{array}{l}-€ 11,419 \text { to } \\
€ 5,544\end{array}$ \\
\hline
\end{tabular}

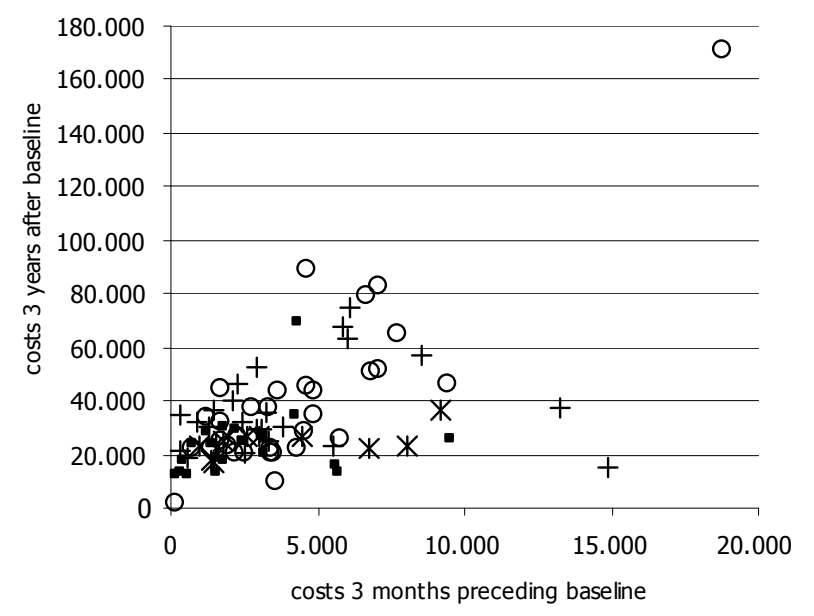

+ SFT not recovered

- SFT recovered

O TFP not recovered

* T FP recovered

Figure 2: Scatter plot of baseline costs versus costs after baseline for TFP and SFT patients, recovered and not recovered. 
no correction

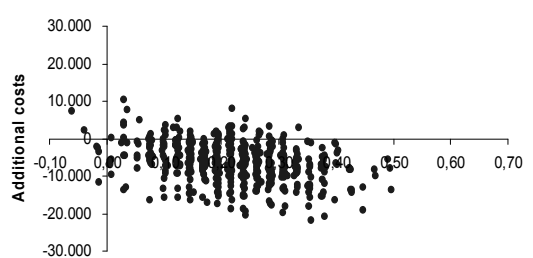

Additional effects

delta

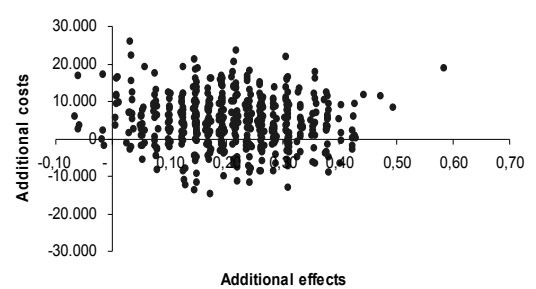

trimmed regression

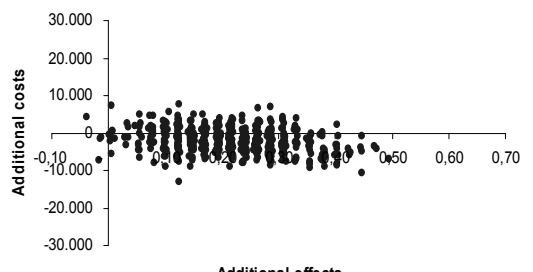

Additional effects mean difference

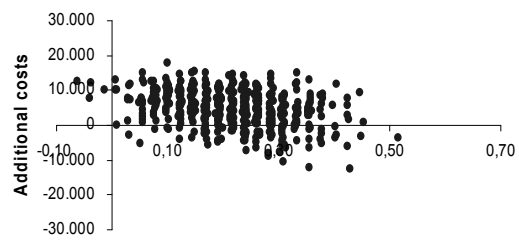

Additional effects

standard regression

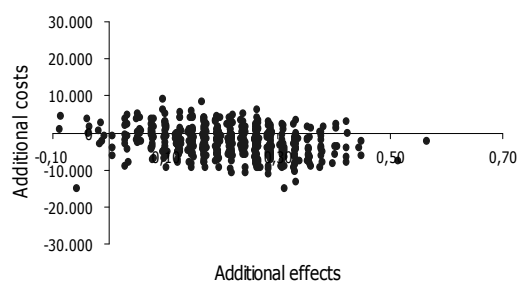

separate regression

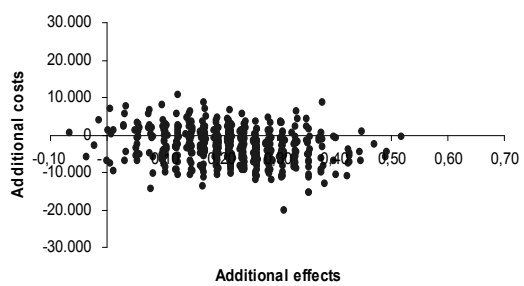

replacement regression

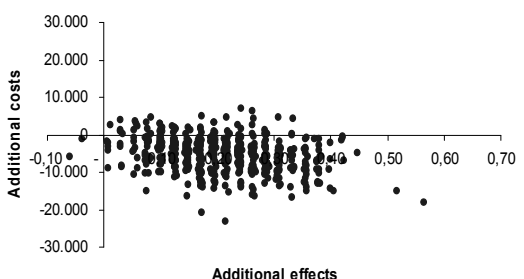

Figure 3: Cost-effectiveness planes with 1000 bootstrap replicates of the incremental cost-effectiveness of SFT versus TFP for unadjusted costs and for 6 adjustments methods 
From figure 2, one can read that baseline costs are positively correlated with costs after baseline, and that patients that do not recover have higher costs, both at baseline and afterwards, than patients that do recover. Total costs over both groups together ranged from $€ 2,225$ to $€ 171,333$, with a mean of $€ 33,747$ and a median of $€ 25,884$. The histogram showed that the larger part of the patients had costs up to around $€ 50,000$, and that there was a small number of patients with much higher costs. Total costs therefore did not have a normal distribution. When we left out patients with costs higher than the $90^{\text {th }}$ percentile of total costs, the distribution was normal as tested by the Kolmogorov-Smirnov test. Cutting off at the $90^{\text {th }}$ percentile meant that 8 out of 86 patients, i.e. those with costs higher than $€ 63,488$ were labelled as outliers. Regression for the 80 patients below the $90^{\text {th }}$ percentile cutoff point resulted in a $\beta_{\text {baseline }}$ of 1.25 (SE 0.44), whereas the $\beta_{\text {baseline }}$ for the highest 10 percentile group was 6.85 (SE 1.35). When no adjustment for the baseline difference was performed, SFT was dominant, since it had a better treatment outcome and lower costs than TFP. Figures 3 and 4 show the cost-effectiveness planes with bootstrap replications and the bootstrapped CEAC curves, respectively, for the unadjusted data and all adjustment methods. From figure 3 it is clear that both the mean difference and the delta adjustment cause an upward shift in incremental costs, whereas the incremental costs from the regression adjustments are more similar to the unadjusted costs situation. In figure 4, the upper two curves represent the unadjusted data and the replacement regression, followed by the other three regression curves (trimmed regression, split regression and standard regression). The mean difference and delta adjustments are represented by the lowest curves. The curves indicate that the experimental treatment is most preferred in the base case. However, this changes after adjusting for the baseline cost difference. Adjusting with regression shifts the curve a bit downward, meaning that the experimental condition is less dominant here than in the base case. For replacement regression however, the curve is not essentially different from the one for the unadjusted data, indicating that regression on only the non-outliers does not actually adjust for the group as a whole. When using the delta adjustment or the mean difference adjustment, the control condition seems more preferable, at least up to a certain point of the limit on the incremental cost effectiveness ratio (ICER). At a ceiling ratio of $€ 20,000$ per recovered patient, the probability that SFT is cost-effective is $97 \%$ for both the unadjusted data and the replacement regression. 


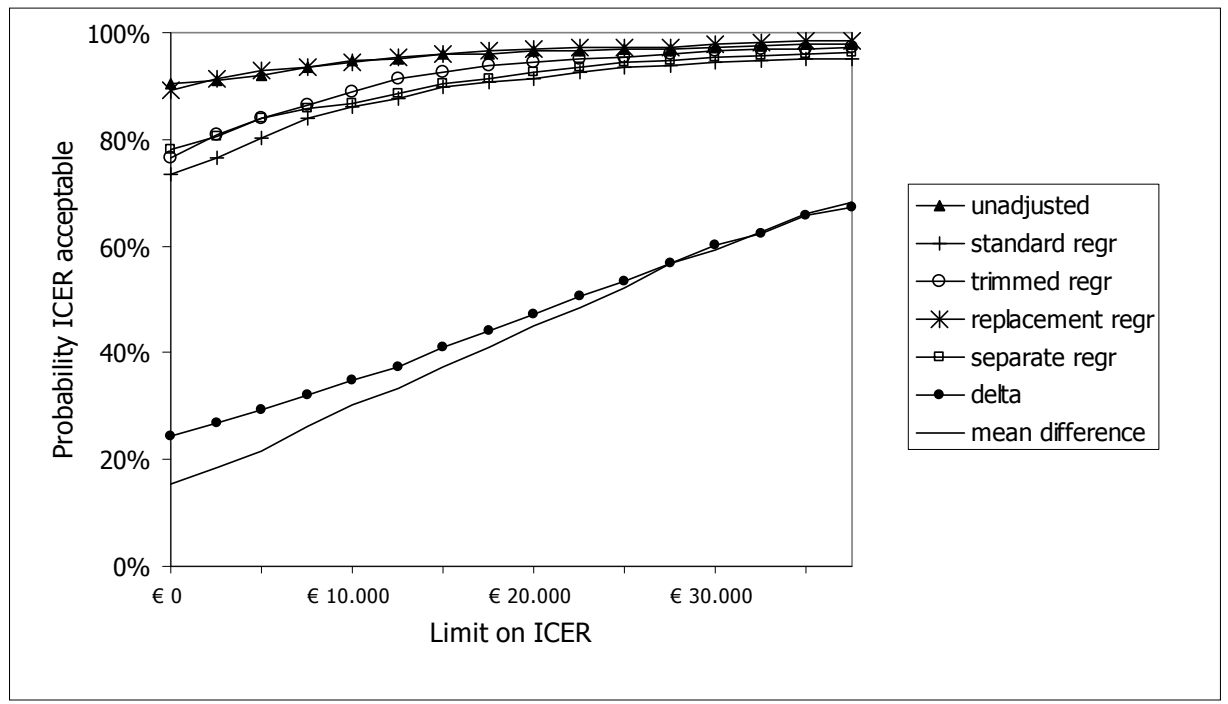

Figure 4: Cost Effectiveness Acceptability Curves (CEACs) for the cost-effectiveness of SFT versus TFP with unadjusted costs and 6 adjustment methods

The probability for the other regression-based adjustments varies from $91 \%$ to $95 \%$, and the mean difference and delta adjustments result in $42 \%$ and $47 \%$ probabilities, respectively, of SFT being cost-effective. The difference between mean difference and delta adjustment has its origin in a changed variance for the delta adjustment.

\section{DISCUSSION}

From the results of the present study, it is clear that adjusting for a baseline cost difference has an impact on the outcome of an analysis and that the size of this impact is dependent on the method used.

In our example, the regression analysis is hampered by the non-normal distribution of the costs, a not uncommon phenomenon in cost-effectiveness analyses. This necessitated some extra statistical manoeuvres. We used three methods, leading to comparable results, suggesting that for these data the used method is robust. Which of the three regression-based methods is most suitable can however depend on the data. Our suggestion would be to perform all three methods and check whether the outcomes are similar. If not and when there is a clear bi-modal distribution, which can be checked by testing if there are two separate normal distributions present in the dataset, the separate regression is probably the best approach. When this is not the case, one could take a look at the baseline costs for the outliers. If the baseline costs for these persons are also exceptionally high, the trimmed regression is probably preferable over the replacement regression, since the replacement regression does not adjust at all for the outliers where the trimmed regression does.

Outliers could be explained by the same regression model when the baseline costs are also high. This could be checked by looking at the residuals and the cut-off for 
defining outliers could also be based on these residuals. However, this model will partly be based on outliers which cannot be explained, leading to incorrect estimates of the coefficients. Therefore, we based our cut-off on the observed costs.

To our knowledge, baseline adjustment for cost differences in trial based costeffectiveness analyses has never been described in literature. For QALYs this is done occasionally. In a recent review ${ }^{(5)}$ only $22 \%$ of the studies adjusted for baseline differences in utilities, all using the delta adjustment. Manca et al. ${ }^{(6)}$ proposed a regression model to adjust the QALY for baseline utilities but this is not suitable to perform bootstrap procedures and construct CEACs, since it will only generate two adjusted group means and not adjusted values for individuals. Of course, one could argue whether estimating uncertainty is a necessity in cost-effectiveness analysis. However, as CEACs are already widely adopted in most medical journals ${ }^{(16)}$, including estimates of uncertainty is the preferred option in our view. The regression-based adjustment as we propose it is not much more complicated and results in individually adjusted values allowing constructing CEACs.

The routine starting point of an analysis should always be an unadjusted analysis of the cost-effectiveness. Baseline costs can be used to check whether treatment groups are comparable with respect to prognostic variables. When a baseline cost difference exists, one should of course first check carefully whether this difference might be due to some kind of selection process or problem in the randomization, or whether the cost difference is resolved after adjusting for baseline imbalances in patient or disease characteristics. When there is a fundamental problem in the randomization, propensity score matching could be an option ${ }^{(17)}$. If this is not the case, additionally an adjustment should be made. Preferably, this should be done by reported patient characteristics, or, when these are not collected in sufficient detail, by baseline costs as a substitute.

In the absence of a gold standard, it is not possible to prove one of the adjustment methods as optimal. However, it is possible to make a choice based on theoretical grounds. Assuming that an adjustment is necessary, methods such as the mean difference and delta adjustments mentioned in the present paper will not adjust for regression to the mean effects, and therefore will probably overadjust for the baseline difference. They will also result in an unjustified strong influence of outliers in the baseline measurement. The regression-based method takes into account this regression to the mean and will therefore be the most accurate adjustment method. There can be circumstances however, under which a simple mean difference or delta adjustment might be satisfactory. When the $\beta$ baseline resulting from the regression is 1 , this means that the influence of the baseline costs is unchanged in the trial. A mean difference or delta adjustment will then lead to the same results as the regressionbased adjustment. Since cost-effectiveness analysis is concerned with the average person, including those few patients who tend to be very expensive, methods that reduce the influence of outliers, such as the trimmed regression in our example, are not recommendable.

In the present analysis, we only included baseline costs and treatment condition as explanatory variables in the regression. Of course, as mentioned above, dependent on baseline differences, we could have included for instance age, and sex, because 
the older patients may be more or less costly and men and women may differ in their spending and (healthcare) consuming patterns. Also, severity of disease could be important in the analysis, so the baseline BPDSI could also have been an explanatory variable. However, since the purpose of this paper was only to explain the method, we have omitted these extra variables from the analysis.

How important is this adjustment for baseline effects? The magnitude of the impact of baseline costs could be checked for by performing 2 regressions, one with only the treatment and one with the treatment as well as the baseline costs as explaining variable(s). When the $\beta_{\text {treatment }}$ changes noticeably after adding baseline costs, this means that baseline costs have an impact on total costs that can not be neglected. Our suggestion for a definition of 'noticeable' in this sense would be a $10 \%$ change. For illustration, in our case the $\beta_{\text {treatment }}$ changed from -5989 to -2422 with adding baseline costs to the regression, a $60 \%$ decrease. In addition, the influence of the outliers should be checked by means of a sensitivity analysis by comparing the results of applying different approaches to the outliers in the regression analysis.

A limitation to our study was that we used a cost-interview with a 3-month recall period. The fact that patients had to report their resource use retrospectively might have led to so-called recall bias. However, previous research has shown that a 3 month recall period is acceptable for a cost-interview ${ }^{(18,19)}$. In addition, since bias would have been present in both groups, and at all assessments, we think that that had only minimal influence on our results. Another limitation was that we carried the last observation forward to impute for missing values due to dropouts, which is regarded as a naïve method ${ }^{(20)}$. It biases total cost estimates, since trends are frozen. In our study, most patients were experiencing improvement, so in that respect one could say that carrying the last observation forward might have overestimated total costs, although this is merely an assumption. However, the method of imputation does not further influence the adjustments, since all adjustments are based on the same unadjusted costs. In other words, the bias is limited to the unadjusted costs.

The implication of our study is that, although the routine starting point of an analysis should always be an unadjusted analysis of the cost-effectiveness, a baseline difference between treatment groups should be adjusted for in an additional analysis. This should be done by reported patient characteristics, or, when these are not sufficiently present, by baseline costs as a substitute. This adjustment should be done most preferably with a regression-based method, taking into account possible outliers and skewness of the distribution. 


\section{REFERENCES}

1 Pocock SJ, Assmann SE, Enos LE, Kasten LE. Subgroup analysis, covariate adjustment and baseline comparisons in clinical trial reporting: current practice and problems. Stat Med. 2002 Oct 15;21(19):2917-30.

2 Moher D, Schulz KF, Altman DG. The CONSORT statement: revised recommendations for improving the quality of reports of parallel-group randomized trials. Ann Intern Med. $2001 \mathrm{Apr}$ 17;134(8):657-62.

3 Altman DG, Schulz KF, Moher D, Egger M, Davidoff F, Elbourne D, et al. The revised CONSORT statement for reporting randomized trials: explanation and elaboration. Ann Intern Med. 2001 Apr 17;134(8):663-94.

4 Kleinbaum DG. Logistic Regression, ch. 7. New York: Spinger-Verlag; 1994.

5 Richardson G, Manca A. Calculation of quality adjusted life years in the published literature: a review of methodology and transparency. Health Econ. 2004 Dec;13(12):1203-10.

6 Manca A, Hawkins N, Sculpher MJ. Estimating mean QALYs in trial-based cost-effectiveness analysis: the importance of controlling for baseline utility. Health Econ. 2005 May;14(5):487-96.

7 Briggs AH, Wonderling DE, Mooney CZ. Pulling cost-effectiveness analysis up by its bootstraps: a non-parametric approach to confidence interval estimation. Health Econ. 1997 JulAug;6(4):327-40.

8 Efron B, Tibshirani RJ. An introduction to the bootstrap. Londen: Chapmann \& Hall; 1993.

9 Fenwick E, Byford S. A guide to cost-effectiveness acceptability curves. Br J Psychiatry. 2005 Aug;187:106-8.

10 Giesen-Bloo J, van Dyck R, Spinhoven P, van Tilburg W, Dirksen C, van Asselt T, et al. Outpatient psychotherapy for borderline personality disorder: randomized trial of schema-focused therapy vs transference-focused psychotherapy. Arch Gen Psychiatry. 2006 Jun;63(6):649-58.

11 Arntz A, van den Hoorn M, Cornelis J, Verheul R, van den Bosch WM, de Bie AJ. Reliability and validity of the borderline personality disorder severity index. J Personal Disord. 2003 Feb;17(1):45-59.

12 Bland JM, Altman DG. Some examples of regression towards the mean. BMJ. 1994 Sep 24;309(6957):780.

13 Fletcher RH, Fletcher SW, Wagner EH. Clinical Epidemiology, the essentials, ch. 2. 2nd ed. Baltimore: Williams \& Wilkins; 1988.

14 Barber J, Thompson S. Multiple regression of cost data: use of generalised linear models. J Health Serv Res Policy. 2004 Oct;9(4):197-204

15 Oostenbrink JB, Bouwmans CAM, Koopmanschap MA, Rutten FF. Manual for cost research. Methods and unit-prices for economic evaluations in health care [in Dutch] actualized version. College voor zorgverzekeringen, 2004.

16 Fenwick E, O'Brien BJ, Briggs A. Cost-effectiveness acceptability curves--facts, fallacies and frequently asked questions. Health Econ. 2004 May;13(5):405-15.

17 Joffe MM, Rosenbaum PR. Invited commentary : propensity scores. Am J Epidem 1999; 150(4): 327-33.

18 Severens JL, Mulder J, laheij RJ, Verbeek AL. Precision and accuracy in measuring absence from work as a basis for calculating productivity costs in the Netherlands. Soc Sci Med 2000; 51(2): 243-9.

19 van den Brink M, van den Hout WB, Stiggelbout AM, putter H, van de Velde CJ, Kievit J. Selfreports of health-care utilization: diary or questionnaire? Int J Technol Assess Health Care 2005;21(3): 298-304.

20 Oostenbrink JB, Al MJ. The analysis of incomplete cost data due to dropout. Health Econ 2005; 14: 763-776. 

THE EQ-5D: A USEFUL ASSESSMENT INSTRUMENT IN BORDERLINE PERSONALITY DISORDER?

A.D.I. van Asselt, C.D. Dirksen, A. Arntz, J. H. Giesen-Bloo, J.L. Severens

Submitted 


\section{ABSTRACT}

INTRODUCTION Borderline Personality Disorder (BPD) is a severe psychiatric disorder, associated with impaired quality of life. The aim of the present study is to assess the internal and external responsiveness of the EuroQoL (EQ-5D) in BPD patients.

PATIENTS AND METHODS Data from completers $(\mathrm{N}=49)$ of a multi-center Dutch randomized trial were used. We used both EQ-5D utility score and EQ-VAS, and the Borderline Personality Disorder Severity Index-IV (BPDSI-IV). To determine internal responsiveness, we calculated the standardized response mean (SRM). To determine external responsiveness, we calculated Spearman correlations of the change scores, and compared EQ-5D scores for clinically improved versus non-clinically improved patients as measured with the BPDSI-IV.

RESULTS Patient scores improved on all instruments during the three years. SRMs for BPDSI-IV were significantly higher for EQ-5D utility. Three-year Spearman correlation between change scores of BPDSI-IV and EQ-5D utility was .487, between BPDSI-IV and EQ-VAS .404, both statistically significant. EQ-5D utility scores for patients who clinically improved were significantly higher than for patients who did not.

DISCUSSION We conclude that the EQ-5D is fairly responsive in BPD, and therefore, especially because of its brevity and user-friendliness, can serve as a useful tool in economic evaluations in patients with BPD. 


\section{INTRODUCTION}

Individuals who suffer from Borderline Personality Disorder (BPD) constitute a very severe group of psychiatric patients, who are difficult to treat. The problematic nature of BPD is characterized by recurring crises, hospitalisations, self-mutilation, suicide attempts, addictions and episodes of depression, anxiety and aggression. Also typical for BPD is its chronic nature. The onset of BPD generally takes place in adolescence, and prevalence in the general population is estimated to be ranging from 0.5 to $2.0 \%{ }^{(1,2)}$. The suicide risk is estimated up to $10 \%{ }^{(3)}$. From these facts, it may be clear that Health Related Quality of Life (HRQoL) in patients with BPD is significantly impaired compared to that of healthy individuals. HRQoL can be measured in several ways. For instance, there are generic and disease-specific instruments. Generic instruments are suitable for all diseases, and disease-specific instruments are especially designed for one disease. In economic evaluations, generic HRQoL instruments are preferred, as they allow us to determine the allocative efficiency of alternative actions. As argued by Dowie ${ }^{(4)}$, it is the outcomes from all alternative treatments for the condition that determine the relevant HRQoL measure, not the outcomes from the condition itself, or any one treatment. A well-known generic instrument for measuring HRQoL is the EuroQol (EQ-5D) $)^{(5)}$, which allows for calculation of a utility score ranging from -.59 to 1, with a higher score indicating a higher HRQoL. The EQ-5D utility score can also be used to calculate so-called Quality Adjusted Life Years (QALY), where one QALY is the equivalent of one year spent in perfect health (i.e. with a utility score of 1 ). For BPD patients, in a Dutch randomized trial, an EQ-5D utility score of 0.48 (SD 0.28) was found at baseline ${ }^{(6)}$. The BOSCOT trial found comparable results using the EQ-5D, around $0.50^{(7)}$. These figures confirm that BPD indeed is associated with a severely decreased HRQOL, as HRQoL in the general population in various countries has been found to range between 0.83 and $0.87^{(8-10)}$ as measured with the EQ-5D.

There is consensus that instruments for measuring health status should be tested for validity and reliability before they can be used in clinical studies. For instruments developed to measure changes over time, responsiveness or sensitivity to change is also considered an important aspect ${ }^{(11)}$. Although the EQ-5D is by far the most widespread instrument for measuring HRQoL and calculating Quality Adjusted Life Years (QALYs) within the context of economic evaluations ${ }^{(12)}$, its validity in psychiatric populations has not yet been established unambiguously. For instance, König et al. ${ }^{(13)}$ found the EQ-5D to be a reasonably valid instrument for a population with schizophrenia, since different response levels at the EQ-5D dimensions were generally associated with significantly different scores of measures used for comparison, such as the Symptom Checklist-90R (SCL-90R)and the Positive and Negative Syndrome Scale (PANSS). However, van de Willige et al. ${ }^{(14)}$ concluded that the use of the EQ-5D utility score as the core measure in economic evaluation does not seem appropriate in the field of psychiatry, because of the fact that the EQ-5D did not correspond with changes in social and psychological wellbeing as measured on the WHOQOL-BREF (i.e. the short version of the WHOQoL-100) in a population with schizophrenia. The authors argued that this was probably due to the fact that in 
calculating the utility score based on EQ-5D, the physical components are overstressed for use in a psychiatric population. For patients with a major depression, Sapin et al. ${ }^{(15)}$ found significant differences in mean EQ-5D utilities by level of disease severity assessed by the Clinical Global Impression of Severity (CGI-S), and that the EQ-5D correlates well with the Short Form-36 ${ }^{(16)}$, a descriptive generic HRQoL instrument, and with the Quality of Life for Depression Scale (QLDS), a diseasespecific HRQoL instrument. Therefore, and also because the EQ-5D is easy to collect in large sample surveys because of its brevity and simplicity, they conclude that the EQ-5D is suitable for use in depression. Günther et $\mathrm{al}^{(17)}$ investigated responsiveness of the EQ-5D in patients with depression by comparing it with the WHOQoL-BREF and several clinical measures, such as the CGI-S. They found that the EQ-5D utility score is less responsive than the EQ-VAS and the other measures and that larger sample sizes were needed to detect meaningful differences.

Regarding BPD, there is very little evidence on the validity of the EQ-5D. Soeteman et al. ${ }^{(18)}$ compared the EQ-5D with the Global Severity Score (GSI) of the SCL-90R for patients with complex personality problems and personality disorders, and found a correlation (Pearson's r) of -0.49 . As this was a cross-sectional correlation, it still is possible that even though patients improve clinically, this does not reflect upon the EQ-5D scores when the domains that the patients improve on are not present in the EQ-5D, or are not prominent enough in the EQ-5D scoring algorithm. Brazier et al ${ }^{(19)}$ have pointed out in a recent HTA-technology report that validation of the EQ-5D in BPD patients is necessary.

The aim of the present study is to assess the responsiveness of the EQ-5D when used in a BPD population, by comparing the EQ-5D with a clinical instrument, the Borderline Personality Severity Index-IV (BPDSI-IV).

\section{STUDY POPULATION AND DATA COLLECTION}

Data were collected as part of a multi-centre, randomized trial in the Netherlands, comparing two types of outpatient psychotherapy for Borderline Personality Disor$\operatorname{der}^{(20)}$. Sample size at baseline was 86 patients. The time horizon of the study was four years, with an assessment at every three months during the first three years, and a final follow-up assessment after the fourth year. There was a significant number of patients lost to follow-up. Dropout rate was $40 \%$ after three years, and was mainly caused by patients not having confidence in the therapy or therapist. For detailed information, see Giesen-Bloo et al. ${ }^{(20)}$. For the present analysis, we decided to only include the completers up to three years, since censored data would not be of any use to assess responsiveness. For the present study, data from both treatment conditions were combined. Also, we only analyzed 4 of the 13 available assessments: the baseline measurement, and one, two, and three years after baseline. The reason for this decision was to keep the results surveyable. In the results section, we will refer to these measurements as T0, T1, T2, and T3, respectively. Excluding the dropouts from the analysis meant that 49 patients were left in the sample. As there was one patient 
with a missing baseline value for the EQ-VAS, the analyses for EQ-VAS were performed for 48 patients. Mean age of the patients was 31 years (SD 8.55), and $90 \%$ was female.

\section{Instruments}

The BPDSI-IV ${ }^{(10,21)}$ is a 70-item index with 9 dimensions reflecting the 9 DSM-IV criteria of BPD, such as for instance unstable relationships, lack of anger control, recurrent suicidal behaviour, and chronic feelings of emptiness. The aggregated score ranges from 0 to 90 . In general, when the BPDSI-IV-score is less than 15, a person scores below the clinical cut-off score, and falls in the normal range. Thus, a patient is considered to be recovered from BPD when BPDSI-IV scores drop below 15. In accordance with Giesen-Bloo et $\mathrm{al}^{(20)}$, we also applied the concept of reliable change. For the BPDSI-IV, reliable change was calculated at 11.70. This means that when patients' BPDSI-IV score after three years was $\geq 11.70$ points lower compared to baseline, the patient was considered to be reliably improved.

The EQ-5D instrument ${ }^{(5)}$ is a descriptive system with five questions, each representing one dimension of HRQoL, which are mobility, self-care, daily activities, pain/discomfort, and depression/anxiety. Each dimension can be rated at three levels: no problems, some problems, and major problems, and together classify persons into one of 243 possible health states. By means of a scoring function ${ }^{(22)}$, based on preferences for 42 out of 243 health states derived with the time trade off (TTO), each health state can be assigned a utility score, ranging from -.59 (worst imaginable health state) to +1 (best imaginable health state). The preferences were assessed in a representative sample from the general UK population. The EQ-5D also includes a visual analogue scale (VAS), a rating scale thermometer at which respondents can directly score their HRQoL on a scale from 0 to 100 , with 0 representing the worst imaginable health state and 100 representing the best imaginable health state. So, the EQ-5D utility score is a reflection of members of the general population value the patient's health state, and the EQ-VAS is a reflection of how patients value their own health state. Therefore, the EQ-VAS is less suitable for use in economic evaluations, since it does not represent a societal perspective.

\section{Assessment of responsiveness}

In this study, both internal and external responsiveness are assessed ${ }^{(23)}$. The concepts of internal and external responsiveness are sometimes also referred to as distributionbased and anchor-based methods ${ }^{(24)}$. Internal responsiveness characterizes the ability of a measure to change over a particular pre-specified time frame. Assessing the internal responsiveness is usually performed by calculating effect sizes. Assessing the external responsiveness can be performed in various ways. One method is calculating correlation coefficients, reflecting the extent to which changes in a measure over a pre-specified time frame relate to corresponding changes in a reference measure of health status. In an alternative way, external responsiveness is synonymous with 
discriminative ability, as score changes on a health status instrument should distinguish patients who improve from those who do not ${ }^{(25)}$. For instance, discriminative ability can be assessed by classifying patients as improved or not improved according to a clinical anchor, and testing for significant differences between those categories in the instrument under investigation.

\section{Analyses}

\section{General}

We calculated scores for both the VAS and utility scores of the EuroQoL, as well as for the BPDSI-IV total score at T0, T1, T2 and T3. We also measured the EQ-5D dimension scores at all four time points. For EuroQoL utility score and VAS, as well as for the BPDSI-IV, change scores were calculated by subtracting scores at T0 from scores at T1, T2, and T3.

\section{Internal responsiveness}

To assess the internal responsiveness, we calculated the standardized response means (SRM), which is a kind of effect size, for the BPDSI-IV change scores and EQ$5 \mathrm{D}$ utility change scores, by dividing the individual change score by the standard deviation of the change score for the patient group. Furthermore, we tested whether the SRMs of both instruments were statistically significantly different from each other by performing paired t-tests on the individual scores that are obtained when each patient's change score is divided by the standard deviation of the change score.

\section{External responsiveness}

First, to assess the external responsiveness, we correlated the EQ-5D dimensions, EQ-VAS, and EQ-5D utility change scores with the BPDSI-IV total change score using the Spearman correlation coefficient. In general, it was expected that when a patient would improve on the BPDSI-IV, implying less severe BPD-symptoms, the patient's HRQoL would also improve. The expected direction of the correlation between BPDSI-IV change scores and EQ-VAS and EQ-5D utility change scores is negative, since the BPDSI-IV gives higher scores for higher severity, and the EuroQol VAS and utility score give a higher score for better HRQoL. The EQ-5D dimensions are expected to correlate positively with the BPDSI-IV, as a higher score indicates more problems.

Second, we performed a t-test to establish whether there was a difference in EQ-5D utility change scores at T3 compared to baseline between patients who had a reliable change (change $\geq-11.70$ ) as measured with the BPDSI-IV-IV, and those who did not. The same test was performed for patients who had recovered according to BPDSI-IV (score $<15$ ) and those who had not, however here we used the EQ-5D utility scores at T3 instead of the change compared to baseline, since the BPDSI-IV recovery criterion is also based on the T3 BPDSI-IV score. When the EQ-5D utility scores for reliably changed and recovered patients is significantly higher than for patients who did not reliably change or recover, respectively, one could conclude that the EQ-5D 
utility score is capable of discriminating between clinically improved and clinically not improved patients.

\section{RESULTS}

Table 1 shows EQ-VAS and utility scores, as well as the BPDSI-IV total score. In the three years that are comprised in this analysis, all scores improve considerably. Figure 1 shows the distribution of the three response levels on the different dimensions of the EQ-5D over time. Not only problems on the anxiety/depression dimension are prominent, but also for the pain/discomfort and usual activities dimensions, the majority of patients indicated to have some or severe problems $(86 \%$ for the usual activities and anxiety/depression dimensions, and $80 \%$ for the pain/discomfort dimension). In the mobility and self-care dimensions, only between $10 \%$ and $20 \%$ of the patients reported some or severe problems at baseline. There were 2 patients (4\%) who scored 'no problems' on all dimensions, resulting in a EQ-5D utility score of 1 . These 2 patients both scored 60 on the EQ-VAS and 25 and 31 on the BPDSIIV, respectively. Of the 3 dimensions with elevated scores, only anxiety/depression shows the monotonic change from severe to less severe scores during time that one expects.

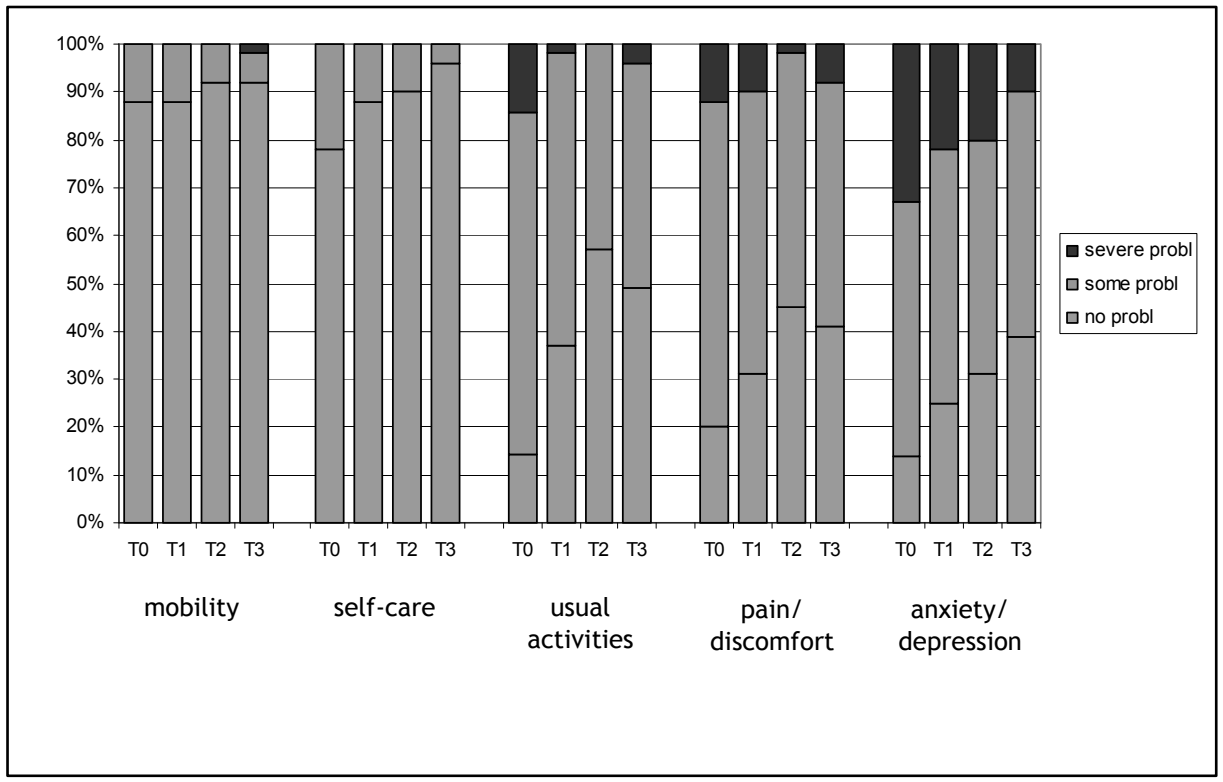

Figure 1: percentage of responses for each level of each dimension of the EQ-5D $(N=49)$ 
Table 1: mean (SD) and change (SD of change) EQ-VAS and EQ-5D utility score, and BPDSI-IV total score $(\mathrm{N}=49$, for $\mathrm{EQ}-\mathrm{VAS} \mathrm{N}=48)$

\begin{tabular}{lccccccc}
\hline & T0 & T1-T0 & T1 & T2-T0 & T2 & T3-T0 & T3 \\
\hline EQ-VAS & 50.50 & 5.04 & 55.54 & 13.00 & 63.50 & 13.46 & 63.96 \\
& $(17.80)$ & $(28.36)$ & $(23.11)$ & $(26.75)$ & $(20.28)$ & $(23.54)$ & $(20.51)$ \\
EQ-5D & $0.50(0.31)$ & $0.12(0.36)$ & $0.61(0.30)$ & $0.19(0.35)$ & $0.69(0.27)$ & $0.20(0.37)$ & $0.69(0.28)$ \\
utility & & & & & & & \\
BPDSI-IV & 33.96 & -10.72 & 23.24 & -16.27 & 17.69 & -17.53 & 16.43 \\
& $(8.28)$ & $(9.75)$ & $(9.24)$ & $(9.58)$ & $(10.10)$ & $(11.01)$ & $(9.71)$ \\
\hline
\end{tabular}

\section{Internal responsiveness}

The SRMs (table 2) are significantly higher for the BPDSI-IV. For all instruments, the largest part of the effect is attained in the first year. The incremental effect in the second year is smaller. For both the EQ-5D utility score and the BPDSI-IV, the SRM after three years is smaller than after two years. This is caused by the fact that the SD of the change is larger in the third year. For the EQ-VAS, the SD of the change score in the third year is smaller, which causes the SRM to be continuously increasing. From the table it is also clear that the EQ-5D utility score in general is more capable in detecting change than the EQ-VAS (i.e. in the first two years), although the difference in not statistically significant.

\section{External responsiveness}

Table 3 shows Spearman correlations for the change scores of BPDSI-IV and EQ-5D. The EQ-VAS change scores correlate significantly with the BPDSI-IV change scores, as well as the anxiety/depression dimension, and to a lesser extent the EQ-5D utility change scores and usual activities dimension. As was to be expected, the EQ-VAS and EQ-5D utility change scores correlate negatively with the BPDSI-IV change score, and the change scores on the dimensions in general correlate positively with the BPDSI-IV change score. Correlations on the mobility and self-care dimension are all non-significant, which can be explained by the fact that the score on these dimensions predominantly consist of 'no problems' at baseline, leaving almost no room for improvement in these dimensions, as can be seen in figure 1.

Change in clinical score is strongest associated with change in the anxiety/depression and usual activities domains. Overall, the utility and VAS change scores of the EuroQoL after three years of treatment correlate significantly with the BPDSI-IV change score.

Table 4 shows the EQ-5D utility scores for patients who did and did not reliably change on the BPDSI-IV, as well as for patients who did and did not recover. There is a clear difference in change in EQ-5D utility scores between the groups. Patients who reliably changed had a significantly higher change in EQ-5D utility than patients who did not. Patients who recovered had significantly higher utility scores at T3 than those that did not recover. 
Table 2: standardized response means (change/SD of change) of BPDSI-IV and EQ-5D utility ( $N=49$, for EQVAS $\mathrm{N}=48$ )

\begin{tabular}{lllllll}
\hline & EQ-5D & $\begin{array}{l}\text { p-value } \\
\text { EQ-5D vs. } \\
\text { EQ-VAS }\end{array}$ & EQ-VAS & $\begin{array}{l}\text { p-value } \\
\text { EQ-VAS vs. }\end{array}$ & BPDSI-IV & $\begin{array}{l}\text { p-value } \\
\text { EQ-5D vs. } \\
\text { BPDSI-IV }\end{array}$ \\
\hline T1 - T0 & 0.321 & 0.360 & 0.178 & 0.00 & -1.099 & 0.00 \\
T2 - T0 & 0.546 & 0.774 & 0.486 & 0.00 & -1.699 & 0.00 \\
T3 - T0 & 0.525 & 0.560 & 0.572 & 0.00 & -1.592 & 0.00 \\
\hline
\end{tabular}

Table 3: Spearman Correlations between change scores (compared to baseline) of BPDSI-IV versus EQ5D domains, utility and VAS ( $\mathrm{N}=49$, for EQ-VAS N=48)

\begin{tabular}{lccc}
\hline & T1-T0 & T2-T0 & T3-T0 \\
\hline EQ-5D domains & & & -.073 \\
-mobility & -.243 & -.002 & -.046 \\
-self-care & .039 & -.073 & $.466^{* *}$ \\
-usual activities & .276 & $.367^{* *}$ & $.288^{*}$ \\
-pain/discomfort & .138 & .021 & $.592^{* *}$ \\
-anxiety/depression & $.337^{*}$ & $.391^{* *}$ & $-.404^{* *}$ \\
EQ-VAS & $-.381^{* *}$ & $-.415^{* *}$ & \\
& & & $-.487^{* *}$ \\
EQ-5D utility & -.254 & $-.350^{*}$ &
\end{tabular}

* significant at the 0.05 level (2-tailed) ** significant at the 0.01 level (2-tailed)

Table 4: mean (SD) EQ-5D utility scores for patients with and without reliable change after 3 years on BPDSI-IV, and patients who did and did not recover at T3 according to BPDSI-IV ( $\mathrm{N}=49)$

\begin{tabular}{lcc}
\hline & $\begin{array}{c}\text { reliable change over 3 yrs } \\
\text { yes }(\mathrm{N}=31) / \text { no }(\mathrm{N}=18)\end{array}$ & $\begin{array}{c}\text { recovered at T3 } \\
\text { yes }(\mathrm{N}=20) / \mathrm{no}(\mathrm{N}=29)\end{array}$ \\
\hline & EQ-5D utility & EQ-5D utility \\
change over 3 yrs & score at T3 \\
\hline Yes & $0.32(0.31)$ & $0.86(.13)$ \\
No & $-0.01(0.39)$ & $0.58(.30)$ \\
p-value for difference & 0.005 & 0.000 \\
\hline
\end{tabular}

\section{DISCUSSION}

The aim of this explorative study was to assess the internal and external responsiveness of the EQ-5D in a Borderline population. For this purpose, we calculated standardized response means and correlations, and performed statistical tests to determine whether the EQ-5D could discriminate between patients who did and did not reliably change or recover based on BPDSI-IV scores.

With respect to the internal responsiveness, standardized response means were higher for the BPDSI-IV. The SRM for the EQ-5D can be regarded as moderate, since they are higher than 0.5 (except for the first year). An SRM of less than 0.5 is generally classified as small, values over 0.8 as large, and values in between as moderate ${ }^{(27-29)}$. SRMs of the BPDSI-IV were approximately 3 times as high compared to the EQ-5D utility and EQ-VAS scores. In itself, the fact that SRMs for BPDSI-IV are higher 
than for the EQ-5D is completely logical, since the intervention was aimed at improving BPD severity, and not primarily at improving HRQoL.

Concerning the external responsiveness, the Spearman correlations between the EuroQoL and the BPDSI-IV for the whole three year period were between 0.4 and 0.5 for both utility score and the VAS, and statistically significant. Most proposed classifications ${ }^{(29-31)}$ consider a Spearman's correlation of $>0.5$ to be strong, a correlation of $0.3 / 0.35-0.5$ to be moderate, and a correlation of $<0.3 / 0.35$ to be weak. Thus, the correlations between the EQ-5D utility and EQ-VAS score and the BPDSIIV should be classified as moderate.

Moreover, the EQ-5D utility score showed discriminative ability, since it was significantly higher for patients that had a reliable change on the BPDSI-IV or no longer met the cut-off point for having a BPD diagnosis.

Taken all results together, effect sizes were higher for BPDSI-IV, EQ-5D change scores were moderately correlated with BPDSI-IV change scores and the EQ-5D utility score discriminated significantly between 'responders' and 'non-responders' to the therapy in the trial. Does this mean that the EQ-5D is responsive in a BPD population? It is rather complicated to compare our results with other studies that assessed the responsiveness of the EQ-5D. First, results regarding the responsiveness of an instrument cannot be compared across different populations and interventions. Apart from that, both internal and external responsiveness can be assessed in many different ways ${ }^{(11,23)}$. The fact that there are no unambiguous criteria to decide what 'good enough' responsiveness is (when comparing an HRQoL-instrument with a clinical instrument) is another complicating factor.

However, when relying on existing classifications ${ }^{(29-31)}$ we could state that the EQ-5D is fairly responsive in a BPD population. In addition, as discriminative ability generally is believed to be a relevant aspect of an HRQoL instrument ${ }^{(32,33)}$, this also speaks for a favourable evaluation of the EQ-5D in our sample. Nevertheless, the effects assessed with the EQ-5D utility score were much weaker than those assessed by the BPDSI-IV. It is unclear to what degree this reflects the true state of affairs, i.e. that HRQoL changes less than clinical symptoms, or that this reflects insufficient capacity of the EQ-5D to measure a change in HRQoL. In this respect it is noteworthy that baseline quite some patients rated absence of problems on the domains, clearly not reflecting the true state of $\mathrm{HRQOL}$ in a sample of severely disturbed patients willing to enter a lengthy and difficult treatment. However, mean utility score in our sample showed severely impaired HRQoL, and there were only 2 patients who scored absence of problems on all 5 dimensions. The scores of these patients on the EQVAS and BPDSI-IV were also less severe than average, but did not indicate complete absence of problems. The reason for these deviant and unusually high EQ-5D utility scores is unclear. It might be in the EQ-5D itself, it might also be in the patients showing some kind of denial behaviour.

On the other hand, the finding that clinically recovered patients report utility scores in the normal range further supports the validity of the EQ-5D in the context of 
treatment of BPD. Patients that recovered from BPD reported an average utility of .86 after 3 years, which lies well in the normal population range of $.83-.87^{(8-10)}$, whereas the not-recovered patients remained at a low level of .58 on average. Thus, patients recovering from BPD through the investigated psychotherapies also 'recovered' from abnormal low HRQoL.

There is an important limitation to this study that should be addressed. We used only completers of the trial for our analyses, since we reasoned that imputing for missing values would endanger the validity of the results. Besides the fact that this diminishes the sample size, it also disregards the fact that responsiveness in dropouts might be different than in completers, which might have a significant impact here when considering the high percentage of dropouts in the trial. The most sophisticated way to solve the problem of censored data is using Multiple Imputation (MI) ${ }^{(34)}$. We have attempted to perform $\mathrm{Ml}$ for our data, however, as described elsewhere in more detail ${ }^{(6)}$, the results of the MI were unstable, and tended heavily toward extreme values. Alternatively, one could use the last observation carried forward method (LOC-F), but this would not be suitable to assess responsiveness, since the values of dropouts then would remain unchanged, and thus artificially unresponsive. Therefore, we calculated effect sizes and correlations also for dropouts over the change score between T0 and T1. The scores for dropouts were not dramatically different, in the sense that the standardized response means were higher, about 30 to $40 \%$, for both the EQ-5D and the BPDSI-IV, and that the Spearman correlation coefficient was lower, and non-significant, for the EQ-VAS and higher for the EQ-5D utility score. We believe that these outcomes do not suggest that excluding the dropouts has distorted or artificially improved the results of the present study.

\section{CONCLUSION}

In this study, the responsiveness of the EQ-5D was assessed in a population of patients with Borderline Personality disorder. We conclude that internal and external responsiveness measures in general are moderate, and the EQ-5D utility score discriminates significantly between responders and non-responders. Therefore we think that the EQ-5D, especially because of its brevity and user-friendliness, can serve as a useful tool for assessing HRQoL in patients with BPD in economic evaluations. However, we recommend that more research is done in this area, especially in establishing the concurrent responsiveness of the EQ-5D with other generic HRQoLinstruments used in economic evaluations. 


\section{REFERENCES}

1. APA. Diagnostic and Statistical Manual of Mental Disorders, fourth edition. 1994, Washington, D.C.: American Psychiatric Association.

2. Samuels J, Eaton WW, Bienvenu OJ, 3rd, et al. Prevalence and correlates of personality disorders in a community sample. Br J Psychiatry, 2002. 180: p. 536-42.

3. Paris $\mathrm{J}$. The treatment of borderline personality disorder in light of the research on its long term outcome. Can J Psychiatry, 1993. 38 Suppl 1: p. S28-34.

4. Dowie J. Decision validity should determine whether a generic or condition-specific measure HRQOL measure is used in health care decisions. Health Economics, 2002. 11: p. 1-8.

5. EuroQol--a new facility for the measurement of health-related quality of life. The EuroQol Group. Health Policy, 1990. 16(3): p. 199-208.

6. van Asselt ADI, Dirksen C, Arntz A, et al. Outpatient psychotherapy for borderline personality disorder: cost-effectiveness of schema-focused therapy versus transference-focused psychotherapy. Br J Psychiatry, accepted for publication.

7. Palmer S, Davidson $K$, Tyrer $\mathrm{P}$, et al. The cost-effectiveness of cognitive behavior therapy for borderline personality disorder: results from the BOSCOT trial. J Personal Disord, 2006. 20(5): p. 466-81.

8. Burstrom K, Johannesson M, Diderichsen F. Swedish population health-related quality of life results using the EQ-5D. Qual Life Res, 2001. 10(7): p. 621-35.

9. Luo N, Johnson JA, Shaw JW, et al. Self-reported health status of the general adult U.S. population as assessed by the EQ-5D and Health Utilities Index. Med Care, 2005. 43(11): p. 1078-86.

10. Saarni SI, Suvisaari J, Sintonen $\mathrm{H}$, et al. The health-related quality-of-life impact of chronic conditions varied with age in general population. J Clin Epidemiol, 2007. 60(12): p. 1288-97.

11. Terwee CB, Dekker FW, Wiersinga WM, Prummel MF, Bossuyt PMM. On assessing responsiveness of health-related quality of life instruments: Guidelines for instrument evaluation. Quality of Life Research, 2003. 12:p.349-362.

12. Rasanen $\mathrm{P}$, Roine $\mathrm{E}$, Sintonen $\mathrm{H}$, et al. Use of quality-adjusted life years for the estimation of effectiveness of health care: A systematic literature review. Int J Technol Assess Health Care, 2006. 22(2): p. 235-41.

13. Konig $\mathrm{HH}$, Roick C, Angermeyer MC. Validity of the EQ-5D in assessing and valuing health status in patients with schizophrenic, schizotypal or delusional disorders. Eur Psychiatry, 2007. 22(3): p. 177-87.

14. van de Willige G, Wiersma D, Nienhuis FJ, Jenner JA. Changes in quality of life in chronic psychiatric patients: a comparison between EuroQol (EQ-5D) and WHOQoL. Qual Life Res, 2005. 14(2): p. 441-51.

15. Sapin C, Fantino B, Nowicki ML, Kind P. Usefulness of EQ-5D in assessing health status in primary care patients with major depressive disorder. Health Qual Life Outcomes, 2004. 2: p. 20.

16. Ware JE, Snow KK, Kolinski M, Gandeck B. SF-36 Health survey manual and interpretation guide. 1993, Boston, MA: The Health Institute, New England Medical Centre.

17. Gunther $\mathrm{OH}$, Roick $\mathrm{C}$, Angermeyer MC, Konig HH. The responsiveness of EQ-5D utility scores in patients with depression: A comparison with instruments measuring quality of life, psychopathology and social functioning. J Affect Disord, 2008. 105(1-3): p. 81-91.

18. Soeteman DI, Timman R, Trijsburg RW, et al. Assessment of the burden of disease among inpatients in specialized units that provide psychotherapy. Psychiatr Serv, 2005. 56(9): p. 11535.

19. Brazier J, Tumur I, Holmes $M$, et al. Psychological therapies including dialectical behaviour therapy for borderline personality disorder: a systematic review and preliminary economic evaluation. Health Technol Assess, 2006. 10(35): p. iii, ix-xii, 1-117.

20. Giesen-Bloo J, van Dyck R, Spinhoven P, et al. Outpatient psychotherapy for borderline personality disorder: randomized trial of schema-focused therapy vs transference-focused psychotherapy. Arch Gen Psychiatry, 2006. 63(6): p. 649-58. 
21. Arntz A, van den Hoorn M, Cornelis J, et al. Reliability and validity of the borderline personality disorder severity index. J Personal Disord, 2003. 17(1): p. 45-59.

22. Dolan P. Modeling valuations for EuroQol health states. Med Care, 1997. 35(11): p. 1095-108.

23. Husted JA, Cook RJ, Farewell VT, Gladman DD. Methods for assessing responsiveness: a critical review and recommendations. J Clin Epidemiol, 2000. 53(5): p. 459-68.

24. Crosby RD, Kolotkin RL, Williams GR. Defining clinically meaningful change in health-related quality of life. J Clin Epidemiol, 2003. 56(5): p. 395-407.

25. Stucki G, Liang MH, Fossel AH, Katz JN. Relative responsiveness of condition-specific and generic health status measures in degenerative lumbar spinal stenosis. J Clin Epidemiol, 1995. 48(11): p. 1369-78.

26. Liang $\mathrm{MH}$, Fossel AH, Larson MG. Comparisons of five health status instruments for orthopedic evaluation. Med Care, 1990. 28(7): p. 632-42.

27. Beaton DE, Hogg-Johnson S, Bombardier C. Evaluating changes in health status: reliability and responsiveness of five generic health status measures in workers with musculoskeletal disorders. J Clin Epidemiol, 1997. 50(1): p. 79-93.

28. Garratt AM, Ruta DA, Abdalla MI, Russell IT. SF 36 health survey questionnaire: II. Responsiveness to changes in health status in four common clinical conditions. Qual Health Care, 1994. 3(4): p. 186-92.

29. Haywood KL, Garratt AM, Dziedzic K, Dawes PT. Generic measures of health-related quality of life in ankylosing spondylitis: reliability, validity and responsiveness. Rheumatology (Oxford), 2002. 41(12): p. 1380-7.

30. Pickard AS, Johnson JA, Feeny DH. Responsiveness of generic health-related quality of life measures in stroke. Qual Life Res, 2005. 14(1): p. 207-19.

31. Marra CA, Woolcott JC, Kopec JA, et al. A comparison of generic, indirect utility measures (the HUI2, HUI3, SF-6D, and the EQ-5D) and disease-specific instruments (the RAQoL and the HAQ) in rheumatoid arthritis. Soc Sci Med, 2005. 60(7): p. 1571-82.

32. Hayhurst $\mathrm{H}$, Palmer $\mathrm{S}$, Abbott $\mathrm{R}$, et al. Measuring health-related quality of life in bipolar disorder: relationship of the EuroQol (EQ-5D) to condition-specific measures. Qual Life Res, 2006. 15(7): p. 1271-80.

33. Lamers LM, Bouwmans CA, van Straten A, et al. Comparison of EQ-5D and SF-6D utilities in mental health patients. Health Econ, 2006. 15(11): p. 1229-36.

34. Rubin DB, Schenker N. Multiple imputation in health-care databases: an overview and some applications. Stat Med, 1991. 10(4): p. 585-98. 

GENERAL DISCUSSION 
CHAPTER 7 


\section{INTRODUCTION}

This thesis had three aims. The first was to estimate cost of illness of Borderline Personality Disorder for the Netherlands. The second aim was to perform an economic evaluation of two outpatient therapies for the treatment of BPD, and pronounce upon the preferred therapy for this patient population. Third, the thesis aimed to discuss how an economic evaluation can be performed in BPD patients, and how to resolve some typical methodological problems that may emerge. In this final chapter, we will briefly summarize the main findings, and discuss some methodological issues that relate to economic evaluations in a BPD population. Furthermore, suggestions for future research will be given.

\section{SUMMARY OF FINDINGS}

\section{The societal burden of BPD}

In chapter 2, the societal cost-of-illness of BPD for the Netherlands, based on a sample of 88 patients, was calculated at approximately 2,2 billion euro annually, which is $€ 16,852$ per patient per year. Calculations were performed bottom-up, which implies that societal costs were assessed for the patients in the sample, and then extrapolated for the Dutch population. Costs were assessed by means of a cost interview. We used a prevalence-based approach, which means that costs should be interpreted as the total yearly costs for all prevalent cases in that year. Total societal costs primarily $(>77 \%)$ consisted of costs outside the health care sector, such as costs of informal care and costs of lost productivity. Our findings differed substantially from the annual costs for a psychiatric patient of $€ 3,200$ as reported by Smit et al. ${ }^{(1)}$ We recognize that a bottom-up approach has some drawbacks. For instance, the representativity of the patient sample could be questioned. However, using a topdown approach also leads to problems, especially in the case of BPD, which is difficult to diagnose and rather poorly registered in databases, i.e. the BPD diagnosis is often not mentioned as the reason for resource use, sick leave or work disability, prescribing medication and so on. This will result in underestimation of societal costs. Therefore, even though our estimate may not be completely accurate, and also not entirely comparable to the findings of Smit et al. ${ }^{(1)}$, we concluded that the societal monetary burden of BPD is considerable, especially when it concerns the nonmedical costs. Moreover, the costs of BPD are probably higher than the average costs of other psychiatric disorders.

\section{Economic evaluation of Schema Focused Therapy (SFT) versus Transference Focused Psychotherapy (TFP)}

Chapter 3 described the economic evaluation of two types of outpatient psychotherapy for 86 patients with BPD. We calculated societal costs for both treatment groups 
over four years of follow-up, and related those to two outcome measures: the proportion of recovered patients as measured with the Borderline Personality Disorder Severity Index-IV (BPDSI-IV), and the number of Quality Adjusted Life Years (QALYs). Total mean bootstrapped costs were €37,826 for SFT and €46,795 for TFP. The number of QALYs was not statistically significantly different between the treatment groups: 2.15 for SFT and 2.27 for TFP. Giesen-Bloo et al. ${ }^{(2)}$ had already shown that Schema Focused Therapy (SFT) was more effective than Transference Focused Psychotherapy (TFP) in terms of recovery as measured with the BPDSI-IV. With SFT, after 3 years, 52.3\% recovered, with TFP, 28.6\% did. Based on costs per recovered patient, we concluded that SFT was dominant, in the sense that it was both more effective and less costly than TFP. The ICER for the costs per QALY was €90,457 saved per QALY lost. Based on a cost-effectiveness acceptability curve and considering a threshold value of $€ 20,000$ per QALY, SFT had a chance of $84 \%$ of being a cost-effective treatment strategy.

\section{Productivity costs of work-disablement in BPD}

From chapter 2 and 3, it was already clear that productivity costs were an important part of total societal costs for BPD. However, as also became apparent, a large part of the BPD-patients in our sample was work-disabled. In economic evaluations, it is common practice not to include productivity costs of work-disabled patients when they are already disabled at the start of the study. As a consequence, in populations with a high percentage of work-disablement, productivity costs are only calculated over the working part of the sample, and work disablement is, in a way, ignored. In chapter 4, we calculated productivity costs with and without the costs of the workdisablement, and assessed the differences. We found that results changed dramatically with including the work-disabled in the productivity costs. We therefore concluded that whether or not including productivity costs for patients who are workdisabled at baseline can, in theory, lead to contradictory conclusions, and that researchers should be very explicit about the methods they have used for estimating productivity costs. In chapter 3, we did not include the work-disabled at baseline. When we would have done so, the costs of SFT compared to TFP would have increased, but SFT would still have been cost-saving, and therefore the conclusions of the economic evaluation would not have changed.

\section{Baseline cost differences}

In the economic evaluation in chapter 3, we found that the mean costs measured over the three months preceding the baseline measurement were higher for TFP than for SFT. This difference remained more or less unchanged during the rest of the follow-up period, and this led to the conclusion that SFT was less costly than TFP. However, it is very difficult to say to what extent this difference in total costs (after baseline) might have been explained by the initial difference in baseline costs. In contrast to clinical and patient reported outcome, it is not very usual to report baseline costs in economic evaluations and there is no literature on this subject. There- 
fore, in chapter 5, several methods were reported to adjust for a baseline difference in costs, and compared the outcomes. One way to adjust for a baseline cost difference is to subtract the difference from the alternative with the highest cost (or, analogously, to add the difference to the alternative with the lowest costs). Another way is to only look at the changes in costs. We also performed a regression analysis, with baseline costs as an independent variable, and total costs (after baseline), as the dependent variable. Our conclusion was that when costs at baseline differ between two treatment strategies, an adjustment should be made, preferably with the regression method. Also, we recommend that baseline costs should always be measured accurately and reported. In chapter 3, reporting the cost-effectiveness analysis, we added the regression correction as a secondary analysis, which in this case did not change the conclusions of the economic evaluation.

\section{Usefulness of the EQ-5D in BPD}

In chapter 3, The outcome for recovered patients based on the BPDSI-IV deviated from the outcome for QALYs. This was due to the fact that the EuroQoL-5D utility, on which the QALY is based, in the first year for SFT did not improve at the same rate as the BPDSI-IV did. One explanation for the divergence could be that the responsiveness of the EQ-5D to changes in clinical status is limited in a BPD population. As to date there is very little information on the use of the EQ-5D in BPD, in chapter 6 we investigated the responsiveness of the EQ-5D for a BPD population. We assessed internal and external responsiveness, the latter including discriminative ability. We found moderate correlations between the BPDSI-IV and the EQ-5D. Standardized response means for the EQ-5D were also moderate, and much smaller than for the BPDSI-IV. Discriminative ability, which was defined as the difference between EQ-5D scores for responders versus non-responders to therapy, was statistically significant. Although there are no standards to refer to when it concerns responsiveness, we concluded that the EQ-5D is reasonably responsive in a BPD population. It would however be useful to investigate the responsiveness of other generic HRQoL instruments next to the EQ-5D in a BPD-population. Giesen-Bloo et al. ${ }^{(2)}$ did include the WHOQoL-100 ${ }^{(3)}$ in their measurements, which is meant as a generic HRQoL instrument. However, it is not possible (yet) to derive a utility or total score from the WHOQoL-100, so the responsiveness of the EQ-5D and the WHOQoL-100 as a whole cannot be compared directly, and moreover, it is not possible to obtain a QALY from the WHOQoL-100.

\section{METHODOLOGICAL CONSIDERATIONS}

\section{Comparators in economic evaluation}

In the economic evaluation that is described in chapter 3, we have compared two therapies. Neither of these therapies exactly correspond with the therapy that is currently offered to BPD-patients in Dutch practice. In fact, it is very difficult to give 
a description of the 'treatment as usual' (TAU) for BPD-patients in the Netherlands. The typical TAU, as far as we can speak of one TAU, as there are many local and regional differences, is probably considerably less extensive than the therapies were investigated in our trial. A recent international review concerning psychological therapies for borderline personality disorder ${ }^{(4)}$ found that the 7 studies that used TAU as a comparator all used a different definition of TAU, varying from continuation of existing treatment ${ }^{(5)}$ and 60 minutes of weekly individual therapy ${ }^{(6)}$ to day hospital treatment ${ }^{(7)}$. Although only one of these studies was Dutch, and therefore the differences could be just reflecting practice variation between countries, we believe it also to be exemplary for the very broad definition of the TAU concept. This poses a problem for the interpretation of the results of the economic evaluation. We have found that SFT is probably the more cost-effective alternative. However, this conclusion is only valid when SFT is compared with TFP, as TAU and other possible alternatives were not part of the comparison. According to Gold et al. ${ }^{(8)}$, studies from the societal perspective should compare the intervention to existing practice (the TAU) for addressing the health problem. The question then being addressed is, 'what is the cost-effectiveness of replacing the existing practice with the new intervention?'. They also state that if an intervention is not compared with existing practice, results can be deceptive, since this comparison will not reflect the value of an incremental change in practice. We were aware of all these drawbacks when we performed our economic evaluation. In a way, TFP might be considered as TAU, as in the nineties, within the field of psychotherapy, for BPD, psychodynamic therapy was the standard in the Netherlands, and TFP is an optimized form of psychodynamic psychotherapy. However, TFP is not a representative of general TAU for BPD, given the fact that non-psychotherapeutic approaches are common. Since, as mentioned, thus far nobody has been able to identify the typical TAU for BPD, we decided to include a psychotherapy TAU as a comparator. This had the additional advantage that important aspects like the aim of the treatment, the intensity, duration, and frequency of the treatment, and the training of the therapists was controlled for. Would we have succeeded in including patients for a TAU-condition, then there probably would have been a Hawthorne-effect in therapists and patients, meaning that the TAU would change as a consequence of the fact that patients are undergoing assessments for the trial. This effect might be even stronger because of the absence of protocols and rules concerning TAU. Also, Sculpher et al. ${ }^{(9)}$ emphasise the fact that use of a single RCT as a vehicle for economic analysis will often be an inadequate and partial basis for decision making. They recommend a modelling approach including all possible alternatives, for which RCTs can serve as input. In the case of BPD this concept could be given shape by constructing a model with data for TAU from observational data, such as patient registries (which would have to include economic parameters), and data for new interventions from RCTs.

A very pragmatic solution to the missing and indefinable comparator is to consider baseline as TAU. Of course, there are many arguments against this method, such as the fact that patients who have just been included in a trial are probably not representative of a whole population. Their severity of illness and costs may for instance be higher than in the years before, having led them to seek treatment at this moment. 
However, when we regard the baseline situation as TAU and compare it with the situation after baseline for the two psychotherapies together, than it can easily be concluded that psychotherapy in general is cost-saving and more effective than TAU; the cost level of both treatments is considerably lower at follow-up than at baseline, and both severity of illness and Health Related Quality of Life have much improved with treatment. In numbers: average three-monthly costs after start of treatment were $€ 2,650$ versus $€ 3,770$ at baseline, 35 out of 86 patients $(41 \%)$ recovered from BPD, and the Q-5D utility score, which was 0.48 at baseline, was 0.62 at follow-up after four years.

Recommendations for economic evaluations of BPD-treatments based on trials would be to try and include another TAU condition and follow-up these patients to study a natural course, even though this might be difficult for the reasons described above. Another option might be to include a real 'natural course option', including patients just for control whether they seek treatment on their own initiative or not. Ideally, parallel to any trial based economic evaluation it would be interesting to construct a decision model including all the available evidence -even though this might not be very much at this moment- to be able to compare the cost-effectiveness of all treatment options that have been investigated so far.

\section{Censored costs}

A second methodological consideration for this thesis is the relatively high proportion of censored costs caused by the large dropout rate. Dropout after 3 years was $27 \%$ for SFT and $51 \%$ for TFP. Although the dropout was more or less foreseen and is not unusually high considering the fact that it concerns BPD-patients, it implies a problem for the analysis. In the clinical analysis of Giesen-Bloo et al. ${ }^{(2)}$, the last observation for each dropout was carried forward, what we called the LOC-F method. For our main analyses, we also used this approach. However, as Oostenbrink \& $\mathrm{Al}^{(10)}$ and also Briggs ${ }^{(11)}$ have already assessed, for economic evaluations, the use of naïve methods, of which LOC-F is one, is not advised. Especially since cost data tend to be highly skewed, naïve methods could severely bias the results. Oostenbrink \& Al recommend Multiple Imputation $(\mathrm{MI})^{(12)}$ as the best option for dealing with censored cost data. As we have already mentioned in chapter 3, we have attempted to use the $\mathrm{Ml}$ approach in our data, but in the last measurements, probably due to the fact that the number of missing had become too large after 4 years, the estimates became instable. We therefore did not report the Ml-estimates in chapter 3. We performed a secondary analysis where we imputed baseline values for dropouts, to more or less simulate the assumption that dropouts would immediately fall back to their situation as it was before treatment. One should bear in mind that this approach is in fact advantageous for SFT, given the fact that the dropout rate in the TFP condition is higher and the assumption that patients have already improved, be it slightly, before they drop out. Therefore, when there is inequality in dropout rates between conditions, baseline imputation in general is not recommendable. Although imputing the baseline values for dropouts did not affect the results substantially, we cannot rule out that the high rate of censored costs and the way we treated the missing data 
have had some influence on the results. Of course, the same goes for the results of chapters 4 and 5, as those are all based on the same data. For chapter 6 we only used data of completers.

For future economic evaluations of BPD-treatment, one can only try and limit the proportion of censored costs for as much as possible, maybe by contacting or visiting the dropouts and ask them to answer some questions concerning their resource use, or, if possible, to administer the standard cost interview. Especially, there should be concern about selective dropouts, such as non-responders to treatment. For the present economic evaluation this procedure was already followed to a large extent, however, there still were many patients that remained unreachable or untraceable, especially after the fourth year. The problem of intractability might be typical for BPD, so maybe there should be extra staff hired in a next trial to exclusively keep track of patients. Despite undertaking every effort to avoid dropouts, there always will be censored data. Of course, as already mentioned, in general the best way to deal with this, in theory, would be MI.

\section{BPDSI-IV versus EQ-5D}

In chapter 3, the cost-effectiveness of SFT versus TFP was calculated in two ways: the cost per recovered patient as defined by a BPDSI-IV score of less than 15, and the cost per QALY, where QALYs were calculated with the EQ-5D. One might expect the EQ-5D, which is a measure of Health-Related Quality of Life (HRQoL) to be rather parallel with the BPDSI, which is a measure of disease severity. After all, when disease severity diminishes, HRQoL would logically benefit. However, in our trial data, the EQ-5D scores show some kind of a lagged response to the BPDSI-changes, especially in the first year after start of treatment. Skodol et al. ${ }^{(13)}$ have found that, although the diagnostic status of patients with BPD may change significantly over a relatively short time interval, functional status improves less significantly and more gradually. For HRQoL, the same pattern could apply, especially since the concept of functional status is part of HRQoL. The result is that, after 4 years, SFT is significantly superior to TFP, while in terms of QALYs, there is no difference. It is very well possible that when follow-up would have been somewhat longer, QALYs would favour SFT as well, as after 4 years the EQ-5D score had crossed and were higher for SFT than for TFP, but unfortunately we do not have any data to support this. Our explorative study in chapter 6 suggests that the EQ-5D is responsive in BPD-patients, but as we did not design our trial for this purpose, and therefore the data were not primarily suitable for assessing responsiveness, the same research should be performed again with different data to check the reproducibility of our results. Because of the discrepancy between the BPDSI-IV and EQ-5D, the two cost-effectiveness outcomes are not corresponding, in the sense that for the cost per recovered patient, SFT is dominant, and for the cost per QALY, it is not, although the probability of SFT being cost-effective is still considerable. Which of the two cost-effectiveness outcomes is the most correct one? On the one hand, in economic evaluations the QALY is the most preferred effect for an incremental cost effectiveness ratio (ICER), since it enables comparison between diseases, and there is some (although not unanimously 
recognized) threshold value for the acceptability of cost per QALY. On the other hand, in a BPD-population, the EQ-5D might not perform as well as in other somatic- diseases, and therefore the cost per BPDSI-IV would be the preferred outcome. Worth mentioning in this respect is the fact that in an ongoing trial of implementing SFT in the Netherlands, the discrepancy between EQ-5D and BPDSI-IV is not present ${ }^{(14)}$. So our study findings concerning this may be nothing more than an artefact, and possibly caused by small sample size. In general, it might not be a good idea to use more than one outcome measure for an economic evaluation, i.e. to perform a cost-utility analysis and a cost-effectiveness analysis next to each other. They will never lead to exactly the same results, and therefore there will always be discussion which of the two is the most valid outcome. It would be recommendable to hypothesize in advance about the most suitable outcome measure for a given problem or research question, and then use this measure only. However, it should be noted that when the goal of an economic evaluation is to attain allocative efficiency, the QALY should be the outcome measure of choice, since this is the only outcome measure that can be used for all disorders. When the goal is to find the optimal treatment for a specific disorder, with a fixed budget for the treatment of this specific disease, then some other outcome measure than the QALY would be suitable as well. An important area for future research, apart from the recommendations we already did when it concerns performing an economic evaluation in BPD, would be to compare the EQ-5D with other generic HRQoL instruments, such as for instance the SF-36, in a BPD population. The EQ-5D and SF-36 are extensively studied instruments, however not in BPD populations. Brazier et al. have also mentioned in a recent HTA-report ${ }^{(4)}$ that psychometric assessment of the validity of the EQ-5D or other generic and condition-specific preference-based measures in BPD is necessary.

\section{IMPLICATIONS OF THE PRESENT THESIS FOR PRACTICE AND POLICY MAKING}

An important finding of the present thesis was that the cost of illness of BPD is high, especially when it concerns the non-medical costs, such as burden to the family and productivity costs. When a top-down instead of a bottom-up approach would have been used, as is done in may COI studies, these costs would probably have been underestimated, or not even revealed at all. So, even though from a healthcare perspective the costs of BPD may seem more or less comparable to many other disorders, from a societal point of view, it is a very urgent problem deserving special attention.

Another finding was the high rate of work-disablement in BPD, a fact that would be largely neglected in economic evaluations when the standard methods for valuation of productivity losses would be applied. In evaluating economic evaluation and prioritizing for healthcare spending, this is an issue which deserves the attention of decision makers, moreover since this is a problem that not only concerns BPD, but probably the majority of psychiatric disorders and also many chronic somatic diseases. 
The economic evaluation as described in chapter 3 of this thesis concludes that psychotherapy in general, and SFT in particular, are cost-effective ways to treat BPD, in the sense that the recovery of patients is possible, HRQoL is improved, and costs are reduced. Although, as mentioned previously in this chapter, these results should be interpreted with caution, they still imply a promising treatment option for a population that, until very recently, was regarded as more or less untreatable. The average number of psychotherapy sessions for completers (i.e. dropouts excluded) that was needed to come to these results was around 200. After three years, which is when according to the protocol the treatment was due to be finished, $85 \%$ of all completers was still in therapy ${ }^{(2)}$. Until very recently, in the Netherlands, for personality disorders, a maximum of 50 psychotherapy sessions was allowed by health insurers. Although since January $1^{\text {st }} 2008$, this maximum has been released because of a new financing system in Dutch Healthcare, the limit to the number of sessions remains a topic of discussion. Although in our economic evaluation, we did not compare short term versus long term psychotherapy, the fact that patients needed and continued to need as many sessions as they did is an indication that 50 sessions is probably completely insufficient to attain optimal cost-effectiveness of treatment for BPD.

\section{OVERALL CONCLUSION}

Based on the summary of findings above, one can conclude that the burden of BPD to society is considerable, and that SFT seems to be a cost-effective therapy for BPD. However, there were some methodological problems in performing the economic evaluation. In our view, work-disablement at baseline of a study should be dealt with much more explicitly. The same applies to baseline costs, especially in case of a difference between groups. Furthermore, more research should be done concerning the responsiveness of the EQ-5D in BPD. The message in the assembled methodological considerations that were discussed, is that all results and conclusions we have brought forward in this thesis should be interpreted with caution and bearing in mind these considerations; SFT can be considered cost-effective only when compared to TFP, the results may have been influenced by the way that censored data were treated, and the responsiveness of the EQ-5D in a BPD-population has thus far, despite our explorative study in chapter 6 , not been proven indisputably.

Nevertheless, the cost of illness and economic evaluation as described in this thesis were, to our knowledge, the first to extensively study the costs of BPD and the costeffectiveness of some of the treatment options from a societal perspective. Therefore, it can be considered guiding for economic evaluations in the field of BPD. 


\section{REFERENCES}

1. Smit F, Cuijpers P, Oostenbrink J, et al. Costs of nine common mental disorders: implications for curative and preventive psychiatry. J Ment Health Policy Econ, 2006. 9(4): p. 193-200.

2. Giesen-Bloo J, van Dyck R, Spinhoven P, et al. Outpatient psychotherapy for borderline personality disorder: randomized trial of schema-focused therapy vs transference-focused psychotherapy. Arch Gen Psychiatry, 2006. 63(6): p. 649-58.

3. The World Health Organization Quality of Life Assessment (WHOQOL): development and general psychometric properties. Soc Sci Med, 1998. 46(12): p. 1569-85.

4. Brazier J, Tumur I, Holmes $M$, et al. Psychological therapies including dialectical behaviour therapy for borderline personality disorder: a systematic review and preliminary economic evaluation. Health Technol Assess, 2006. 10(35): p. iii, ix-xii, 1-117.

5. Tyrer P, Tom B, Byford S, et al. Differential effects of manual assisted cognitive behavior therapy in the treatment of recurrent deliberate self-harm and personality disturbance: the POPMACT study. J Personal Disord, 2004. 18(1): p. 102-16.

6. Koons C, Robins C, Tweed J, et al. Efficacy of dialectical behavior therapy in women veterans with borderline personality disorder. Behavior Therapy 2001. 32: p. 371-90.

7. Wilberg T, Friis $S$, Karterud $S$, et al. Outpatient group psychotherapy: a valuable continuation treatment for patients with borderline personality disorder treated in a day hospital? A 3-year follow-up study. Nord J Psychiatry, 1998. 52: p. 213-21.

8. Gold M, Siegel J, Russell L, Weinstein M, eds. Cost-effectiveness in health and medicine. 1996, Oxford University Press: New York.

9. Sculpher MJ, Claxton K, Drummond M, McCabe C. Whither trial-based economic evaluation for health care decision making? Health Econ, 2006. 15(7): p. 677-87.

10. Oostenbrink JB, AI MJ. The analysis of incomplete cost data due to dropout. Health Econ, 2005. 14(8): p. 763-76.

11. Briggs A, Clark T, Wolstenholme J, Clarke P. Missing. .. presumed at random: cost-analysis of incomplete data. Health Econ, 2003. 12(5): p. 377-92.

12. Rubin DB, Schenker N. Multiple imputation in health-care databases: an overview and some applications. Stat Med, 1991. 10(4): p. 585-98.

13. Skodol AE, Pagano ME, Bender DS, et al. Stability of functional impairment in patients with schizotypal, borderline, avoidant, or obsessive-compulsive personality disorder over two years. Psychol Med, 2005. 35(3): p. 443-51.

14. Nadort M, van Dyck R, Smit JH, et al. Implementation of out-patient schema-focused therapy for borderline personality disorder in general psychiatry. Ongoing study. 

SAMENVATTING 
SAMENVATTING 
Borderline Persoonlijkheidsstoornis (BPS) een complexe en ernstige psychiatrische aandoening, die wordt gekarakteriseerd door instabiliteit op allerlei vlakken. Symptomen zijn bijvoorbeeld impulsiviteit op gebieden die potentieel zelfbeschadigend zijn (zoals misbruik van drank en drugs, roekeloos rijgedrag), herhaald suïcidaal gedrag of zelfmutilatie. Tot voor kort was er eigenlijk geen goede behandeling voor BPS. Er zijn echter twee nieuwe ambulante therapieën, Shema Focused Therapy (SFT) en Transference focused Psychotherapy (TFP). Deze twee therapieën zijn met elkaar vergeleken in een Nederlandse studie. Deelnemende patiënten waren afkomstig van behandelcentra in Amsterdam, Leiden, Den Haag en Maastricht. 44 patiënten werden behandeld met SFT, en 42 met TFP. De behandeling bestond uit 3 jaar therapie, 2 maal per week. Beide therapieën bleken, zoals onderzocht door Josephine Giesen-Bloo, effectief in, onder anderen, het terugdringen van BPS-symptomen en het verbeteren van de kwaliteit van leven. SFT bleek echter superieur op alle uitkomstmaten.

Het onderwerp van dit proefschrift is het economische aspect van deze borderlinebehandelstudie Het doel van dit proefschrift was drieledig:

- becijferen van de totale monetaire last van BPS voor de maatschappij: de zogenaamde 'cost of illness'.

- $\quad$ economisch evalueren van de twee eerder genoemde ambulante therapieën en uitspraak doen over de te prefereren behandeling

- bespreken hoe een economische evaluatie gedaan zou moeten worden in een BPS-populatie, welke methodologische problemen zich kunnen voordoen en hoe die problemen aangepakt zouden moeten worden

\section{DE MAATSCHAPPELIJKE 'LAST' VAN BPS}

In hoofdstuk 2 wordt de maatschappelijke 'cost of illness' van BPS in Nederland becijferd op ongeveer 2,2 miljard Euro per jaar (gebaseerd op een steekproef van 88 patiënten), wat gelijk staat aan $€ 16.852$ per patiënt per jaar. De berekeningen werden bottom-up uitgevoerd, wat betekent dat eerst de maatschappelijke kosten voor de patiënten in de steekproef werden bepaald, en dat die vervolgens geëxtrapoleerd werden naar de gehele Nederlandse bevolking. De kosten werden vastgesteld op basis van een zogenaamd kosten-interview, waarin vragen over alle mogelijke kostenposten waren opgenomen, zoals verlies van arbeidsproductiviteit, kosten van medicijnen, zorgconsumptie, de belasting van familie en vrienden, etc. De totale kosten bestonden voornamelijk (voor bijna 80\%) uit kosten buiten de gezondheidszorg, zoals de kosten van mantelzorg en verlies van arbeidsproductiviteit. Uiteraard heeft een bottom-up benadering zoals in onze studie een aantal nadelen. De representativiteit van de steekproef is bijvoorbeeld twijfelachtig. Desalniettemin leidt het gebruik van een top-down benadering, waarbij van bovenaf bepaald wordt welk gedeelte van de kosten in een bepaalde sector voor rekening van een bepaalde patiëntengroep komt, ook tot problemen in het geval van BPS. Dat komt met name 
omdat BPS een moeilijk te diagnosticeren aandoening is en er mede daardoor onderregistratie plaatsvindt. Als gevolg daarvan is BPS in databases niet terug te vinden als oorzaak voor bijvoorbeeld zorgconsumptie, medicijngebruik en productiviteitsverlies. Het gebruik van een top-down benadering zal daarom in het geval van BPS naar verwachting leiden tot een onderschatting van de maatschappelijke kosten. Daarom is de conclusie van deze studie dat, ook al is onze schatting waarschijnlijk niet geheel accuraat, de maatschappelijke monetaire last van BPS aanzienlijk is, met name waar het de niet-medische kosten betreft. Ook zijn de kosten van BPS waarschijnlijk hoger dan de gemiddelde kosten van andere psychiatrische aandoeningen.

\section{ECONOMISCHE EVALUATIE VAN SCHEMA FOCUSED THERAPIE (SFT) VERSUS TRANSFERENCE FOCUSED PSYCHOTHERAPIE (TFP)}

Hoofdstuk 3 beschrijft de economische evaluatie van twee soorten ambulante psychotherapie voor 86 patiënten met BPS. De totale maatschappelijke kosten over 4 jaar voor beide behandelgroepen werden berekend, en deze werden vervolgens gerelateerd aan de twee uitkomstmaten: ten eerste het percentage patiënten dat geen BPS-diagnose meer had (gemeten met de Borderline Personality Disorder Severity Index-IV, de BPDSI-IV), en ten tweede het aantal voor kwaliteit gecorrigeerde levensjaren (Quality Adjusted Life Years, oftewel QALYs). De totale gemiddelde gebootstrapte kosten waren $€ 37.826$ voor SFT and $€ 46.795$ voor TFP. Het aantal QALYs was 2,15 voor SFT en 2,27 voor TFP. Uit de studie naar de effectiviteit was al gebleken dat SFT het beter deed dan TFP in termen van herstel gemeten met de BPDSI-IV. Bij SFT had na 3 jaar 52,3\% geen diagnose BPS meer, bij TFP was dat percentage 28,6\% Gebaseerd op de kosten per herstelde patiënt kan geconcludeerd worden dat SFT dominant is, dat wil zeggen dat SFT én effectiever, én goedkoper is dan TFP. De uitkomst voor de kosten per QALY was een besparing van €90.457 per verloren QALY. Met andere woorden: bij SFT treedt een, weliswaar klein, verlies op in kwaliteit van leven, maar dit wordt gecompenseerd door een kostenbesparing. Wanneer de maatschappij bijvoorbeeld bereid zou zijn om $€ 20.000$ voor een QALY te betalen (dit is een gangbaar bedrag), dan is de kans dat SFT een kosten-effectieve behandeling is $84 \%$.

\section{PRODUCTIVITEITSVERLIEZEN BIJ ARBEIDSONGESCHIKTHEID DOOR BPS}

Uit hoofdstuk 2 en 3 was al duidelijk geworden dat de kosten van verlies van productiviteit een belangrijk aandeel hebben in de totale maatschappelijke kosten van BPS. Wat ook bleek, was dat een groot deel van de BPS-patiënten in onze steekproef arbeidsongeschikt was. In economische evaluaties worden de kosten van verlies van productiviteit doorgaans niet meegerekend wanneer een patiënt bij aanvang van de studie al arbeidsongeschikt was. Als gevolg daarvan worden in populaties met veel arbeidsongeschikten de productiviteitsverliezen alleen berekend voor het werkende deel van de patiënten, en wordt arbeidsongeschiktheid in zekere zin dus genegeerd. 
In hoofdstuk 4 zijn de productiviteitsverliezen met én zonder de kosten van arbeidsongeschiktheid berekend. Het includeren van de kosten van arbeidongeschiktheid was van grote invloed op de resultaten. De conclusie van dit hoofdstuk was dat het al dan niet buiten beschouwing laten van de productiviteitsverliezen door arbeidsongeschiktheid tot tegenstrijdige conclusies kan leiden, en dat onderzoekers daarom zeer expliciet de gehanteerde methoden met betrekking tot productiviteitsverliezen dienen te vermelden. In hoofdstuk 3 zijn de kosten van arbeidsongeschiktheid niet meegenomen in de totale kosten. Wanneer dat wel was gebeurd dan zouden de kosten van SFT ten opzichte van TFP licht gestegen zijn, maar de conclusies van de economische evaluatie zouden niet zijn gewijzigd.

\section{BASELINE KOSTENVERSCHILLEN}

In de economische evaluatie in hoofdstuk 3 bleek dat de kosten zoals gemeten over de drie maanden voorafgaand aan de eerste meting (de baseline meting) voor de TFP-groep hoger waren dan voor de SFT-groep. Dit verschil bleef min of meer constant gedurende de rest van de studieperiode, en de conclusie luidde uiteindelijk dat SFT minder kostbaar was dan TFP. Het is echter heel moeilijk te zeggen in hoeverre het verschil in totale kosten verklaard zou kunnen worden uit het initiële verschil op baseline. Hoewel het bij klinische en patiënt-gerelateerde uitkomstmaten gebruikelijk is om de uitgangswaarden op baseline te rapporteren, geldt dat niet voor het baseline kostenniveau in economische evaluaties. Er is ook geen literatuur over dit onderwerp. Daarom zijn in hoofdstuk 5 een aantal methoden uitgetest die corrigeren voor een baseline kostenverschil. Eén manier om het verschil te corrigeren is om het op baseline aanwezige verschil bij alle vervolgmetingen af te trekken van de groep met de hoogste baseline kosten Een andere manier is om alleen naar de kostenstijgingen en -dalingen ten opzichte van baseline te kijken. Daarnaast is nog een regressie-analyse verricht, met baseline kosten als onafhankelijke variabele en totale kosten (na baseline) als afhankelijke variabele. De conclusie van deze studie was dat wanneer er op baseline een verschil is in kosten tussen de groepen, er en correctie plaats zou moeten vinden, waarbij de regressie methode de voorkeur heeft. Een andere aanbeveling is dat baseline kosten altijd gemeten en gerapporteerd zouden moeten worden. In hoofdstuk 3, de economische evaluatie, is de regressiecorrectie methode toegevoegd als een secundaire analyse. In dit geval had de correctie geen invloed op de conclusies van de economische evaluatie.

\section{TOEPASBAARHEID VAN DE EQ-5D BIJ BPS}

In hoofdstuk 3 week de uitkomst op basis van de BPDSI-IV (percentage herstelde patiënten) af van de uitkomst op basis van QALYs (voor kwaliteit gecorrigeerde levensjaren). Dit werd veroorzaakt door het feit dat de utiliteitsscore zoals berekend met de EuroQoL-5D (EQ-5D, een meetinstrument om kwaliteit van leven mee te bepalen) in het eerste jaar voor de de SFT-groep niet in dezelfde mate verbeterde als 
voor de TFP-groep. En mogelijke verklaring hiervoor is dat de gevoeligheid van de EQ-5D voor veranderingen in de klinische toestand beperkt is in een BPS-populatie, omdat de EQ-5D slechts 5 vragen bevat waarvan er 4 met name op fysieke aspecten van gezondheid zijn gericht. Aangezien er tot op heden er heel weinig bekend is over het gebruik van de EQ-5D in bij BPS, is in hoofdstuk 6 de responsiviteit van de EQ-5D in een BPS-populatie onderzocht. Zowel interne als externe responsiviteit zijn berekend, waarbij externe responsiviteit ook het begrip 'discriminative ability' omvatte, dat is de mate waarin een instrument significant verschillende scores laat zien bij klinisch verschillende patiëntencategorieën. Tussen de BPSDI-IV en de EQ$5 \mathrm{D}$ bleken middelmatige correlaties te bestaan. De standardized response means voor de EQ-5D waren ook middelmatig, en veel kleiner dan voor de BPDSI-IV. Dit suggereert dat de BPDSI-IV in deze populatie gevoeliger is voor veranderingen dan de EQ-5D. De discriminative ability, die was gedefinieerd als het verschil in EQ-5D scores tussen zogenaamde responders en non-reponders op de therapie, was statistisch significant. Hoewel er geen standaarden of maatstaven zijn wat betreft responsiviteit, hebben we geconcludeerd dat de EQ-5D redelijk responsief is in een BPSpopulatie. Het zou echter de zeer moeite waard zijn om, ter vergelijking, de responsiviteit van andere generieke gezondheidsgerelateerde kwaliteit van leven instrumenten te onderzoeken in deze patiëntengroep.

\section{DISCUSSIE EN ALGEMENE CONCLUSIE}

Gebaseerd op de samenvatting van de resultaten kan geconcludeerd worden dat de maatschappelijke last van BPS aanzienlijk is, en dat SFT een kosten-effectieve therapie lijkt. Er waren echter een aantal methodologische problemen bij het uitvoeren van de economische evaluatie. Ons inziens moet arbeidsongeschiktheid bij aanvang van een studie veel explicieter benaderd worden, net als het kostenniveau op baseline, zeker wanneer dit verschilt tussen groepen. Verder is nog meer onderzoek nodig naar de toepasbaarheid van de EQ-5D bij BPS. De boodschap uit de methodologische overwegingen in het discussiehoofdstuk is dat alle resultaten en conclusies in dit proefschrift met voorzichtigheid geïnterpreteerd dienen te worden. Met deze boodschap in het achterhoofd kan SFT alleen kosten-effectief worden geacht in directe vergelijking met TFP, en dient men zich verder te realiseren dat de resultaten beïnvloed kunnen zijn door de manier waarop ontbrekende data zijn geïmputeerd, en dat over de responsiviteit van de EQ-5D in een borderline-populatie tot nu toe, ondanks onze verkennende studie, erg weinig bekend is.

De cost of illness studie en de economische evaluatie zoals beschreven in dit proefschrift waren desalniettemin, voorzover ons bekend, de eerste studies die de kosten van BPS en de kosten-effectiviteit van een aantal behandelmogelijkheden uitgebreid hebben omschreven vanuit een maatschappelijk perspectief, en dit proefschrift kan daarom als richtinggevend gezien worden voor economische evaluaties op het gebied van BPS. 
DANKWOORD 
DANKWOORD 


\section{DANK!}

Eindelijk is het dan klaar, en daar ben ik ontzettend blij om. Uiteraard heb ik zelf de nodige uren (jaren!) in dit proefschrift gestoken, maar het zou allemaal niet mogelijk zijn geweest zonder de hulp en steun van een heleboel mensen, die ik daarvoor hieronder met naam wil noemen en bedanken.

Allereerst mijn promotores, de professoren Hans Severens en Arnoud Arntz, en mijn co-promotor, dr. Carmen Dirksen. Jullie hebben in de totstandkoming van dit proefschrift een onmisbare rol gespeeld en hadden stuk voor stuk een heel positieve instelling, ook toen mijn eerste artikel door het zesde tijdschrift op rij afgewezen werd. Gelukkig ging het met de rest een stukje vlotter!

Hans, het heeft een beetje langer geduurd dan gepland (en dan jij had gehoopt) maar nu is het dan toch zover. Dank voor het leveren van de inspiratie om een artikel steeds nét een niveau hoger te tillen. Ik hoop dat onze goede samenwerking zich in de toekomst zal voortzetten.

Arnoud, de besprekingen met Hans en Carmen samen waren, behalve erg gezellig, ook altijd heel verfrissend door jouw invalshoek. Het was vaak best puzzelen om 'onze' MTA-technieken los te kunnen laten op 'jouw' patiëntenpopulatie, en zonder jouw input was dat zeker niet zo goed gelukt. Dank daarvoor, en ook voor je altijd snelle en opbouwende reacties op mijn versie nummer $x$ van een artikel.

Carmen, qua werkhouding zijn we een beetje tegenpolen: ik ben soms behoorlijk makkelijk en jij bent heel precies. Ik werd, dat geef ik eerlijk toe, wel eens een beetje moedeloos van de zoveelste leesronde. Maar het eindresultaat mag er zijn! Heel veel dank voor je bijdrage daaraan, en voor het feit dat ik altijd even binnen kon komen lopen, vooral in de eindfase, om acute problemen te bespreken. O ja, en gelukkig hoefden we niet écht terug te vallen op 'Horse \& Hound'.

Ik wil de leden van de beoordelingscommissie, prof. dr. Jan van Busschbach, dr. Silvia Evers, prof. dr. Madelon Peeters, prof. dr. Johan Polder, en prof. dr. Guy Widdershoven, hartelijk danken voor hun inspanningen om dit proefschrift te evalueren.

Veel dank ook aan alle mensen die het Borderline project mogelijk hebben gemaakt, allereerst uiteraard de patiënten, maar ook screeners, onderzoeksassistenten en therapeuten. Heel veel dank voor jullie jarenlange inzet! Rosanne Janssen, bedankt voor je snelle service als ik weer 'ineens' heel dringend een bepaald bestand nodig had. De leden van de projectgroep, die behalve Arnoud Arntz, Carmen Dirksen en mijzelf bestond uit Richard van Dyck, Philip Spinhoven, Marjon Nadort, Ismay Kremers en Jospehine Giesen-Bloo, wil ik hartelijk danken voor de fantastische manier waarop ze dit project tot een goed einde (met een vervolg!) hebben gebracht, en ook voor de bijzonder prettige samenwerking. En Marjon en Josephine, ik ga heel graag nog eens met jullie naar een congres!

Josephine, nog een speciaal woordje voor jou natuurlijk, als jij er niet was geweest was dit proefschrift er niet gekomen, want jij hebt, naast je eigen onderzoek, ongelo- 
felijk veel werk verzet voor de logistiek van het project, en dus ook voor mijn gegevensverzameling. Ik heb veel bewondering voor de manier waarop je dat gedaan hebt. Ik vond het ook prettig dat we altijd even konden kletsen, over het project en andere zaken. Dank!

Mijn Groningse collega's uit een ver verleden, Nienke, Petra, en Jan-Paul, wil ik bedanken voor de enorm gezellige tijd, vooral die buiten de werkvloer. Mijn kennismaking met MTA is dankzij jullie heel prettig verlopen. We zijn inmiddels allemaal nogal uitgevlogen, maar ik vind het erg leuk dat we van tijd tot tijd nog contact hebben.

Al mijn collega's en ex-collega's bij KEMTA, en ook de leden van de MTAwerkgroep in Maastricht, bedankt voor een gezellige en inspirerende werkomgeving. Brigitte, jij bent al mijn kamergenoot sinds mijn allereerste dag bij KEMTA,ruim 8 jaar geleden nu. Ik zou zo nóg 8 jaar een kamer met je willen delen, alhoewel dat er waarschijnlijk niet in zit (maar wie weet...). Dank je wel dat het altijd zo gezellig was! Ghislaine, Jody, Brigitte, de etentjes met zijn vieren zijn altijd heel geslaagd, en ook nuttig voor het uitwisselen van promotielief en -leed. Als het goed is zijn we binnenkort alle vier gepromoveerd (wie had dat ooit gedacht!), maar we vinden vast wel iets anders om over te ouwehoeren. Fons, heel veel dank voor je inspanningen bij de analyse en het schrijven van het Baseline artikel. Mede dankzij jou is het vlak voor het ter perse gaan van dit proefschrift nog geaccepteerd voor publicatie.

Dan wil ik ook nog iedereen bedanken die mij op minder directe wijze heeft gesteund door er gewoon te zijn. Mijn familie, schoonfamilie, vriendinnen en vrienden, en ook Odeonners en Mutsen: dank voor gezelligheid en ontspanning, vocaal, virtueel of 'gewoon'.

Lianne \& Bart, we kennen elkaar al honderd jaar en hoewel we tegenwoordig een behoorlijk eind uit elkaar wonen, is het altijd gezellig om even bij elkaar te komen 'sprinkhanen'. Ik hoop dat dat nog lang zo mag blijven! Lianne, ik ben heel blij dat jij mijn paranimf bent.

Bert \& Janny en Sander \& Marte. Ik ben nooit zo heel mededeelzaam geweest over mijn werk, en wat ik erover vertelde zal wel niet helemaal duidelijk zijn geweest. Ik wil jullie bedanken dat jullie toch altijd geïnteresseerd zijn gebleven. En nu kunnen jullie alles nog eens rustig nalezen! Bert \& Janny ook heel veel dank voor de bereidheid om in te springen als er zich weer eens een kortsluiting in de planning voordeed. Jullie zijn een super opa en oma!

Annemarie \& Marike, Arjan \& Esther: Bedankt dat ik altijd tegen jullie aan mocht zeuren. Hoewel we niet bepaald bij elkaar om de hoek wonen, zien we elkaar gelukkig toch regelmatig. Het is fijn om zo'n nuchter stel mensen om je heen te hebben, vooral voor iemand met (soms) lichtelijk hysterische neigingen zoals ik. Pimmie, fijn dat jij mijn paranimf bent. 
Papa en mama, het was nooit met zoveel woorden, maar jullie hebben mij altijd gesteund en mij vrij gelaten in mijn keuzes, ook al waren die misschien niet altijd zo verstandig. Dank jullie wel. En ook, vooral mama, dank voor alle extra oppas-dagen zodat ik een eindsprintje kon trekken met mijn artikelen.

Yuri, lieverd, dank voor je geduld met mij. Ooit ga ik mijn leven beteren.

Koen, Nina en baby Pietertje. Jullie zijn, samen met papa, mijn drukke maar altijd gezellige en vrolijke thuishaven. Ik hoop dat we, net als in de verhaaltjes, nog heel lang en gelukkig leven! 

CURRICULUM VITAE 
CURRICULUM VITAE 
Thea van Asselt was born on September 18th, 1972 in Meppel, the Netherlands. After she finished secondary school at the Johannes Calvijn Lyceum in Kampen in 1990, she studied economics in Groningen. She graduated in 1996 and in that same year started working at ING-group as an ICT trainee. After 2 years she switched to the MTA-office of the University Medical Center in Groningen, working as a researcher on a number of cost-effectiveness studies. After another two years, in 2000, she started working at the department of Clinical Epidemiology and Medical Technology Assessment of the Maastricht University Medical Center, partly as a researcher for the Dutch borderline treatment study (the subject of the present thesis), and partly as a member of the diagnosis related groups (DRG) projectgroup (until the end of 2003). Apart from the BPD-project, she has also been participating in various other research projects, most of them involving modelling techniques.

Thea and her partner Yuri Blaauw have three children: Koen (2003), Nina (2005), and Pieter (2008). 